\title{
Flammable Gas Program Topical Report
}

G. D. Johnson

Date Published

October 1996

Prepared for the U.S. Department of Energy Office of Environmental Restoration and

Waste Management

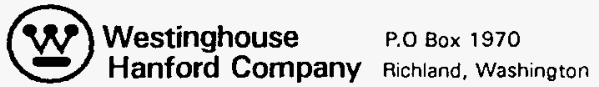

Hanford Operations and Engineering Contractor for the

U.S. Department of Energy under Contract DE-ACO6.87RL 10930

Purpose and Use of Document This document was prepared for use within the U.S. Department of Energy arnd the contractors. It is to be used only to perform. direct. or integrato work under U.S. Dopartment of Eneray contrecte. This documont is not approved for public raloase until roviowed.

Patent Status This document copy, tince it is vansmitted in advance of patent clearance, ie made available in confidence sololy for Uso in performance of wark under contracts with the U.S. Department of Energy. This

document is not to be publithed nor its contents otherwise dis eominated or used for purposes other then epocifiod abovo bofore patent approval for euch rolease or use has been secured, upon request, from the Patent Councal.

U.S. Department of Energy, Fichland Operations Office, Richlond, WA. 


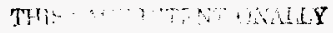
Nit: 
LOUL DISCIAINER

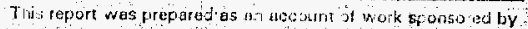
Ein agency of the Unitad States Gavernient. Weither tha

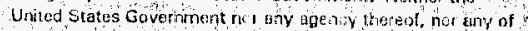

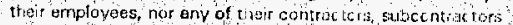

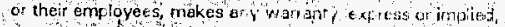

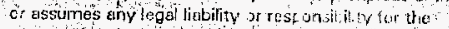
accuracy, completenoss or a $7 y$ thit pan's usa or the results of such use of any information, appiaratcs, priduct, er process disctosedior reptesents that il cise would not infringe privatêly ówned rights Roference fierein to anv spocilic commerclal product prócess, or servict by trade nan trademark, manulacture or othorwise, does not necessarily constifute or inplyits endorselment, recimniendation, of tevorng by the United States Government or eny egency thereof or its contractors or subcont accurs The views and opinions of authors expressed herain do ncit necessarily atste

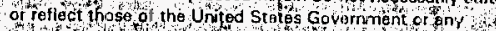

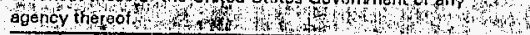

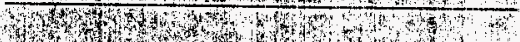

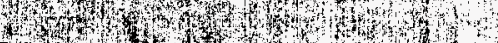
This report kas been reproduced from the best avalabla goph

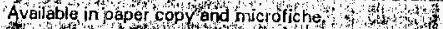

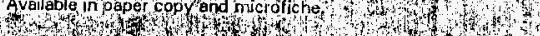

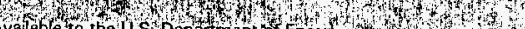
and its contostors fom

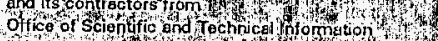

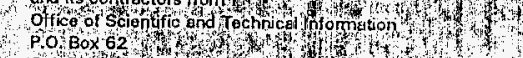

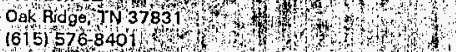

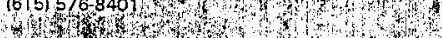

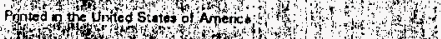

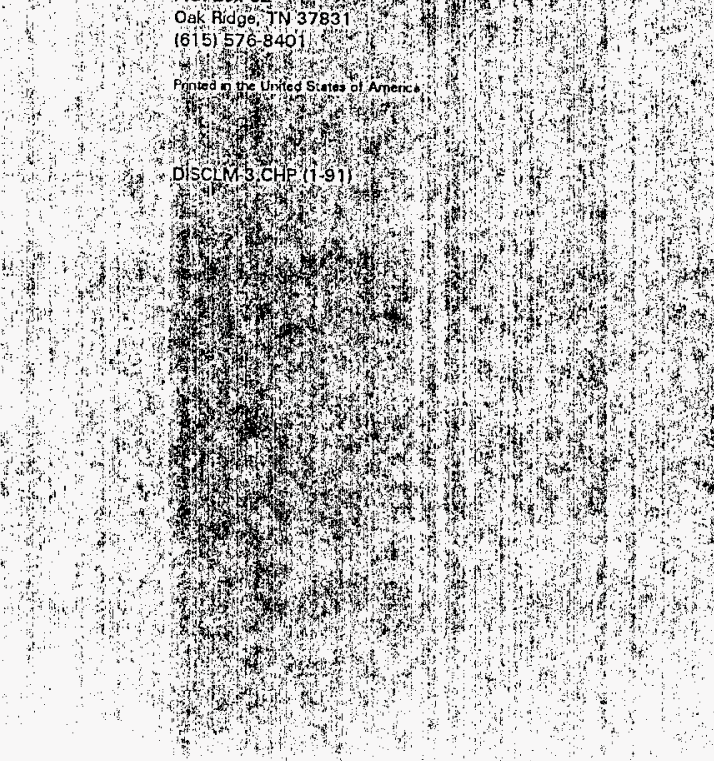
का (n) 


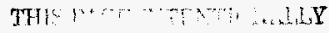
initif. 


\section{RELEASE AUTHORIZATION}

Document Number: WHC-SP-1193, Rev. 0

Document Title: Flammable Gas Project Topical Report

Release Date: $\quad 10 / 30 / 96$

This document was reviewed following the procedures described in WHC-CM-3-4 and is:

APPROVED FOR PUBLIC RELEASE

WHC Information Release Administration Specialist:
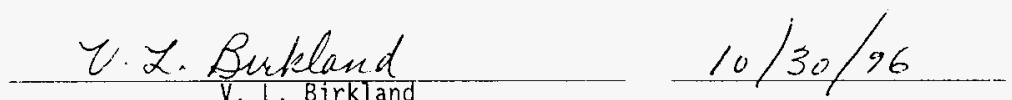


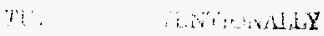
1... BLANK 


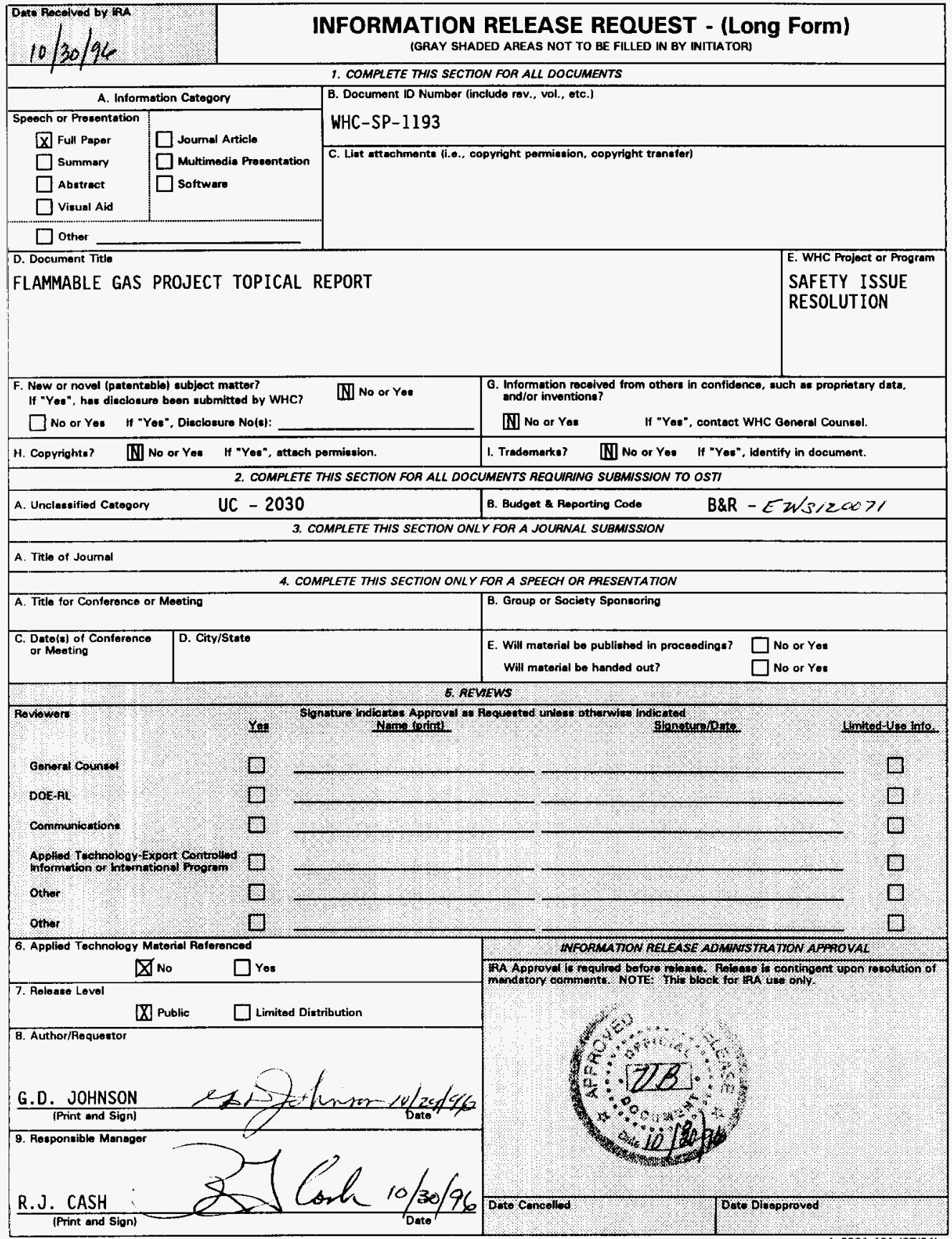




$$
\text { i... I BLANK }
$$


WHC-SP-1193

Document ID Number

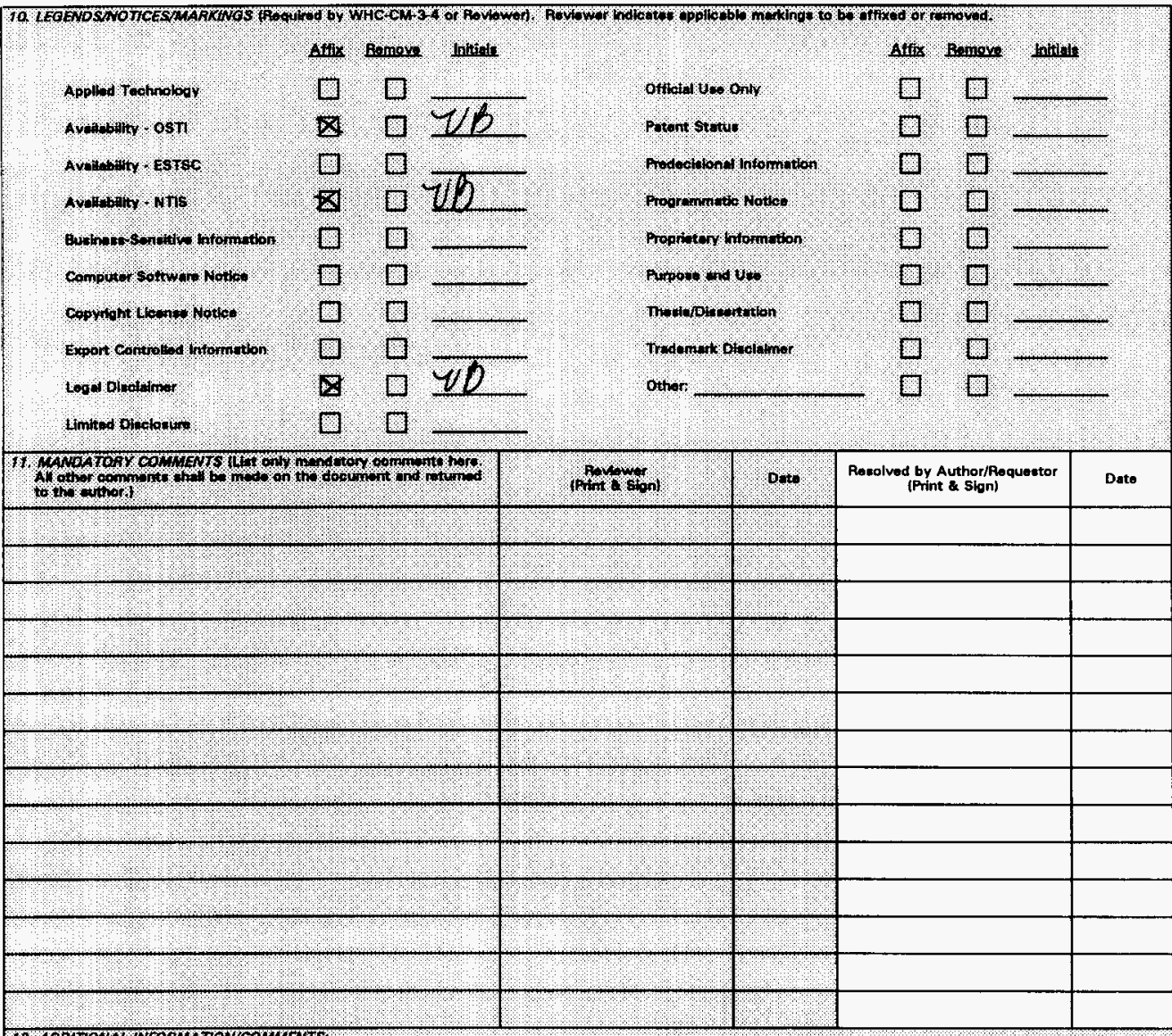


WHC-SP-1193 Rev. 0

\section{CONTENTS}

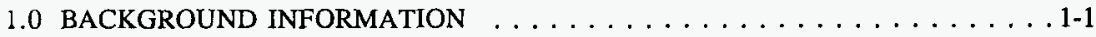

1.1 INTRODUCTION . . . . . . . . . . . . . . . .1-1

1.2 ELEMENTS OF THE FLAMMABLE GAS SAFETY ISSUE $\ldots \ldots \ldots \ldots 1-1$

1.3 THE UNREVIEWED SAFETY QUESTION $\ldots \ldots \ldots \ldots \ldots \ldots \ldots$

1.4 FLAMMABLE TANK WATCH LIST/PUBLIC LAW 101-510 $\ldots \ldots \ldots 1-3$

2.0 IDENTIFICATION OF WATCH LIST FLAMMABLE GAS TANKS . . . . . . 2-1

2.1 SCREENING TANKS USING WASTE LEVEL $\ldots \ldots \ldots \ldots \ldots \ldots .2-2$

2.1.1 Tank Rankings for Potential Hazard . . . . . . . . . . . . . . 2-5

2.2 FLAMMABLE GAS TANK EVALUATION METHODOLOGY $\ldots \ldots .2-5$

2.2.1 Methodology . . . . . . . . . . . . . 2-6

2.3 REVIEW OF THE METHODOLOGY $\ldots \ldots \ldots \ldots \ldots \ldots \ldots \ldots .2-8$

2.3.1 The Issue of More Watch List Tanks . . . . . . . . . . . . 2-8

2.3.2 The Recommended Resolution . . . . . . . . . . . . . . . 2-9

2.4 PRIORITIZATION OF SINGLE-SHELL TANKS

BY WASTE CONFIGURATION $\ldots \ldots \ldots \ldots \ldots \ldots \ldots \ldots \ldots$

2.4.1 Definition of Waste Configurations . . . . . . . . 2-14

2.4.2 Prioritization of Waste Configurations . . . . . . 2-18

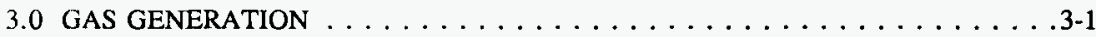

3.1 STUDIES USING SIMULATED WASTES $\ldots \ldots \ldots \ldots \ldots \ldots \ldots$ 3-1

3.2 STUDIES USING ACTUAL WASTE CORES $\ldots \ldots \ldots \ldots \ldots \ldots \ldots$ 3-6

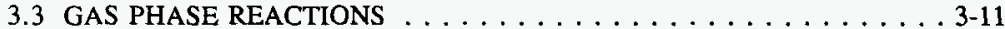

3.4 GAS SOLUBILITIES . . . . . . . . . . . . . . . 3-12

3.5 DETERMINATION OF IN-TANK GAS COMPOSITION . . . . . . 3-13

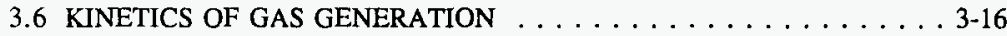

4.0 STORED GAS RETENTION . . . . . . . . . . . . . . . . . 4-1

4.1 GAS BUBBLE RETENTION MECHANISMS . . . . . . . . . . 4-1

4.2 EFFECT OF WASTE STRENGTH ON BUBBLE RETENTION $\ldots \ldots .4$ 4-2

4.3 EFFECT OF WASTE STRENGTH ON BUBBLE RELEASE . . . . . . . 4-4

4.4 COMPARISONS OF BUBBLE RETENTION MECHANISMS $\ldots \ldots \ldots$. . . 6

4.5 MECHANISMS DEPICTION OF GAS RETENTION . . . . . . . . . . . 4-7

4.6 ACTUAL WASTE STUDY, TANK 241-S-102 SALTCAKE . . . . . . . 4-11

4.7 MECHANISM OF RETENTION AND MAXIMUM RETENTION . . . 4-11

4.8 ESTIMATION OF RETAINED GAS . . . . . . . . . . . . 4-13

4.9 RETAINED GAS VOLUME DETERMINATION FROM LEVEL

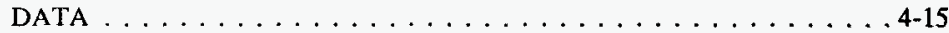




\section{CONTENTS}

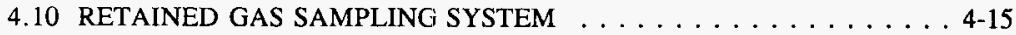

4.10.1 Push Mode Core Sampling System . . . . . . . . . 4-16

4.10.2 Retained Gas Sampler . . . . . . . . . . . . . 4-16

4.10.3 Extrusion/Extraction/Data Collection System . . . . . . . 4-16

4.10.4 Gas Sample Analysis System . . . . . . . . . . . 4-16

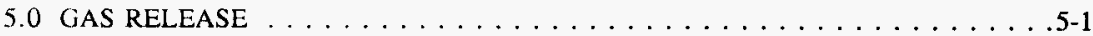

5.1 RELEASE MECHANISMS: UNDISSOLVED GAS . . . . . . . 5-1

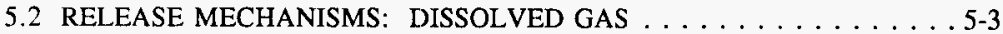

5.3 ESTIMATION OF GAS RELEASE EVENT FREQUENCIES $\ldots \ldots \ldots \ldots$. . . . .

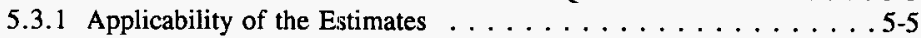

5.3.2 Potential for Improving the Results . . . . . . . . . . . 5-5

5.4 MODELING RELEASED GAS MIXING/CONCENTRATIONS $\ldots \ldots .5-5$

5.5 LEAN COMBUSTION OF GAS MIXTURES IN AIR . . . . . . . 5-6

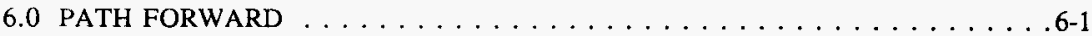

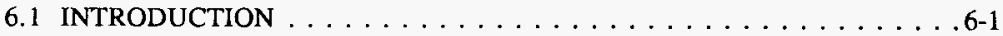

6.2 LABORATORY WORK REMAINING TO

UNDERSTAND GAS GENERATION . . . . . . . . . 6-1

6.3 LABORATORY WORK REMAINING TO

UNDERSTAND GAS RETENTION $\ldots \ldots \ldots \ldots \ldots \ldots \ldots$. . . . .

6.4 DIRECT MEASUREMENTS OF GAS BEHAVIOR IN WASTE TANKS . . 6-3

6.4.1 Measurement of Stored Gas Volume . . . . . . . . . 6-3

6.4.2 Measurement of Headspace Gases . . . . . . . . . . . 6-4

6.4 .3 Summary . . . . . . . . . . . . . . . . . . 6-10

6.5 UPDATING METHODOLOGY FOR EVALUATING

POTENTIAL FLAMMABLE GAS TANKS . . . . . . . . 6-11

6.6 APPROACH FOR CLOSURE OF THE FLAMMABLE GAS USQ . . . 6-12

6.6 .1 Background . . . . . . . . . . . . . 6-12

6.6 .2 Path Forward . . . . . . . . . . . . . . . 6-13

6.7 EVALUATION OF TANKS FOR REMOVAL FROM THE WATCH

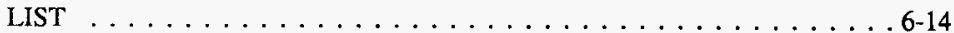

6.7.1 Steady-State Release of Flammable Gas . . . . . . . . . 6-15

6.7.2 Episodic Gas Release Events . . . . . . . . . . . 6-15

7.0 REFERENCES . . . . . . . . . . . . . . . . . .

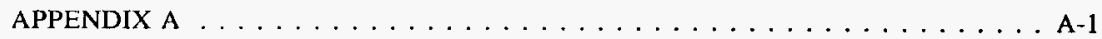




\section{LIST OF FIGURES}

3-1 Consumption of HEDTA and Appearance of Fragments as a Function of Time . . . 3-2

3-2 Generation of Hydrogen, Nitrogen, Nitrous Oxide, and Ammonia as a Function of Time.

3-3 Hydrogen Yield per Molecule HEDTA Consumed Versus Time for Tests with Air Cover Gas and with Argon Cover Gas . . . . . . . . . . . 3-5

3-4 Gas Generation Rates at Various Temperatures in the Presence and Absence of an External Source of Gamma Radiation . . . . . . . 3-7

3-5 Arrhenius Plot of Total Gas Generation Rates for Convective Layer of Tank 241-SY-103 . . . . . . . . . . . . . . . . 3-8

3-6 Comparison of Total Gas Generation from a Tank 241-SY-101 Core Composite and a Tank 241-SY-103 Convective Layer Sample . . . . . . . . . . 3-10

4-1 Schematic of Bubble Displacing Particles and a Dendritic Bubble Fingering

4-2 Bubbles Displacing Waste when Surface Tension Dominates $\left(\tau, D_{\text {particie }} / \gamma<<1\right)$ and when the Waste Strength Dominates $\left(\tau_{\mathrm{g}} \mathrm{D}_{\text {particle }} / \gamma>>1\right) \ldots \ldots \ldots \ldots \ldots \ldots \ldots$

4-3 Plot Showing the Location of Different Bubble Retention Regimes . . . . . . . 4-5

4-4 Bubble Growth and the Formation of a Connect Pathway of Bubbles . . . . . . 4-5

4-5 Gas Bubble Retention Mechanisms . . . . . . . . . . . . . . . . . . 4-9

4-6 Comparison of the Maximum Retention in Actual Waste Samples with the Results for Bentonite Clay Simulants . . . . . . . . . . . . . 4-12 
WHC-SP-1193 Rev. 0

\section{LIST OF TABLES}

2-1 Flammable Gas Watch List Tanks . . . . . . . . . . . . . . 2-1

2-2 Tanks Flagged by the Screening Calculation ................ $2-3$

2-3 Short List of High Priority Tanks ... . . . . . . . . . . 2-12

$2-4$ Tanks Ranked by Cluster $\ldots \ldots \ldots \ldots \ldots \ldots \ldots \ldots \ldots$. . . . . . . . . . . . .

3-1 Comparison of Yields from the Reaction of HEDTA in a Simulated Waste . . . . 3-4

3-2 Henry's Law Constants for Mother Liquor of Tank SY-101 Calculated Using Schumpe Model with Modified Gas Interaction Constants . . . . . . . . . . . 3-12

3-3 Estimated Quantity of Gas Dissolved in Entire Tank 241-SY-101 Wastes . . . . 3-13

3-4 Estimates of the Overall Composition of Gases at $46{ }^{\circ} \mathrm{C}$ in Tank 241-SY-101 . . 3-14

3-5 Hydrogen to Nitrous Oxide Ratios Calculated from Mass Spectrometry Analyses of Grab Samples . . . . . . . . . . . 3-15

4 - I Summary of Results . . . . . . . . . . . . . . . . . . . 4-14

5-1 Order of Magnitude Estimated Frequency of Gas Release Events Which Could Lead to Tank Dome Failure . . . . . . . . . . . . . . . . . . 5-4

6-1 Waste Tank and Gas Monitor Prioritization $\ldots \ldots \ldots \ldots \ldots$ 


\section{LIST OF TERMS}

DOE-RL

DST

FIC

HDW

$\mathrm{JCO}$

LFL

SCOPE

TWRS

TOC

USQ

USQD

VFI
U.S. Department of Energy, Richland Operations Office Double-Shell Tank

Food Instrument Corporation

Hanford Defined Waste

Justification for Continued Operation

lower flammability limit

Safety Control Optimization by Performance Evaluation

Tank Waste Remediation System

total organic carbon

Unreviewed Safety Question

Unreviewed Safety Question Determination

void fraction instrument 
WHC-SP-1193 Rev. 0

This page intentionally left blank. 
WHC-SP-1193 Rev. 0

\subsection{BACKGROUND INFORMATION}

\subsection{INTRODUCTION}

This report was prepared to satisfy the DNFSB Recommendation 93-5 Implementation Plan (DOE-RL 1996), Milestone 5.4.3.5.h. The milestone states the following: "Letter reporting completion of supporting technical document on Flammable Gas Safety Issue. (This topical report will describe the current understanding of the issue and future work for resolution)." The text of the Recommendation 93-5 Implementation Plan states:

"The flammable gas hazard will continue to exist until the wastes are retrieved from the tanks. However, DOE plans to resolve the Flammable Gas Safety Issue on a tank by tank basis when the following steps are completed: a) determination of the amount and composition of gas retained in the wastes; b) establishment of an adequate understanding of the mechanisms for gas generation, retention and release; and c) updating the Authorization Basis for the Manage Tank Waste Function."

The major emphasis of this report is to describe what has been learned about the generation, retention, and release of flammable gas mixtures in high-level waste tanks. A brief overview of efforts to characterize the gas composition will be provided. The report also discusses what needs to be learned about the phenomena, how the Unreviewed Safety Question will be closed, and the approach for removing tanks from the Watch List.

\subsection{ELEMENTS OF THE FLAMMABLE GAS SAFETY ISSUE}

Flammable gases, such as hydrogen and ammonia, are generated in radioactive wastes stored in 177 high-level waste tanks at the Hanford Site. These gas mixtures also contain an oxidizer (nitrous oxide) and an inert component (nitrogen). Some tanks retain the gas mixture until a fairly large amount builds up, then a short-term release occurs into the tank headspace. Such a release can result in a flammable concentration in the tank headspace. For this condition, the only remaining element required for a deflagration is an ignition source present at the time of the gas release.

The safety issue can be present in two situations: where a chronic release of gas occurs and where episodic gas releases occur. In the case of chronic releases, the problem resides in the balance between the rate of release of the gases and the rate of removal by the tank ventilation system. All 28 double-shell tanks have active ventilation systems, and chronic release is not a problem. However, 134 of 149 single-shell tanks have passive ventilation systems. Headspace samples were taken for these tanks to verify there is no problem with chronic releases of flammable gas mixtures. It was found that no tank had concentrations exceeding $25 \%$ of the lower flammability limit (LFL) (see Appendix A). 
In the case of episodic releases of gas, it is necessary to know how gases are retained, the amount and composition of the stored gas, the mode of release, and the amount released. These items will be addressed in subsequent sections. In addition, analytical methods were prepared for estimating the amount of stored gas will be discussed.

Because of episodic releases of flammable gases in tank 241-SY-101, an Unreviewed Safety Question (USQ) was declared in early 1990. At that time, the USQ encompassed 23 tanks. A Watch List was created in 1990 in response to the National Defense Authorization Act for Fiscal Year 1991, (Public Law 101-510, Section 3137, "Safety Measures for Waste Tanks at the Hanford Nuclear Reservation"). Tanks covered by the USQ were declared to be Watch List tanks. Today the Flammable Gas Watch List has 25 tanks. Although the USQ and Watch List were created at different times, the flammable gas safety issue is considered to involve both the USQ and the Watch List. Therefore, closing the safety issue requires closing the USQ, then removing affected tanks from the Watch List.

\subsection{THE UNREVIEWED SAFETY QUESTION}

The potential for flammable and/or explosive conditions resulting from the generation, retention, and release of flammable gas (for example, hydrogen) in high-level radioactive waste has been recognized as a hazard for some time. In 1990, the entrapment of large quantities of flammable gases in tank 241-SY-101 waste was recognized as a unique situation requiring special attention and control. In April 1990, administrative controls were implemented to control activities in tank 241-SY-101 and in other tanks that potentially had similar behavior (Bracken 1990).

In May 1990, the U.S. Department of Energy-Richland Operations Office (DOE-RL) determined that hydrogen and nitrous oxide evolution in the material of certain waste tanks and the possibility of its ignition constituted a USQ (Lawrence 1990). The USQ was applied to tanks previously identified as tanks of concern in Bracken (1990).

In July 1996, the Westinghouse Hanford Company updated the original USQ and consolidated previous USQ determinations (USQD) into one USQD and transmitted it to DOE-RL on July 31,1996 . The USQD expands the USQ in the following key areas:

- Flammable gas composition

- Applicability of USQ to additional structures

- Methods of gas generation, gas release events, and release potential (gas generation, spontaneous and induced episodic releases, steady state release, release potential)

- Location of hazard 
- Energetics and characteristics of burns

Concurrent with the USQD submittal, there was a submittal of a justification for continued operation (JCO). The JCO provides detailed descriptions and data for the flammable gas hazards identified in the USQD. Work controls and equipment requirements were developed and documented. The controls and requirements include adaptations, expansions, and refinements to existing Authorization Basis controls and other administrative practices currently used to manage the flammable gas hazard.

\subsection{FLAMMABLE TANK WATCH LIST/PUBLIC LAW 101-510}

In November 1990, the National Defense Authorization Act for Fiscal Year 1991 (Public Law 101-510, Section 3137, "Safety Measures for Waste Tanks at the Hanford Nuclear Reservation," [the Wyden Amendment] was passed. It required the Secretary of Energy to identify within 90 days high-level nuclear waste tanks that could have a "serious potential for release of high-level waste due to uncontrolled increases in temperature or pressure." The identified tanks contained flammable gas, ferrocyanide ions, organic chemicals, and high radioactive decay heat.

In January 1991, the Westinghouse Hanford Company formally submitted a Watch List of tanks subject to the law (Harmon 1991a). In February 1991, Westinghouse Hanford submitted a method for selecting flammable gas tanks (Harmon 1991b). This selection process improved the original 1990 process, and two additional tanks were placed on the Watch List. Harmon (1991b) also proposed a method for removing tanks from the Watch List. The Watch List identified 23 tanks with flammable gas hazards subject to National Defense Authorization Act for Fiscal Year 1991. In 1994, two additional tanks were added to the Watch List.

The Westinghouse Hanford Company recognized that improvements could be made in the selection criteria used for determining tanks that should be on the Flammable Gas Watch List. In August 1994, Westinghouse Hanford issued the Criteria for Flammable Gas Watch List Tanks (Hopkins 1994). A revised criteria document for selecting Flammable Gas Watch List tanks was submitted to DOE in 1996 (Bacon 1996). Currently, the revised criteria are being considered by DOE.

The proposed criteria for selecting tanks for the Flammable Gas Watch List include the following:

- Tanks in which the entire headspace could reach $100 \%$ of the LFL, or

- Tanks in which a plume, if ignited, would pressurize the tank and cause structural damage. 
WHC-SP-1193 Rev. 0

The proposed criterion for removing tanks from the Flammable Gas Watch List is as follows:

- Tanks can be removed from the Watch List where controls or mitigative features are implemented and maintained within the DOE-approved authorization basis. 


\subsection{IDENTIFICATION OF WATCH LIST FLAMMABLE GAS TANKS}

Identifying tanks that should be included on the Flammable Gas Watch List has occurred over time. Initially, the tanks identified were those likely to retain significant quantities of gas. The identification was based on a review of historical data and the judgment of engineers. A list of characteristics was developed that were considered important contributors to gas release type behavior in tanks or that indicated such behavior existed. The process of identifying tanks was revised twice. As a result, 23 tanks were placed on the Flammable Gas Watch List when it was established in 1991. Subsequently, tank 241-AW-101 was added (1992) because a gas release event was responsible for a level drop in the tank. Tank 241-U-107 was added (1993) because data indicated the tank was retaining gas. No tank has been removed from the Flammable Gas Watch List, and no formal criteria have been developed to establish a threshold for removing a tank from the Watch List although proposed criteria have been submitted to DOE.

Section 2.0 describes recent screening activities and a method to evaluate flammable gas tanks. The issue of conservatism in the evaluation is addressed. Table 2-1 lists the tanks on the Flammable Gas Watch List (Hanlon 1996).

Table 2-1. Flammable Gas Watch List Tanks. (2 sheets)

\begin{tabular}{|c|c|}
\hline 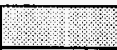 & Ypor \\
\hline A-101 & SST-4 \\
\hline $\mathrm{AN}-103$ & DST \\
\hline AN-104 & DST \\
\hline AN- 105 & $\overline{D S T}$ \\
\hline AW-101 & DST \\
\hline$A X-101$ & SST-4 \\
\hline $\mathrm{AX}-103$ & SST-4 \\
\hline$S-102$ & SST-3 \\
\hline$S-111$ & SST-3 \\
\hline$S-112$ & SST-3 \\
\hline$S X-101$ & SST-4 \\
\hline $\mathrm{SX}-102$ & SST-4 \\
\hline SX-103 & SST-4 \\
\hline SX-104 & \begin{tabular}{|l|} 
SST- \\
\end{tabular} \\
\hline$S X-105$ & \begin{tabular}{|l|} 
SST-4 \\
\end{tabular} \\
\hline SX-106 & SST-4 \\
\hline SX-1092 & SST-4 \\
\hline
\end{tabular}


Table 2-1. Flammable Gas Watch List Tanks. (2 sheets)

\begin{tabular}{|l|l|}
\hline \multicolumn{1}{|c|}{ Watch WistuSO Tanks } & \multicolumn{1}{|c|}{ Type': } \\
\hline SY-101 & DST \\
\hline SY-103 & DST \\
\hline T-110 & SST-2 \\
\hline $\mathrm{U}-103$ & SST-2 \\
\hline $\mathrm{U}-105$ & SST-2 \\
\hline $\mathrm{U}-107$ & SST-2 \\
\hline $\mathrm{U}-108$ & SST-2 \\
\hline $\mathrm{U}-109$ & SST-2 \\
\hline
\end{tabular}

Notes:

$$
\begin{aligned}
& \text { SST }=\text { Single-shell tank } \\
& \text { DST }=\text { Double-shell tank } \\
& \text { 'Tank capacities are as follows: } \\
& \text { SST-1 }=208 \mathrm{~kL}(55,000 \mathrm{gal}) \\
& \text { SST-2 }=2,006 \mathrm{~kL}(530,000 \mathrm{gal}) \\
& \text { SST-3 }=2,869 \mathrm{~kL}(758,000 \mathrm{gal}) \\
& \text { SST-4 }=3,785 \mathrm{~kL}(1,000,000 \mathrm{gal}) \\
& \text { DST }=4,391 \mathrm{~kL}(1,160,000 \mathrm{gal})
\end{aligned}
$$

This tank was placed on the Watch List because five other Watch List tanks vent into it.

\subsection{SCREENING TANKS USING WASTE LEVEL ${ }^{1}$}

Gases, generated in the waste, may be trapped and cause an increase in the waste volume. This volume is reflected in an increase in the waste level. Early work on tank 241-101-SY showed an inverse correlation between waste level measurements and ambient atmospheric pressure. The interpretation of this relationship is that increased atmospheric pressure compressed the gas trapped in the waste, thereby decreasing the waste level. Using this observed relationship, an algorithm was developed to look at the historical level data with respect to barometric pressure for all tanks and to identify those tanks for which a statistical correlation exists. The algorithm produced results equivalent to $95 \%$ confidence that a flagged tank did indeed have the correlation of interest.

Waste level measurements are made to monitor tanks for leaks and intrusions. Four measurement devices are used: three measure the level of the waste surface (manual tape, Food Instrument Corporation [FIC], and ENRAF surface level tapes); the fourth uses a

\footnotetext{
${ }^{1}$ Whitney (1995)
} 
neutron probe within a well embedded in the waste to monitor the liquid level (where the level is below a dry waste surface).

The screening was applied to data from each measurement device in each tank. No assessment was made about data quality. If any data for a single-shell tank indicated trapped gas, that tank was flagged by the screening process. This resulted in 58 of 177 Hanford tanks being flagged as potentially containing trapped gas. It included 21 of 25 tanks currently on the Flammable Gas Watch List.

Table 2-2 presents the results of this screening study. Tank/instruments combinations are marked "gas," "ng," and "-" depending on whether they were flagged as containing trapped gas, not flagged, or where data was insufficient for the screening to proceed. An asterisk indicates the tanks on the Flammable Gas Watch List.

This study was qualitative because it only identified tanks that showed evidence of gas retention. No attempt was made to develop quantitative estimates of the amount of gas trapped.

Table 2-2. Tanks Flagged by the Screening Calculation.' ${ }^{1}$ ( 3 sheets)

\begin{tabular}{|c|c|c|c|c|}
\hline (1) & TTC & WT & BNAW & Neriron 1 Th \\
\hline $\mathrm{A}-101^{*}$ & gas & gas & - & ng \\
\hline$\overline{A-103}$ & gas & ng & - & ng \\
\hline$A N-103^{*}$ & gas & - & - & - \\
\hline $\mathrm{AN}-104^{*}$ & gas & - & - & - \\
\hline AN-105* & gas & - & - & - \\
\hline AP-105 & gas & ng & - & - \\
\hline AP- 107 & gas & ng & - & - \\
\hline$A W-101 *$ & gas & ng & - & - \\
\hline$A W-103$ & gas & - & - & - \\
\hline $\mathrm{AW}-104$ & gas & ng & - & - \\
\hline$A W-106$ & ng & gas & - & - \\
\hline $\mathrm{AX}-103^{*}$ & gas & - & - & - \\
\hline$A Y-101$ & $\mathrm{ng}$ & gas & - & - \\
\hline AZ-101 & ng & gas & - & - \\
\hline $\mathrm{BX}-104$ & gas & ng & - & - \\
\hline $\mathrm{BX}-107$ & gas & - & - & - \\
\hline $\mathrm{BX}-112$ & gas & ng & - & - \\
\hline BY -101 & - & ng & - & gas \\
\hline BY-102 & - & gas & - & ng \\
\hline
\end{tabular}


Table 2-2. Tanks Flagged by the Screening Calculation. ${ }^{1}$ ( 3 sheets)

\begin{tabular}{|c|c|c|c|c|}
\hline Tank & TrC & MT & ENRA $F^{2}$ & Newtron III \\
\hline BY-103 & - & gas & - & ng \\
\hline BY-105 & - & $n g$ & - & gas \\
\hline BY-109 & gas & - & $\mathrm{ng}$ & $\mathrm{ng}$ \\
\hline$C \cdot 104$ & $\overline{\text { gas }}$ & $\mathrm{ng}$ & - & - \\
\hline C-105 & $\mathrm{ng}$ & gas & $=$ & - \\
\hline$\overline{C-107}$ & gas & - & - & - \\
\hline S-101 & gas & $\mathrm{ng}$ & - & $\mathrm{ng}$ \\
\hline$S-102^{*}$ & gas & ng & - & $\mathrm{ng}$ \\
\hline S-103 & gas & $\mathrm{ng}$ & $\mathrm{ng}$ & $\mathrm{ng}$ \\
\hline$S-105$ & $\mathrm{ng}$ & $\mathrm{ng}$ & - & gas \\
\hline S-106 & gas & $\mathrm{ng}$ & gas & gas \\
\hline S-107 & gas & $\mathrm{ng}$ & $\overline{n g}$ & - \\
\hline S-109 & $\overline{\mathrm{ng}}$ & $\mathrm{ng}$ & - & gas \\
\hline$S-111^{*}$ & gas & $\mathrm{ng}$ & gas & $\mathrm{ng}$ \\
\hline$S X-102^{*}$ & gas & gas & - & $\mathrm{ng}$ \\
\hline $\mathrm{SX}-102^{*}$ & gas & $\mathrm{ng}$ & - & $\mathrm{ng}$ \\
\hline $\mathrm{SX}-103^{*}$ & gas & $\mathrm{ng}$ & - & ng \\
\hline SX-104* & gas & $\mathrm{ng}$ & - & $\mathrm{ng}$ \\
\hline $\mathrm{SX}-105^{*}$ & gas & $\mathrm{ng}$ & - & $\mathrm{ng}$ \\
\hline $\mathrm{SX}-106$ & gas & $\mathrm{ng}$ & $\mathrm{ng}$ & gas \\
\hline SY-101 & gas & gas & $\mathrm{ng}$ & - \\
\hline SY-103* & gas & ng & $\mathrm{ng}$ & - \\
\hline$T-107$ & gas & - & $\mathrm{ng}$ & - \\
\hline T-111 & gas & - & - & $\mathrm{ng}$ \\
\hline TX-102 & - & gas & - & $\mathrm{ng}$ \\
\hline TX-107 & gas & - & - & - \\
\hline TX-111 & - & gas & - & gas \\
\hline $\mathrm{TX}-112$ & - & gas & - & gas \\
\hline TX-113 & - & $\mathrm{ng}$ & - & gas \\
\hline $\mathrm{TX}-115$ & - & $\mathrm{ng}$ & - & gas \\
\hline $\mathrm{TY}-102$ & gas & - & - & - \\
\hline TY-103 & gas & - & - & $\mathrm{ng}$ \\
\hline $\mathrm{U}-102$ & gas & - & - & gas \\
\hline
\end{tabular}


Table 2-2. Tanks Flagged by the Screening Calculation. ${ }^{1}$ ( 3 sheets)

\begin{tabular}{|c|c|c|c|c|}
\hline Tank & TIO & $\mathrm{MT}$ & GNR P $^{2}$ & Mentron II \\
\hline U-103* & gas & - & $\mathrm{ng}$ & gas \\
\hline $\mathrm{U}-105^{*}$ & gas & gas & ng & ng \\
\hline U-106 & gas & - & ng & gas \\
\hline $\mathrm{U}-107^{*}$ & gas & - & ng & gas \\
\hline $\mathrm{U}-108$ & gas & & - & ng \\
\hline $\mathrm{U}-109^{*}$ & gas & - & ng & ng \\
\hline
\end{tabular}

Notes:

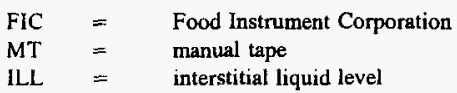

'Whitney (1995)

2ENRAF is a trademark of the ENRAF Corporation, Houston, Texas.

\subsubsection{Tank Rankings for Potential Hazard}

Based on the screening, it is not possible to rank tanks accurately by degree of flammable gas hazard. The analysis is qualitative, and the information base supporting Table 2-2 is insufficient to support calculations. Additional information and analyses are needed to rank the tanks including the following: tank waste density, gas distribution in the tank, gas composition, tank headspace volume, headspace ventilation rates, probability of a gas release event, probability of an ignition, and the amount of gas released in each gas release event.

\subsection{FLAMMABLE GAS TANK EVALUATION METHODOLOGY²}

After publishing the Flammable Gas Watch List, the Westinghouse Hanford Company developed criteria for identifying future tanks which should be placed on the Flammable Gas Watch List (Hopkins 1994). The criteria were based on the following four flammable gas conditions that might be factors in releasing waste to the environment: a steady-state concentration of flammable gas in the tank headspace, a concentration of trapped gas after an episodic release, the ignition of a gas plume as it escapes from the waste, and an over pressurization of the tank exhaust filter caused by the release of pressurized gas from the waste. To provide a margin for error in the calculations, $25 \%$ of each quantity stated above

\footnotetext{
${ }^{2}$ Hopkins (1995)
} 
was established as the threshold. This level is consistent with National Fire Protection Association practice.

The overall logic for evaluating tanks was based on a three-stage approach.

- When little or no tank-specific information is available, perform bounding (worst-case) calculations of potential gas releases/concentrations using general information (for example, total waste volume, surface level history, type waste) and information about tank 241-SY-101 and other flammable gas tanks.

- When indirect measures of trapped gas content/releases or headspace concentration become available, use the information to improve the calculations. These results supersede the worst case calculations.

- When direct measures become available, use the information to further improve the calculations. These results supersede the worst case calculations or indirect measures.

\subsubsection{Methodology}

To evaluate tanks against the criteria, a three step process was developed. Estimates must be made of the inventory of flammable gas at risk. Once the inventory is known, it is released to the tank headspace, then the resulting condition of interest (concentration, plume size, pressure, etc.) is calculated. Because many physical mechanisms that control these processes were not well understood, a large number of conservative assumptions were made.

2.2.1.1 Steady State Concentration. Because a headspace sampling program was in place, a significant body of data is available to compare calculated steady-state flammable gas concentration to actual measurements. This comparison showed the calculated methods always overstated the flammable gas concentration, sometimes by more than $1,000 \%$. Because of this and because direct measurements are available, this measurement is always used if any question exists in the calculations passing the criteria.

2.2.1.2 Gas Release Event. An estimate must be made of the gas inventory stored in the tank, the fraction of the inventory released in a single event must be applied, and the gas composition and the volume of headspace available to dilute the gas must be known. Two methods were developed to estimate the gas inventory in a tank: 1) the surface level rise method uses the long-term change in tank surface level from the time the tank was filled to the present, and 2) the barometric pressure effect method, an enhancement of the screening method. Each method relies upon several unvalidated assumptions, corrections based on limited historical data, and simplistic physical models.

The release fraction is applied uniformly to all tanks regardless of waste configuration. A bounding value of $25 \%$ was chosen. This figure is larger than the release fraction seen in all 
tanks except tank 241-101-SY. It is further assumed that the rate of release is rapid with respect to the ventilation rate of the tank; therefore, no time dependence is introduced into the calculation.

Because the composition of the released gas is unknown for most tanks, a bounding composition of $97 \%$ hydrogen and $3 \%$ waste vapor is used. This composition assumes all the flammable gas is generated by radiolysis of water, a condition which may exist in some cooler, low-organic, single-shell tanks.

The fraction of trapped gas released may occur over several hours, days, or weeks rather than the time frame used currently (minutes), and its flammability may be lower than estimated. The retained-gas sampler is now being used to determine the composition of trapped gases in tank waste. The fraction of $\mathrm{NH}_{3}$ released by mass transport was assumed to be 6.22 times the amount of trapped gas released. However, the possible concentration of $\mathrm{NH}_{3}$ in the headspace may be limited by other factors.

2.2.1.3 Surface Level Rise Method. In principle, the surface level rise method is simple. The level at the time the tank is filled is subtracted from the current level, and the difference between the levels is the volume of trapped gas unless other explanations for differences are available. In practice, this method is very difficult to defend because of the many corrections which can be introduced. The corrections address additions to and losses from the tank or changes in the waste volume caused by intrusions, flushes, equipment installation, recrystalization, condensation, leaks, evaporation, settling, etc. Because some tanks were filled more than once, records showed pre-existing gas volumes based on material balance discrepancies for some tanks. The basis for many corrections is poorly documented or has low resolution so that the corrections themselves introduce potential error terms larger than the magnitude of the measured surface level rise. When applying this method, anything that increased the estimate was included but anything that decreased the estimate was excluded.

2.2.1.5 Data Quality. For some parameters, the data scatter is very wide. Improving the instrumentation used to measure the surface level would greatly reduce data scatter in the barometric pressure effect. With the barometric slope, a very negative slope or a wide range on the slope is a result of poor surface level data. Poor data can result from an imprecise gauge, infrequent readings, or manual readings entered into the Surveillance Analysis Computer System database several hours after being taken. These problems can be solved by installing ENRAF gauges on tanks which do not currently have them and connecting the gauges to the Tank Monitoring and Control System for automatic data capture.

It is important to know where the surface level plummet contacts the surface. It is assumed that the level at which the plummet contacts the waste is the average waste height unless the plummet is in a hole. Without recent photographs or videos, there may be considerable uncertainty about where the plummet contacts the waste. 
Although the methodology allows for a conservative assessment of the flammable gas hazard of the tanks, in combination with the criteria it significantly overestimates the hazard for most tanks.

\subsection{REVIEW OF THE METHODOLOGY ${ }^{3}$}

A critical review was made of the methodology for evaluating flammable tanks. An interdisciplinary team was appointed with members from the DOE-RL, Westinghouse Hanford Company, Pacific Northwest National Laboratory, Los Alamos National Laboratory and Chemical Reactions Subpanel of the High-Level Waste Advisory Panel. The team, technically knowledgeable about tank waste and flammable gas issues, reached a consensus about the flammable gas safety issue and the wisdom of placing additional tanks on the Flammable Gas Watch List.

\subsubsection{The Issue of More Watch List Tanks}

The Westinghouse Hanford Company with the support of the Pacific Northwest National Laboratory screened all 177 Hanford tanks against its criteria for identifying additional Flammable Gas Watch List tanks. As a result of conservative in-depth analysis, 52 tanks were identified as failing the criteria evaluation using the methods discussed. Twenty-one of these tanks were already on the Watch List.

The documentation of the methods and analysis used in analyzing potential Flammable Gas Watch List tanks includes the following:

1. Hopkins, J. D., 1994, Criteria for Flammable Gas Watch List Tanks, WHC-EP-0702, Rev. 0., Westinghouse Hanford Company.

2. Whitney, P. D., 1995, Screening the Hanford Tanks for Trapped Gas, PNL-10821, Pacific Northwest Laboratory.

3. Hopkins, J. D., 1996, Methodology for Flammable Gas Evaluations WHC-SD-WM-TI-724, Rev. 1, Westinghouse Hanford Company.

4. Hodgson, K. M., R. P. Anantamula, S. A. Barker, K. D. Fowler, D. C. Hedengren, J. D. Hopkins, J. A., Lechelt, D. A. Reynolds, R. E. Stout, and R. T. Winward, 1996, Evaluation of Hanford Tanks for Trapped Gas, WHC-SD-WM-ER-526, Rev. 1, Westinghouse Hanford Company.

\footnotetext{
JJohnson (1996a)
} 
Westinghouse Hanford recommended to DOE in December 1995 that 25 additional tanks be added to the Flammable Gas Watch List. A second phase of the analysis, completed in March 1996, expanded the number of candidate tanks for the Watch List to 32. The Tank Waste Remediation System submitted the recommendation to DOE-Headquarters (HQ). The DOE-HQ requested that the Chemical Reactions Subpanel of the Tank Waste Advisory Panel review the recommendation and comment. The subpanel questioned the validity of the model used to calculate the parameters and the quality of the data used. As a result of these comments, DOE-RL formed a team to review the recommendations.

\subsubsection{The Recommended Resolution}

The analysis of the 57 tanks and the recommendation to place them on the Watch List were reviewed by a multi-disciplinary team. Two issues were raised: the criteria that should be used to add tanks to the Watch List, and the information that should be used to make that decision.

The findings of the review team are as follows:

No recommendation should be made or accepted for adding tanks to the Flammable Gas Watch List at this time based on the concepts, assumptions, and data central to the analysis and decision logic underlying the proposal for the following reasons:

1. The results of the analysis are not sufficiently definitive for the following reasons:

The models are elementary and do not represent adequately the physical situation of the waste in all tanks. The calculation bases established by the models need to be validated before they are determined to be reliable for volume estimates.

The data currently available are highly variable and lack the precision and accuracy necessary to make estimates of the retained gas.

A physical mechanism responsible for an assumed large spontaneous release of gas, pertaining to waste configuration characteristic of that in the single-shell tanks, is not, at this time, supported by data or conceptual physical models.

2. The current criteria for the Watch List constitute a simple numerical threshold without additional qualifying conditions. Implementation depends on determining consistently reliable numerical values. Within the context of the potential flammable gas tank conditions and the intrinsic uncertainty in the models and data, the criteria cannot be used equitably for the addition to and removal from the Watch List. At present, it is easy to add tanks to the Watch List, but it is difficult to make the technically authoritative argument, given the existing uncertainty, for removing them when such action is challenged. 
3. Tanks for which a significant potential for a radioactive release exists are required to be controlled by the USQ process for flammable gas. These tanks are maintained under the highest level of operational controls. Adding tanks to the Watch List, on the basis of an unproven methodology, will not provide additional safety benefits.

The team also identified concerns about the screening process used to identify tanks containing trapped gas. Approximately $40 \%$ of the tanks were screened using data that lacked the precision and sensitivity to identify gas that might have been present. The team also recommended that the screening process be reexamined to determine whether tanks had been missed and to define more accurately the nature of the screening process.

The Flammable Gas Watch List remains unchanged as a result of these evaluations. However, the ignition controls on all tanks have been increased.

\subsection{PRIORITIZATION OF SINGLE-SHELL TANKS BY WASTE CONFIGURATION ${ }^{4}$}

It is important to understand the physical characteristics of the waste in which gas is stored. By relating gas retention and release behavior to particle size, liquid content, layering, or other waste properties that can be observed or measured, understanding of the flammable gas hazard and the accuracy of predictions can be increased.

The large number of tanks and the uncertainties about waste properties make it difficult to study them in detail. Accordingly, a prioritized list of single-shell tanks was developed to help select candidates for detailed study. This list includes most single-shell tanks on the current Flammable Gas Watch List and tanks known to store or likely to store significant flammable gas volumes. The list included tanks that exhibited at least one of the following criteria.

1. The tank must be on the flammable gas or organic salt Watch List because it exhibits one or more characteristics that suggest a safety concern.

2. The tank must be flagged by the screening calculation with an estimated response greater than $0.2 \mathrm{~cm} / \mathrm{kPa}$ (Whitney 1995). Such a tank would show evidence of sufficient retained gas volumes to potentially produce flammable mixtures if they were all released into the tank headspace.

3. The tank must be contain high headspace concentrations of hydrogen $(>200$ $\mathrm{ppm}$ ) or ammonia ( $>400 \mathrm{ppm}$ ). This suggests a significant gas generation rate although the gas is not necessarily retained.

\footnotetext{
${ }^{4}$ Stewart et al. (1996a)
} 
Tanks that showed evidence of storing relatively little flammable gas based on one or more of the following factors were eliminated.

1. The tank waste depth was insufficient $(<2.5 \mathrm{~m})$.

2. The tank was interim stabilized, and headspace concentrations of hydrogen and ammonia were low (hydrogen $<100 \mathrm{ppm}$ and ammonia $<200 \mathrm{ppm}$ ) or unavailable.

3. The tank was flagged by Whitney's screening calculation, but it had a level response of magnitude less than $0.2 \mathrm{~cm} / \mathrm{kPa}$. In this case, the screening calculation confirms a relatively small retained gas volume; therefore, the tank is less a concern for gas retention and episodic release, even though it might have Watch List status and/or show high headspace concentrations of hydrogen or ammonia.

4. The tank is passively ventilated and has low observed headspace concentrations (hydrogen $<100 \mathrm{ppm}$ and ammonia $<200 \mathrm{ppm}$ ) indicating that gas generation rates are low.

Elimination was somewhat more subjective. Some tanks with low or borderline depths were retained on the list because of other factors such as a large level response to barometric pressure or high headspace concentrations of some gases. Unusual features of the level history were also considered, for example, large rises, declines, or oscillations.

Table 2-3 shows the 25 tanks that were selected for a high priority "short list." The table lists the Watch List status of each tank: FG or ORG indicates tanks on the flammable gas or organic Watch Lists; fg or org indicates tanks that are proposed for the flammable or organic Watch Lists (Johnson 1996b). The 50th percentile value of the level response (dL/dP) in $\mathrm{cm} / \mathrm{kPa}$ from Hodgson et al. (1996) is given if measured by a FIC or ENRAF instrument. Hydrogen $\left(\mathrm{H}_{2}\right)$ and ammonia $\left(\mathrm{NH}_{3}\right)$ concentrations measured in the headspace are given in parts per million. The priority rating of the tanks was verified with Brown et al. (1995). All but four tanks ranked above the median on this priority score. 
Table 2-3. Short List of High Priority Tanks. (2 sheets)

\begin{tabular}{|c|c|c|c|c|c|c|}
\hline Tank & $\begin{array}{l}\text { Watch } \\
\text { List }\end{array}$ & allof & (mepth & $\mathbf{H}_{2}$ & NH, & Rationale for Selection \\
\hline $\mathrm{C}-102$ & ORG & & 3.78 & 165 & 192 & Watch List (WL), some $\mathrm{H}_{2}, \mathrm{NH}_{3}$ \\
\hline SX-104 & FG & & 5.59 & & & WL, level oscillations \\
\hline S-102 & $\mathrm{FG} / \mathrm{ORG}$ & -0.51 & 5.18 & 670 & 418 & $\begin{array}{l}\text { WL, large } \mathrm{dL} / \mathrm{dP} \text {, slurry growth, } \\
\text { high } \mathrm{H}_{2}, \mathrm{NH}_{3}\end{array}$ \\
\hline S-103 & $\mathrm{fg}$ & -0.34 & 2.70 & & & $\begin{array}{l}\text { WL, dL/dP, erratic slurry } \\
\text { growth, borderline depth }\end{array}$ \\
\hline U-103 & FG/ORG & -0.27 & 4.20 & 557 & 761 & $\begin{array}{l}\text { WL, dL/dP, slurry growth, high } \\
\mathrm{H}_{2}, \mathrm{NH}_{3}\end{array}$ \\
\hline $\mathrm{U}-105$ & FG/ORG & -0.23 & 3.80 & & & $\mathrm{WL}, \mathrm{dL} / \mathrm{dP}$, slurry growth \\
\hline $\mathrm{U}-107$ & FG/ORG & -0.18 & 3.70 & 505 & 474 & WL, slurry growth \\
\hline U-108 & FG/org & & 4.20 & & & WL, slurry growth \\
\hline U-109 & FG/org & -0.20 & 4.20 & & & $\mathrm{WL}, \mathrm{dL} / \mathrm{dP}$, slurry growth \\
\hline $\mathrm{U}-111$ & ORG & & 3.00 & 250 & 682 & $\begin{array}{l}\text { WL, slurry growth, high } \mathrm{H}_{2} \text {, } \\
\mathrm{NH}_{3}\end{array}$ \\
\hline BY-109 & fg & & 3.30 & & & $\begin{array}{l}\text { WL, slurry growth between } \\
\text { pumpings, headspace } \\
\text { concentration not available }\end{array}$ \\
\hline $\mathrm{T}-110$ & FG & & 3.70 & & & $\begin{array}{l}\text { WL, annual oscillation, slight } \\
\text { growth }\end{array}$ \\
\hline SX-102 & FG & -0.35 & 5.00 & & & $\mathrm{WL}, \mathrm{dL} / \mathrm{dP}$ \\
\hline$S X-105$ & FG & & 6.20 & & & $\begin{array}{l}\text { WL, headspace concentration } \\
\text { not available, large linear level } \\
\text { decline }\end{array}$ \\
\hline SX-103 & FG/ORG & -0.57 & 6.10 & $<23$ & 80 & $\begin{array}{l}\text { WL, large } \mathrm{dL} / \mathrm{dP} \text {, linear level } \\
\text { decline }\end{array}$ \\
\hline$S X-106$ & FG/ORG & -0.23 & 5.10 & $<98$ & 188 & $\mathrm{WL}, \mathrm{dL} / \mathrm{dP}$, slurry growth \\
\hline S-106 & $\mathrm{fg}$ & -0.94 & 4.52 & & & WL, large $\mathrm{dL} / \mathrm{dP}$, slurry growth \\
\hline S-111 & FG/ORG & -0.40 & 5.20 & 392 & & $\begin{array}{l}\text { WL, dL/dP, slight slurry } \\
\text { growth, high } \mathrm{H}_{2}\end{array}$ \\
\hline S-112 & FG & & 5.00 & & & $\begin{array}{l}\text { WL, surface decline, liquid rise, } \\
\text { headspace concentration not } \\
\text { available }\end{array}$ \\
\hline
\end{tabular}


Table 2-3. Short List of High Priority Tanks. (2 sheets)

\begin{tabular}{|c|c|c|c|c|c|c|}
\hline Tank & Watch & aldop & Depth. & 1. & $\mathrm{NH}_{3}$ & Rationale ror Selection \\
\hline BY-104 & FG/org & & 3.30 & 312 & & $\mathrm{WL}$, high $\mathrm{H}_{2}$ \\
\hline BY-107 & FG/org & & 2.60 & 698 & 963 & WL, high $\mathrm{H}_{2}, \mathrm{NH}_{3}$ \\
\hline BY -110 & FG/org & & 2.50 & $<160$ & 426 & WL, high $\mathrm{NH}_{3}$ \\
\hline A-101 & $\mathrm{FG} / \mathrm{ORG}$ & -0.15 & 8.76 & 786 & 800 & $\begin{array}{l}\text { WL, large long-term oscillation, } \\
\text { high } \mathrm{H} 2, \mathrm{NH} 3\end{array}$ \\
\hline $\mathrm{AX}-101$ & FG & & 7.00 & & & WL, large short-term oscillations \\
\hline BY- 108 & FG/ORG & & 2.20 & 647 & 1,140 & WL, high $\mathrm{H}_{2}, \mathrm{NH}_{3}$ \\
\hline
\end{tabular}

A major concern in any study or survey of single-shell tanks is the quality and reliability of the data on which it is based. Data are lacking for many tanks on the short list. Most information about the concentration of analytes in single-shell tanks is from the historical tank content estimates, which are based on the tank layering model (Agnew et al. 1995), the historical record for waste transfers, and the HDW (Agnew 1995). Currently, the most uncertain part of the estimates is the HDW, which defines the composition of the waste streams going into the tanks.

Other information is needed for evaluating the tanks for flammable gas generation, retention, and release. Better data are needed on tank constituents to check the accuracy of the historical tank content estimates and to evaluate the tanks for gas generation. Physical property measurements, which appear to be almost nonexistent, are important in determining gas retention mechanisms. Measurements also are important for waste transport and disposal issues. Important physical properties include waste rheology, yield strength, porosity, and particle size distribution.

To make the present data more useful, tanks were grouped into related clusters. In this way, knowledge of the waste configuration for a related tank, even though it does not present a hazard itself, will clarify understanding of the high priority flammable gas tanks. Tank groupings or clusters were formed according to the analysis of Remund et al. (1995) to represent the general characteristics of important tanks. All tanks in a cluster are presumed to be similar so that data for a small number of tanks may provide insights into the waste behavior of the other tanks in the cluster.

The tanks on the short list represented nine of 36 single-shell tank clusters found by Remund et al. (1995) in their grouping study. The list of tanks was expanded by including all tanks in the clusters. The final list contained 54 single-shell tanks. All available information about single-shell tanks was collected and entered into a spreadsheet that was used to evaluate 
different tank clusters for potential flammable gas release. Table 2-4 provides a summary of this information.

Forty-three tanks scored above the median value (33) in the priority rating of Brown et al. (1995). The 11 top-priority tanks according to Brown et al. are included in Table 2-4. Some tanks not on the short list, such as tank 241-TX-118, had high-priority ratings in Brown et al. In these cases, the high-priority rating is caused by a factor such as ferrocyanide or discrepancies in historical information that are unrelated to safety issues associated with flammable gas retention and release.

The spreadsheet confirms that all tanks in a cluster have similar characteristics. This is particularly true for larger clusters where it is possible to generalize about the overall behavior of each property. For example, the tanks in cluster 13 have the following: approximately $0.1 \%$ TOC, relatively high amounts of total radiation, moderate temperatures ( 26.7 to $37.8^{\circ} \mathrm{C}$ [80 to $\left.100{ }^{\circ} \mathrm{F}\right]$ ), high nitrite concentrations, and comparable liquid and surface levels indicating the presence of significant amounts of liquid. Almost all tanks in cluster 13 are on the flammable gas and organic Watch Lists. Most other tank clusters exhibit similar levels of agreement for the tank properties.

\subsubsection{Definition of Waste Configurations}

Clusters were categorized by the waste configuration defined by the amounts of sludge, saltcake, and salt slurry. Four distinct configurations were found in the nine tank clusters: (1) tanks containing saltcake and salt slurry were in clusters 13 and 22, (2) tanks containing primarily saltcake were in clusters 15 and 20 , (3) tanks containing sludge and saltcake were in clusters 11,21 , and 33, and (4) tanks containing all sludge were in clusters 6 and 19. These four waste configurations are described in Table 2-4. Most of the 149 single-shell tanks having a significant waste depth is in one of these four categories.

2.4.1.1 Waste Configuration 1. Most tanks have some saltcake (0 to $75 \%)$ under salt slurry $(25$ to $75 \%$ ) with possibly a thin layer of sludge (0 to $25 \%)$. Subcategory $1 \mathrm{~A}$ (cluster 13) is distinguished from subcategory $1 \mathrm{~B}$ (cluster 22) by the source of saltcake and salt slurry (A or $S$ evaporator campaigns, respectively). Remund et al. (1995) and Agnew (1995) indicate these waste types are very similar, and the distinction between these categories may be artificial. Tank $241-\mathrm{A}-103$ is in this category because of its classification by Remund et al. in cluster 22 , although it has no slurry and thus appears to match waste configuration 2 better. 
Table 2-4. Tanks Ranked by Cluster. (2 sheets)

\begin{tabular}{|c|c|c|c|c|c|c|c|}
\hline Tanls & Wateh Wist & dilap & Deptlo & $\mathbf{H}_{3}$ & $\mathrm{NH}_{1}$ & Clinster & Shor W Wist \\
\hline S-102 & FG/ORG & -0.51 & 5.1 & 670 & 418 & 13 & * \\
\hline S-103 & fg & -0.34 & 2.1 & & & 13 & * \\
\hline SX-106 & FG/ORG & -0.23 & 4.4 & $<98$ & 188 & 13 & * \\
\hline U-103 & FG/ORG & -0.27 & 4.2 & 557 & 761 & 13 & * \\
\hline $\mathrm{U}-105$ & FG/ORG & -0.23 & 3.5 & $<49$ & 354 & 13 & * \\
\hline U-107 & FG/ORG & -0.18 & 3.5 & 505 & 474 & 13 & $*$ \\
\hline $\mathrm{U}-108$ & FG/org & & 4.1 & & & 13 & * \\
\hline U-109 & FG/org & -0.20 & 4.1 & & & 13 & * \\
\hline $\mathrm{U}-111$ & $\overline{\text { ORG }}$ & & 3.0 & 250 & 682 & 13 & * \\
\hline A-101 & FG/ORG & -0.15 & 8.8 & 786 & 800 & 22 & * \\
\hline$A-102$ & org & & 0.3 & & & 22 & \\
\hline A-103 & fg & -0.19 & 3.4 & & & 22 & \\
\hline$A X-101$ & FG & & 6.9 & 103 & 44 & 22 & * \\
\hline S-105 & & -0.30 & & 21 & 36 & 20 & \\
\hline S-106 & $\mathrm{fg}$ & -0.94 & 4.4 & & & 20 & * \\
\hline S-108 & & & 5.6 & & & 20 & \\
\hline S-109 & & & 5.2 & & & 20 & \\
\hline$S-111$ & $\mathrm{FG} / \mathrm{ORG}$ & -0.40 & 5.4 & 392 & 124 & 20 & * \\
\hline$S-112$ & FG & & 4.8 & & & 20 & * \\
\hline SX-102 & FG & -0.35 & 5.0 & & & 20 & * \\
\hline SX-103 & FG/ORG & -0.57 & 6.0 & $<23$ & 80 & 20 & * \\
\hline SX-105 & $\overline{F G}$ & & 6.3 & & & 20 & * \\
\hline U-106 & fg/ORG & -0.06 & 1.9 & 214 & 1,013 & 20 & \\
\hline $\mathrm{BX}-111$ & & & 1.9 & & & 15 & \\
\hline BY-101 & & & 3.6 & & & 15 & \\
\hline BY- 102 & fg/org & & 3.1 & & & 15 & \\
\hline$\overline{B Y-103}$ & $\mathrm{fg} / \mathrm{FG} / \mathrm{org}$ & & 3.7 & 22 & 30 & 15 & \\
\hline BY-106 & $\mathrm{fg} / \mathrm{FG} /$ org & & 5.9 & 104 & 78 & 15 & \\
\hline BY-109 & $\mathrm{fg}$ & 0.001 & 3.9 & & & 15 & * \\
\hline BY-111 & FG & & 4.2 & $<160$ & 61 & 15 & \\
\hline BY-112 & FG & & 2.7 & $<94$ & 71 & 15 & \\
\hline
\end{tabular}


Table 2-4. Tanks Ranked by Cluster. (2 sheets)

\begin{tabular}{|c|c|c|c|c|c|c|c|}
\hline Tank & Watch List & dII $\mathbf{d a p}$ & Depth & $\mathbf{H}_{2}$ & NH. & Chinster: & Short r rith \\
\hline BY-104 & FG/org & & 3.7 & 312 & 255 & 21 & * \\
\hline BY-105 & fg/FG/org & & 4.7 & 87 & 44 & 21 & \\
\hline BY-107 & FG/org & & 2.5 & 698 & 978 & 21 & * \\
\hline BY-110 & FG/org & & 3.7 & $<160$ & 426 & 21 & * \\
\hline S-101 & $\mathrm{fg}$ & -0.15 & 3.8 & & & 11 & \\
\hline$S-110$ & & & 3.6 & & & 11 & \\
\hline SX-104 & $\overline{F G}$ & 0.001 & 5.7 & & & 11 & * \\
\hline BY-108 & FG/ORG & & 2.1 & 647 & 1,140 & 33 & * \\
\hline C- 102 & ORG & & 3.9 & 165 & 192 & 6 & * \\
\hline C-105 & & & 1.4 & 24 & 3 & 6 & \\
\hline $\mathrm{T}-101$ & & & 0.9 & & & 6 & \\
\hline $\mathrm{T}-102$ & & & 0.2 & & & 6 & \\
\hline$T-103$ & & & 0.2 & & & 6 & \\
\hline B-110 & & & 2.3 & & & 19 & \\
\hline B-111 & & & 2.2 & & & 19 & \\
\hline$T-105$ & & & 0.9 & & & 19 & \\
\hline$T-110$ & FG & & 3.5 & & & 19 & * \\
\hline
\end{tabular}

Cluster 13: The nine tanks in this cluster exhibit substantial dL/dP and relatively high $\mathrm{H}_{2}$, $\mathrm{N}_{2} \mathrm{O}$, and $\mathrm{NH}_{3}$ concentrations in the headspace (when values are available). Most tanks exhibit large level rises. Eight tanks in this cluster are on the short list, and all are on the flammable gas or organic Watch List. Except for tank 241-U-107, which is about one-fourth sludge, all tanks in this cluster are a combination of saltcake and salt slurry. The tanks have fairly high levels of total radioactivity and temperatures between 26.7 to $37.8^{\circ} \mathrm{C}$ (80 to $100^{\circ} \mathrm{F}$ ) and high concentrations of nitrite ion and about 0.1 percent TOC.

Cluster 22: Only two of four tanks in this cluster report reliable values of $\mathrm{dL} / \mathrm{dP}$, and these indicate a low to moderate level response. No tank shows any level rise. The tanks contain mostly saltcake and salt slurry and generally have high TOC and nitrite ion concentrations. Although the total radioactivity is variable, the tanks are generally on the warm side, with median temperatures from 32.2 to $65.6^{\circ} \mathrm{C}\left(90\right.$ to $\left.150^{\circ} \mathrm{F}\right)$. Most of these tanks are on the Flammabie Gas Watch List. 
2.4.1.2 Waste Configuration 2. Tanks are primarily saltcake (75 to $100 \%$ ) with possibly thin layers of sludge $(0$ to $25 \%)$ and salt slurry $(0$ to $25 \%$ ). Subcategory $2 \mathrm{~A}$ (cluster 20 ) is distinguished from subcategory 2B (cluster 15) by the source of saltcake (S or BY farms, respectively) which differs significantly in its concentration of nitrite.

Cluster 20: Many of the 10 tanks in this cluster have substantial and reliable $\mathrm{dL} / \mathrm{dP}$ values. Only one tank shows a large level rise, and most tanks show a level decrease. The waste is primarily saltcake with some sludge. The TOC is low $(0.03-0.05 \%)$, and the concentrations of nitrite ion are modest $(0.1-0.16 \mathrm{M})$. All tanks contain high levels of radioactivity, but temperatures in the tanks vary from 21.1 to $76.7^{\circ} \mathrm{C}\left(70\right.$ to $170{ }^{\circ} \mathrm{F}$ ).

Cluster 15: This cluster contains eight tanks, only one of which has a reliable $\mathrm{dL} / \mathrm{dP}$ which is near zero. The waste is mostly saltcake with some sludge. The tanks have low TOC $(0.05 \%)$ and nitrite concentrations around $0.25 \mathrm{M}$. All tanks have moderate to high total radioactivity levels and temperatures from 18.3 to $48.9^{\circ} \mathrm{C}$ (65 to $120^{\circ} \mathrm{F}$ ). Several tanks appear to be quite dry, with liquid levels substantially lower than the surface level (as given by neutron data).

2.4.1.3 Waste Configuration 3. Tanks consist of sludge ( 25 to $75 \%$ ) and saltcake ( 25 to $75 \%$ ) with possibly small amounts of salt slurry (0 to $25 \%$ ). Subcategories $3 \mathrm{~A}, 3 \mathrm{~B}$, and $3 \mathrm{C}$ correspond to clusters 21,11 , and 33 . Sludge may be REDOX type (3B) or ferrocyanide type $(3 A, 3 C)$. Saltcake may have originated in the $S(3 B)$ or $B Y$ farms $(3 A, 3 C)$. Subcategories $3 \mathrm{~A}$ and $\mathrm{C}$ differ mainly in the predominance of saltcake $(3 \mathrm{~A})$ versus sludge $(3 \mathrm{C})$.

Cluster 21: None of the four tanks in this cluster has a reliable $\mathrm{dL} / \mathrm{dP}$ value. Although the waste is primarily sludge and saltcake, a comparison of liquid and surface levels indicates the waste may be on the dry side. The tanks have high TOC, approximately 0.15 to $0.26 \%$, and modest nitrite ion concentrations, 0.15 to $0.18 \%$. They contain moderate radioactivity and, except for tank $241-\mathrm{BY}-107$, temperatures over $37.8^{\circ} \mathrm{C}\left(100^{\circ} \mathrm{F}\right)$. All tanks are on the ferrocyanide and organic Watch Lists. Headspace sampling for several tanks indicates the presence of significant $\mathrm{H}_{2}$ and $\mathrm{NH}_{3}$ concentrations.

Cluster 11: The value of $\mathrm{dL} / \mathrm{dP}$ is low for tank 241-SX-104, but tank 241-S-101 has a moderate value of $-0.15 \mathrm{~cm} / \mathrm{kPa}$. Tank $241-\mathrm{S}-110$ does not report a reliable value.

Tanks 241-SX-104 and 241-S-101 show a level decrease. These tanks are mostly sludge and saltcake, although tank $241-S-101$ has a fair amount of salt slurry as well. All tanks in the cluster have substantial radioactivity but low TOC and modest nitrite ion concentrations. The tanks in this cluster have reasonably high temperatures; the coolest tank has a median temperature of $47.2^{\circ} \mathrm{C}\left(117^{\circ} \mathrm{F}\right)$, and the warmest is $70^{\circ} \mathrm{C}\left(158^{\circ} \mathrm{F}\right)$.

Cluster 33: This cluster has one tank, 241-BY-108. No reliable $\mathrm{dL} / \mathrm{dP}$ value is reported. The tank is mostly sludge with some saltcake. The tank has a high TOC but a low nitrite ion concentration. The total radioactivity is moderate, and the median tank temperature is 28.9 $\left(84^{\circ} \mathrm{F}\right)$. Headspace sampling indicates high concentrations of $\mathrm{H}_{2}$ and $\mathrm{NH}_{3}$. 
2.4.1.4 Waste Configuration 4. Tanks have a predominance of sludge $(>75 \%)$. Category $4 \mathrm{~A}$ has cladding waste, and category $4 \mathrm{~B}$ has $\mathrm{BiPO}_{4}$ waste.

Cluster 6: This cluster has five tanks; none have a reliable $\mathrm{dL} / \mathrm{dP}$ value. In all tanks, the waste is sludge. The radioactivity is fairly low (the highest is 63,000 curies in tank 241-T-101), but all tanks have a fairly high nitrite ion concentration. The temperatures range from 15.6 to $48.9{ }^{\circ} \mathrm{C}\left(60\right.$ to $120^{\circ} \mathrm{F}$ ). Most contain small amounts of waste, and all show low TOC $(0.03 \%$ or less $)$.

Cluster 19: No tank in this cluster has a reliable $\mathrm{dL} / \mathrm{dP}$ value. The tanks contain sludge and have negligible TOC and no appreciable nitrite ion concentration. The $\mathrm{pH}$ for most tanks is relatively low, about 8 to 10 , with one tank at pH 12.7. The total radioactivity for these tanks varies from 200 to $1,300,000$ curies.

\subsubsection{Prioritization of Waste Configurations}

Each waste configuration was examined to determine its priority for further study according to the following criteria.

1. The liquid level, as measured by neutron scattering, is comparable to the surface level. This indicates significant liquid in the waste, which is important for radiolysis, leading to the production of hydrogen gas, and for the more likely gas-retention mechanisms.

2. Moderate or high waste temperatures. Higher temperatures promote reactions leading to gas production.

3. Relatively high TOC. The presence of hydrocarbons leads to higher hydrogen production. If chelates are present (EDTA and HEDTA), they may also promote ammonia production.

4. Relatively high nitrite ion concentration. The presence of nitrite ion may promote production of ammonia and nitrous oxide.

5. High radiation from cesium and strontium. High radiation levels promote flammable gas production from radiolysis and by warming the tank.

6. A pH greater than 13. Concentrations of $\mathrm{OH}-$ greater than $1 \mathrm{M}$ combined with high concentrations of aluminate appear to point to elevated gas production rates. $\mathrm{A} \mathrm{pH}$ in the range 7 to 13 is associated with low gas production rates. Most tanks show an elevated $\mathrm{pH}$, but a few clusters exhibit what appear to be relatively low average $\mathrm{pH}$. From the information available, the concentration of aluminate cannot currently be determined. 
Using these criteria, waste configuration 1 (cluster 13, saltcake and slurry) was the most interesting and has the highest priority. Several tanks in waste configuration 1 have exhibited elevated levels of hydrogen, nitrous oxide, and ammonia in headspace samples, and most have a high $\mathrm{pH}$. All tanks exhibit level rise, and most show substantial $\mathrm{dL} / \mathrm{dP}$. Six of the nine tanks are among the 10 top-priority tanks according to Brown et al. (1995).

Waste configuration $3 \mathrm{~A}$ (cluster 21 , sludge and saltcake), also is potentially interesting. This configuration has high TOC (approximately $0.2 \%$ ), reasonably high radioactivity, and temperatures around $37.8^{\circ} \mathrm{C}\left(100^{\circ} \mathrm{F}\right)$. It also has nitrite concentrations of about $0.15 \mathrm{M}$ and a high $\mathrm{pH}$. All tanks in the cluster exhibit modest level rises and are on the ferrocyanide Watch List.

Waste configuration $2 \mathrm{~A}$ (cluster 20 , saltcake), is a possible candidate for further study because of its high temperature, high radioactivity, and reasonably high nitrite concentrations. No tanks in this cluster exhibit slurry growth, although many have a high $\mathrm{dL} / \mathrm{dP}$. Tank 241-S-106 has the highest $\mathrm{dL} / \mathrm{dP}$ value of all tanks on the short list.

These criteria are important input into the decision about which single-shell tanks to select for retained gas sampling. A constraint on the selection process is whether or not the tank under consideration can be core sampled in push mode with truck 1 because this is the only truck that will work with the retained gas sampling system. Because waste configuration 3 is too hard to push mode sample, the tanks selected for retained gas sampling are from waste configurations $1 \mathrm{~A}, 1 \mathrm{~B}, 2 \mathrm{~A}$, and $2 \mathrm{~B}$. The first single-shell tank selected for retained gas sampling was 241-A-101 (waste configuration 1B). 
WHC-SP-1193 Rev. 0

This page intentionally left blank. 


\subsection{GAS GENERATION}

Gas generation is very important for assessing the safety hazard of individual tanks. Recent progress has been made in determining the rate and stoichiometry of gas generation in the waste tanks. Rate and stoichiometry information has been gathered from laboratory studies with simulated wastes, actual waste core samples (tanks 241-SY-101 and 241-SY-103), thermal and radiolytic reactions in the gas phase, gas solubility evaluations, and in-tank gas composition data.

\subsection{STUDIES USING SIMULATED WASTES}

Studies have established the chemical mechanisms of flammable gas generation and fragmentation pathways for chelators. The mechanism of hydrogen generation from chelators, such as HEDTA and EDTA, involves extensive fragmentation of those molecules. The aluminate and nitrite ions are believed to be important in initiating the decomposition reaction through formation of a trihydroxynitritealuminum complex (Barefield et al. 1995). The coordinated nitrite ligand is expected to be much more electrophilic than the free nitrite ion and more reactive toward chelators. Formaldehyde was proposed as an important hydrogen-producing species, a byproduct of a number of fragmentation steps. Other aldehydic aging products, such as glyoxylate, are also important sources of hydrogen (PNNL 1996). Figure 3-1 shows the normalized concentrations versus time for the HEDTA breakdown. Figure 3-2 shows the relative gas generation for this text.

The long-term thermal decomposition of HEDTA was studied under thermal conditions, and changes were determined in the concentration of HEDTA and decomposition fragments as a function of time approximately 7,000 hours. Breakdown products of HEDTA include ethylenediaminetriacetic acid (ED3A), glycine, asymmetric ethylenediaminediacetic acid ( $u$-EDDA), symmetric ethylenediaminediacetic acid (s-EDDA), ethylenediaminemonoacetic acid (EDMA), imidodiacetic acid (IDA), formaldehyde, formate, and acetate (PNNL 1996).

Hydrogen is produced by the radiolysis of water and radiolytic reactions involving organic solutes from simulated Hanford waste mixtures (Meisel et al. 1991). Hydrogen radicals are formed directly from the radiolysis of water; molecular hydrogen results from the reaction of two hydrogen radicals. The abstraction of a hydrogen atom from an organic solute also yields molecular hydrogen. Capture of the hydrated electron by the nitrate ion, which could otherwise lead to hydrogen radical formation, and capture of the hydrogen radical by the nitrite ion are reactions that dominate radiolytic reactions in Hanford wastes. A correlation between the density of $\mathrm{C}-\mathrm{H}$ and $\mathrm{N}-\mathrm{H}$ bonds in a simulated waste mixture was made, and the radiolytic yield of hydrogen was developed and showed the hydrogen yield to be relatively insensitive to the specific identity of the organic solute (Meisel et al. 1993).

\footnotetext{
${ }^{5}$ Bryan and Pederson (1996b)
} 
Figure 3-1. Consumption of HEDTA and Appearance of Fragments as a Function of Time. ${ }^{6}$

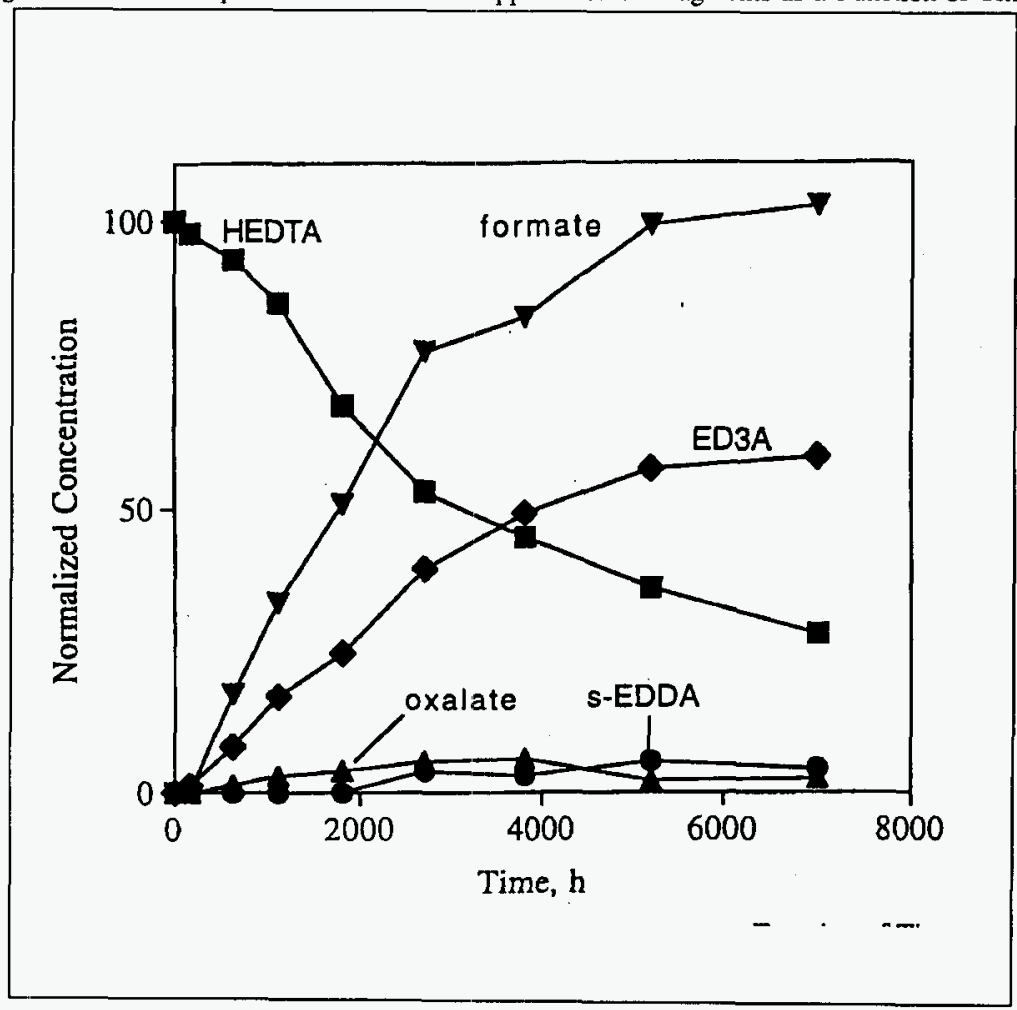

The test was performed at $90^{\circ} \mathrm{C}\left(194^{\circ} \mathrm{F}\right)$ with an argon cover gas. Concentrations are given in units normalized to the initial HEDTA concentration $\left(\right.$ HEDTA $_{\text {initial }}=100$ ). The values shown are the average of two separate tests performed under identical conditions.

${ }^{\circ}$ Adapted from Barefield et al. (1996). 
Figure 3-2. Generation of Hydrogen, Nitrogen, Nitrous Oxide, and Ammonia as a Function of Time. ${ }^{\text {T }}$

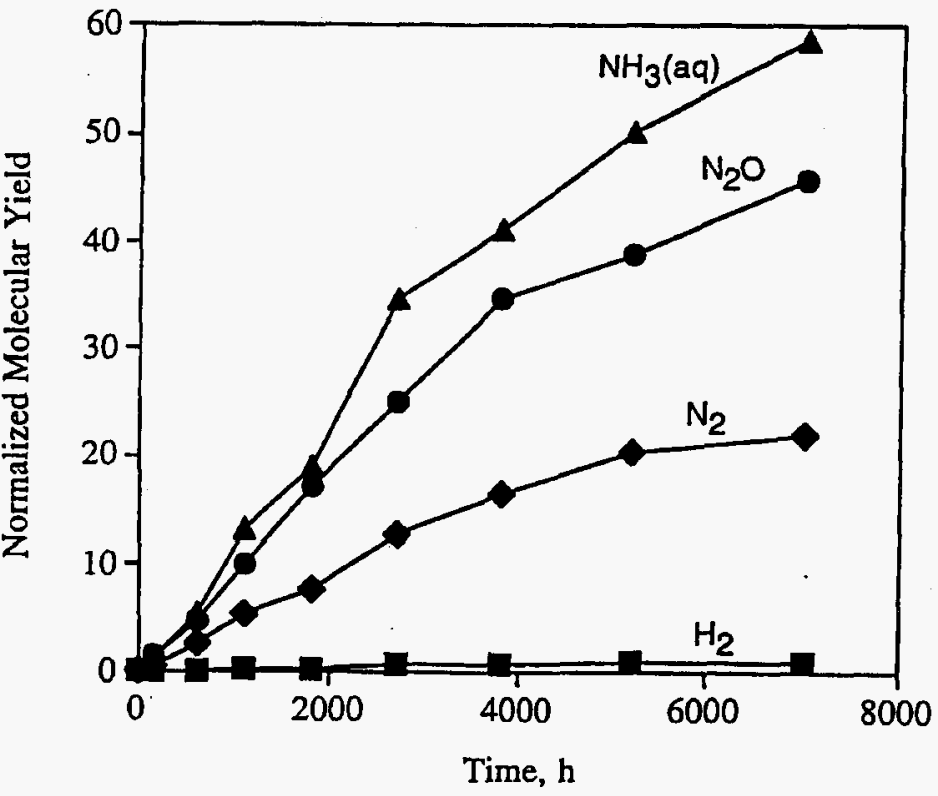

The test was performed at $90^{\circ} \mathrm{C}\left(194^{\circ} \mathrm{F}\right)$ with an argon cover gas. Concentrations are given in units normalized to the initial HEDTA concentration $\left(\right.$ HEDTA $\left._{\text {initi }}=100\right)$. The values shown are the average of two separate tests performed under identical conditions.

${ }^{7}$ Adapted from Barefield et al. (1996). 
Reactions involving the nitrite ion lead to formation of most of the nitrogen-containing gases (nitrogen, nitrous oxide, and ammonia) by thermally activated and radiolytic pathways. Using $5 \mathrm{~N}$-labeled nitrite ions, the nitrite ion was shown to be the most important source of nitrogen in these gaseous products. In the absence of radiation, the aluminate ion is needed to catalyze composition reactions through formation of the trihydro-xynitritoaluminum complex, which acts an NO+ donor. Active nitrogen oxide radicals are formed radiolytically without aluminate. The reaction of active nitrogen oxides with organic radicals results in formation of oximes $(\mathrm{RCH}=\mathrm{NOH})$ that can be hydrolyzed to form an aldehyde plus hydroxylamine. Further reactions hydroxylamine leads to the formation of molecular nitrogen, nitrous oxide, and ammonia.

In long-term aging of HEDTA in simulated waste mixtures, ammonia is produced in higher molar quantities than any other gas. A comparison of yields versus the change in HEDTA for two temperatures is shown in Table 3-1.

Table 3-1. Comparison of Yields from the Reaction of HEDTA in a Simulated Waste.

\begin{tabular}{|c|c|c|c|c|c|}
\hline Temp (\%) & H, $4 \mathrm{HEOMT}$ & N. AHBOMA & Mor 1 HABOH & $\mathrm{MH} / \mathrm{AHH} \mathrm{HT} / \mathrm{x}$ & 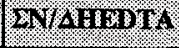 \\
\hline 90 & 0.016 & 0.30 & 0.60 & 0.77 & 2.57 \\
\hline 120 & 0.017 & 0.17 & 0.58 & 0.67 & 2.17 \\
\hline
\end{tabular}

Using oxygen as a cover gas had a marked effect on the distribution of gaseous products formed in thermally activated reactions involving EDTA (Meisel et al. 1991). Hydrogen yields were significantly enhanced in the presence of an oxygen-containing cover gas, and yields of nitrogen-containing gaseous products (nitrous oxide, nitrogen, and ammonia) were greatly reduced. Similar trends were observed in aging studies dominated by radiolytic reactions. Although the mechanism responsible for this behavior is not well understood, it is expected that oxygen reacts with active nitrogen oxide radicals that would otherwise eventually result in the formation of nitrogen-containing gases. Oxygen was recently shown to enhance the formation of hydrogen and suppress nitrogen-containing products in tests using actual wastes from tank 241-SY-101.

Figure 3-3 show a comparison of hydrogen generation yields for tests with argon and air cover gases. 
Figure 3-3. Hydrogen Yield per Molecule HEDTA Consumed Versus Time for Tests with Air Cover Gas and with Argon Cover Gas. ${ }^{8}$

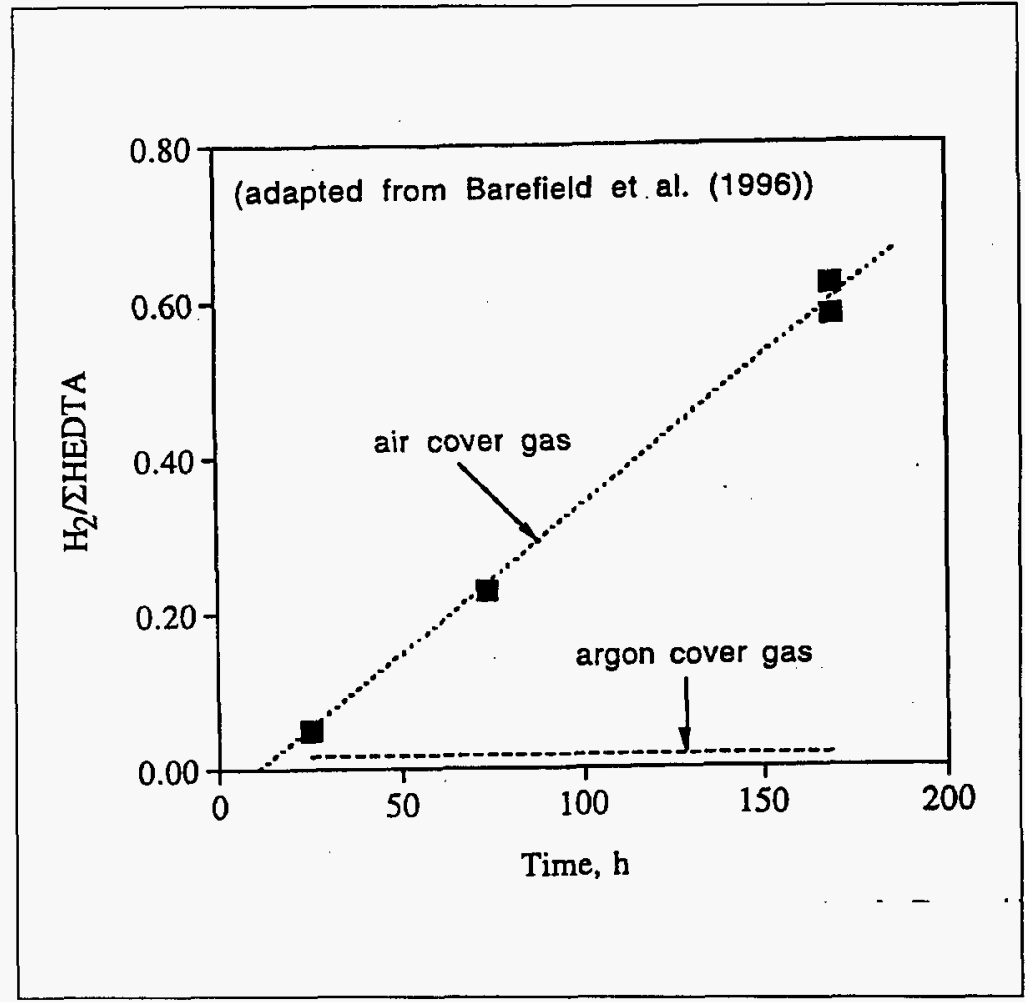

Hydrogen yields are significantly enhanced by the presence of oxygen and increase with time. possibly caused by a buildup of hydrogen peroxide. Yields of nitrogen-containing products are suppressed.

${ }^{8}$ Adapted from Barefield et al. (1996). 
WHC-SP-1193 Rev. 0

\subsection{STUDIES USING ACTUAL WASTE CORES}

Two studies were conducted to measure gas evolution from actual Hanford waste core samples. Gas generation was evaluated from samples of the convective layer of tank 241-SY-103 (Bryan et al. 1996) and a core composite sample from tank 241-SY-101 (Bryan and Pederson 1996a). These studies provide an important complement to the results of mechanistic studies using simulants. Because of the complexity of actual waste mixtures containing perhaps hundreds of different organic constituents and fragments (many of which have not been identified), no simulant is likely to precisely match the gas generation behavior of actual wastes. Through changes in temperature, radiation dose rate, presence or absence of oxygen, and dilution with concentrated sodium hydroxide solution, these two studies have provided significant advances in understanding generation processes in Hanford waste tanks.

Thermal and self-irradiation gas generation rates for the convective layer of tank 241-SY-103 were determined as 60 to $120^{\circ} \mathrm{C}\left(140\right.$ to $\left.248^{\circ} \mathrm{F}\right)$. Figure 3-4 and 3-5 show the results. Thermally activated reactions were dominant in this temperature range. Overall gas generation rates followed standard Arrhenius behavior. Activation energies were determined for overall gas generation $(96.3 \pm 6.3 \mathrm{~kJ} / \mathrm{mol})$, hydrogen $(91.3 \pm 9.0 \mathrm{~kJ} / \mathrm{mol})$, nitrogen $(83.7 \pm 10.2 \mathrm{~kJ} / \mathrm{mol}$ ), and nitrous oxide (1 li $6.7 \pm 9.4 \mathrm{~J} / \mathrm{mol})$. Nitrous oxide generation was favored at high reaction temperatures, and hydrogen generation was favored at temperatures similar to those at which wastes are stored.

Radiolytic gas generation yields were determined for tank 241-SY-103 convective layer samples using an external radiation source and from the deviation of gas generation rates measured at ambient temperature from extrapolated Arrhenius behavior. G-values were measured for each gas component generated. The average value for $\mathrm{G}\left(\mathrm{H}_{2}\right)$ was $0.14( \pm 0.02)$ molecules $/ 100 \mathrm{eV}$ for eight independent experiments representing data from 60 and $75^{\circ} \mathrm{C}$ (140 to $167^{\circ} \mathrm{F}$ ). The average value for $\mathrm{G}\left(\mathrm{N}_{2} \mathrm{O}\right)$ was $0.033( \pm 0.009)$ at $60^{\circ} \mathrm{C}\left(140^{\circ} \mathrm{F}\right)$. The numbers in parentheses represent one standard deviation. Because of the small value for $\mathrm{G}\left(\mathrm{N}_{2} \mathrm{O}\right)$, it was not possible to measure a significant radiolytic increase for this product over the thermal contribution at $75^{\circ} \mathrm{C}\left(167^{\circ} \mathrm{F}\right)$ or above. Radiolytic yields for nitrogen were unusual in that they decreased significantly with time. Whether this behavior is caused by an experimental artifact or to the consumption of a precursor is not known.

Organic speciation results were combined with a correlation to predict hydrogen generation rates for the convective layer of tank 241-SY-103. The correlation relates the $\mathrm{C}-\mathrm{H}$ and $\mathrm{N}-\mathrm{H}$ bond density to the radiolytic yield, without knowledge of the identity of organic solutes. The predicted radiolytic hydrogen yield was approximately a factor of 4 smaller than the measured value; the cause for this difference is not known. Concentrations of specific organic solutes in the actual waste mixture were typically a factor of 10 smaller than used in tests performed with simulated wastes to develop that correlation. 
Figure 3-4. Gas Generation Rates at Various Temperatures in the Presence and Absence of an External Source of Gamma Radiation.

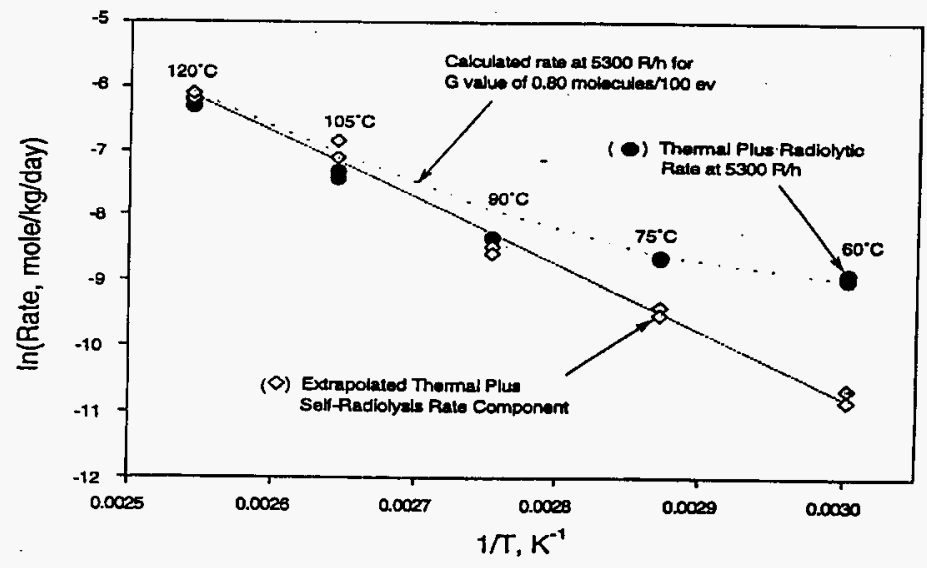


WHC-SP-1193 Rev. 0

Figure 3-5. Arrhenius Plot of Total Gas Generation Rates for Convective Layer of Tank 241-SY-103 (Dashed Line Represents Gas

Generation Corrected for Self-irradiation).

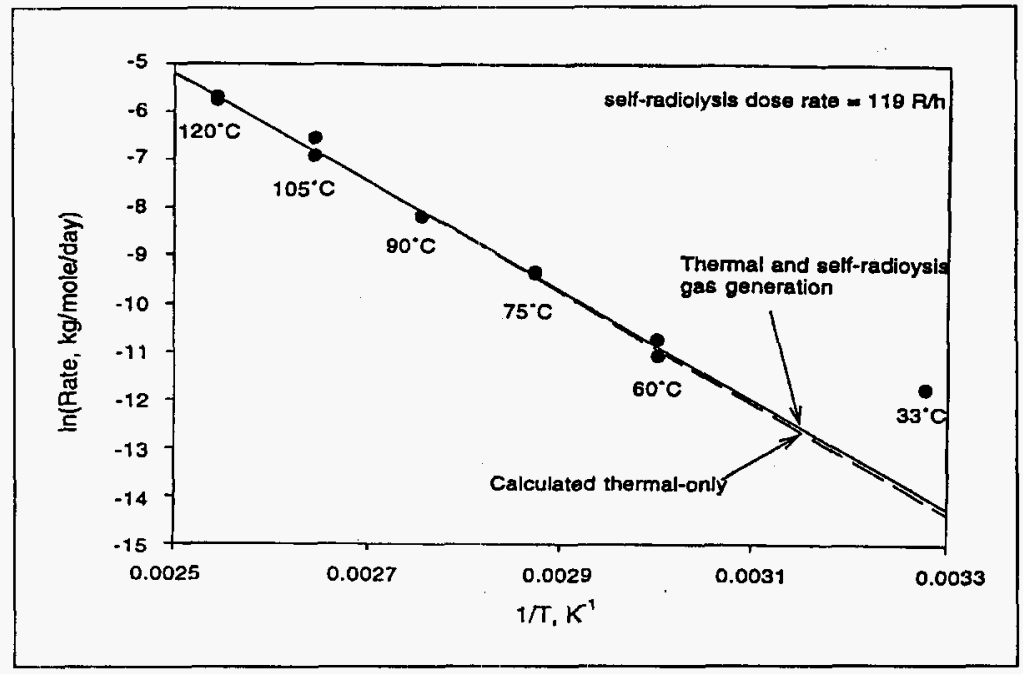


Excellent agreement was obtained between rates of hydrogen generation calculated from kinetic parameters and rates estimated from tank observations. The contribution of radiolytic and thermal hydrogen gas generation was calculated as follows: using the $\mathrm{G}\left(\mathrm{H}_{2}\right)$ value of 0.14 molecules/ $100 \mathrm{eV}$ and a dose rate of $444 \mathrm{R} / \mathrm{h}$ for tank $241-\mathrm{SY}-103$ conditions yields a radiolytic hydrogen generation rate of $1.63 \times 10^{-6} \mathrm{~mol} / \mathrm{kg} /$ day. The thermal hydrogen production rate calculated for tank $241-\mathrm{SY}-103$ temperature $\left(31.7^{\circ} \mathrm{C}\left[89.1^{\circ} \mathrm{F}\right]\right)$ using an activation energy of $91 \mathrm{~kJ} /$ mole yields $3.5 \times 10^{7} \mathrm{~mol} / \mathrm{kg} / \mathrm{day}$. The total calculated hydrogen gas generation from these waste samples is a sum of these two or $2.0 \times 10^{6} \mathrm{~mol}\left(\mathrm{H}_{2}\right) / \mathrm{kg} / \mathrm{day}$. A value of $2.3 \times 10^{-6} \mathrm{~mol} / \mathrm{kg} /$ day was reported for hydrogen production within tank 241-SY-103-using gas composition data for grab samples from the headspace and information on the gas flow rates and headspace volume.

Gas generation has also been evaluated using a core composite sample taken from tank 241-101-SY. The tests were performed in the approximate temperature range of 65 to $100{ }^{\circ} \mathrm{C}$ ( 149 to $212^{\circ} \mathrm{F}$ ) with helium or $30 \%$ oxygen in helium as the cover gas. Additional tests were performed with the waste sample diluted by approximately 50 vol\% with $2.5 \underline{\mathrm{M}}$ sodium hydroxide solution.

Overall rates of gas generation for tank 241-SY-101 waste samples were remarkably similar to results reported for tank 241-SY-103 wastes. Figure 3-6 shows these rates. The hydrogen generation rates for tank 241-SY-101 for the first 10 days of tests performed at $100^{\circ} \mathrm{C}$ $\left(212^{\circ} \mathrm{F}\right)(0.75 \mathrm{~mole} / \mathrm{kg} /$ day $)$, for example, is statistically indistinguishable from the kinetic data from tank 241-SY-103 interpolated to that temperature.

For a given temperature, it is expected that tank 241-SY-101 samples should produce flammable gases at a rate approximately $65 \%$ greater than those produced by thermolysis from tank 241-103-SY samples at the same temperature. The TOC content in tank 241-SY-101 is higher than that in tank 241-SY-103 (1.07 wt\% in the core composite sample, $0.74 \mathrm{wt} \%$ in the convective layer of tank 241-SY-103). Similarly, the aluminate ion concentration is higher in tank 241-SY-101 than in tank 241-SY-103 (3.2 wt\% and $2.8 \mathrm{wt} \%$, respectively). If differences in the hydroxide ion concentrations in the wastes are considered, tank 241-SY-101 should produce hydrogen at about double the rate double that in tank 241-SY-103.

The conditions of waste storage may help to explain why tank 241-SY-101 wastes produces gases at rates lower than estimated based on tank $241-S Y-103$ results. The average waste temperature in tank $241-\mathrm{SY}-101$ is at least $15^{\circ} \mathrm{C}\left(59^{\circ} \mathrm{F}\right)$ warmer and the radiation dose rate two to three times higher than in tank 241-SY-103; therefore, tank 241-SY-101 wastes are likely to have been more extensively aged than those in tank 241-SY-103, with the gas 
Figure 3-6. Comparison of Total Gas Generation from a Tank 241-SY-101 Core Composite $^{9}$ and a Tank 241-SY-103 Convective Layer Sample ${ }^{10}$.

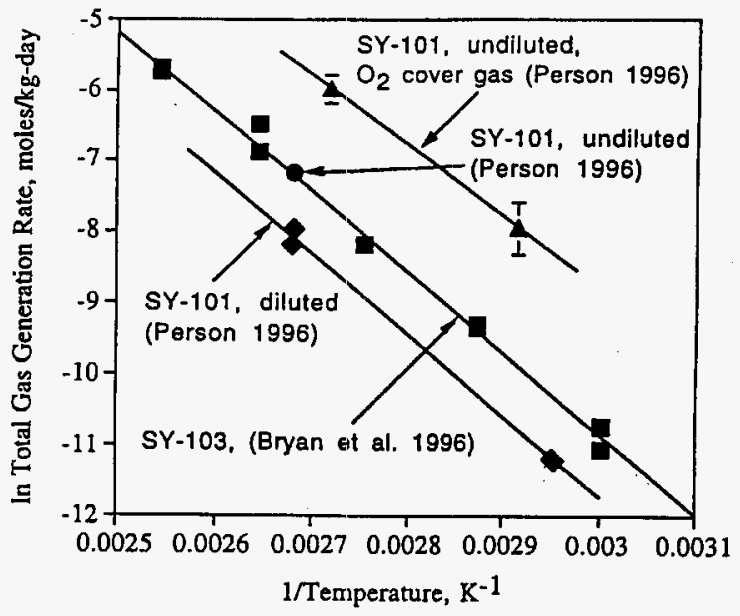

generation capacity likewise lowered. The TOC content results do not provide an ideal scaling parameter for gas generation rates. Insensitive to incremental stages of waste aging, TOC can provide only a crude estimate of gas generation capacity. For example, oxalate contains the same number of organic carbon atoms per molecule as glycine. The former is essentially nonreactive, and the latter reacts to generate flammable gases. Therefore, similar gas generation behavior for the two wastes may be caused more by extensive waste aging in tank 24l-SY-101 inspite of differences in TOC and aluminate ion concentrations.

Including oxygen in the cover gas of laboratory tests increased the overall rate of gas generation. Hydrogen production was significantly increased, and nitrous oxide and nitrogen yields were greatly lowered. This behavior is consistent with observations made in studies that used simulated wastes. Long diffusion times preclude atmospheric oxygen from being an effective source in most waste tanks. Oxygen will be produced radiolytically in low concentrations. Although oxygen is believed to be rapidly consumed in tanks like 241SY-101 and 241-SY-103, oxygen may build up in other tanks containing low concentrations

\footnotetext{
${ }^{9}$ Person (1996)

${ }^{10}$ Bryan et al. (1996)
} 
of reactive organic solutes or in relatively cool wastes. Low temperatures favor hydrogen generation even without oxygen.

\subsection{GAS PHASE REACTIONS}

Gas phase reactions and decompositions are of minor importance. The rates of chemical reactions involving nitrogen, nitrous oxide, hydrogen, and ammonia in the gas phase under thermal and combined thermal and radiolytic conditions were evaluated. This was to assess how reactions between gases trapped in bubbles in Hanford tank wastes may lead to altered gas product distributions depending on how long the bubbles remain trapped. Tests were conducted with dried simulated waste solids present, moist simulated wastes present, and no simulated wastes present. Specific reactions studied included the following: (1) nitrous oxide decomposition with nitrogen and oxygen as primary products, (2) reactions of nitrogen and hydrogen with ammonia as the primary product, (3) reactions of nitrous oxide and hydrogen with ammonia, nitrogen, and nitrogen dioxide as the primary products, and (4) ammonia decomposition with nitrogen and hydrogen as the primary products. Tests were performed at 60 to $150{ }^{\circ} \mathrm{C}\left(140\right.$ to $302^{\circ} \mathrm{F}$ ) and gamma radiation doses were 0 or $10^{7} \mathrm{R}$. The latter corresponds to approximately one year of radiation exposure in tank 241-SY-101 (Bryan and Pederson 1995 and 1996b).

Nitrous oxide decomposition by thermally activated processes was not observed for temperatures up to $150^{\circ} \mathrm{C}\left(302^{\circ} \mathrm{F}\right)$ unless simulated waste solids were present to catalyze the reaction. Nitrous oxide decomposed radiolytically but at very slow rates. (Bryan and Pederson 1996b).

Thermal and radiolytic reactions of nitrous oxide were also very slow. For example, with products of decomposition included nitrogen, oxygen, water, oxides of nitrogen, and ammonia. A typical a dose rate of $1,000 \mathrm{R} / \mathrm{h}$, a mixture of $30 \mathrm{~mol} \%$ nitrogen, $30 \mathrm{~mol} \%$ nitrous oxide, $30 \mathrm{~mol} \%$ hydrogen, and $10 \mathrm{~mol} \%$ ammonia, assuming that all absorbed energy is channeled into nitrous oxide/hydrogen reactions, approximately $2.2 \%$ of the nitrous oxide is estimated to be consumed each year (Bryan and Pederson 1995 and 1996b).

Thermal and radiolytic reactions of nitrogen and hydrogen also appear to be of minor importance under typical Hanford waste storage conditions. A very small quantity of ammonia was produced by thermally activated reactions with or without simulated wastes present, at rates negligible compared with other ammonia-producing reactions (Bryan and Pederson 1995 and 1996b).

Ammonia decomposed slowly by radiolytic reactions. It is estimated that $0.35 \%$ of the ammonia initially present will be decomposed within one year. Such losses will be more than offset by the production of ammonia by means of complexant degradation reactions (Bryan and Pederson 1996b). 


\subsection{GAS SOLUBILITIES}

Dissolution in the liquid phase is one mode by which gases may be retained in Hanford wastes. Gas solubilities are generally lower in concentrated electrolyte solutions than in pure water, but models developed to predict gas solubilities in electrolyte solutions in general are not suited to handle the high salt concentrations and high degree of complexity typical of Hanford wastes. The solubilities of ammonia, oxygen, nitrogen, hydrogen, methane, and nitrous oxide were determined as a function of temperature in simulated waste mixtures to enable better estimates of the quantities of dissolved gases in actual wastes. Only ammonia and, to a lesser extent, nitrous oxide retain solubilities of possible significance to flammable gas safety issues (Norton and Pederson 1994 and 1995).

From experimental results determined for oxygen, nitrogen, hydrogen, methane, nitrous oxide, and ammonia in simulated waste mixtures and the Schumpe ion interaction model (Hermann et al. 1995), Henry's Law constants $K_{H}$ were derived for the mother liquor of the wastes in tank 241-SY-101, which has been described by Reynolds (1992). These constants are shown in Table 3-2 and are defined as

$$
\mathrm{K}_{\mathrm{H}}=\mathrm{m}_{\mathrm{i}} / \mathrm{P}_{\mathrm{i}}
$$

where $\mathrm{m}_{\mathrm{i}}$ is the concentration of the particular gas dissolved in the liquid phase in moles per kilogram solvent (water), and $P_{i}$ is the partial pressure of that gas in atmospheres. Schumpe ion interaction parameters (Hermann et al. 1995) were modified by Norton and Pederson (1995) to account for changes in solubility parameters with temperature. The data in Table 3-2 indicate that ammonia is the only soluble species of significance.

Table 3-2. Henry's Law Constants for Mother Liquor of Tank SY-101 Calculated Using Schumpe Model $^{1}$ with Modified Gas Interaction Constants. ${ }^{2}$

\begin{tabular}{|c|c|c|c|c|c|c|}
\hline $\mathrm{Temp} . \mathrm{C}$ & $\begin{array}{l}\mathrm{K}_{\mathrm{H}} \\
\mathrm{6xpgen}\end{array}$ & Nitrogen & 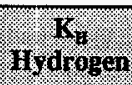 & Melowiro & 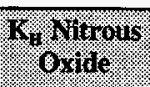 & inmona \\
\hline 20 & $1.52 \mathrm{E}-05$ & 4.79E-06 & $2.32 \mathrm{E}-05$ & $6.34 \mathrm{E}-06$ & $5.83 \mathrm{E}-04$ & 10.56 \\
\hline 35 & $1.21 \mathrm{E}-05$ & $3.94 \mathrm{E}-06$ & 2. $15 \mathrm{E}-05$ & $4.93 E-06$ & $3.85 \mathrm{E}-04$ & 5.67 \\
\hline 50 & $1.03 \mathrm{E}-05$ & $3.48 \mathrm{E}-06$ & $2.09 \mathrm{E}-05$ & 4.17E-06 & $2.78 \mathrm{E}-04$ & 3.23 \\
\hline
\end{tabular}

Notes:

'Hermann et al. (1995)

${ }^{2}$ Norton and Pederson (1995)

'Units of $\mathrm{K}_{\mathrm{H}}$ are mol/ $\mathrm{kg} \mathrm{H}_{2} \mathrm{O}$-atm. 
Table 3-3 shows values of dissolved gas calculated for tank 241-SY-101 wastes assuming all wastes are in equilibrium with trapped gases or with air.

Table 3-3. Estimated Quantity ${ }^{1}$ of Gas Dissolved in Entire Tank 241-SY-101 Wastes.

\begin{tabular}{|c|c|c|c|c|c|c|}
\hline Temperafure & (Oxgren & Wirogen & Horogen & Methane & orite ros & Minonia \\
\hline 20 & 6.1 & 6.0 & 25.3 & 0.084 & 541 & $4.4 \mathrm{E}+06$ \\
\hline 25 & 5.6 & 5.5 & 24.6 & 0.077 & 467 & $3.6 E+06$ \\
\hline 30 & 5.1 & 5.2 & 24.0 & 0.071 & 407 & $2.9 \mathrm{E}+06$ \\
\hline 35 & 4.8 & 4.9 & 23.5 & 0.066 & 357 & $2.4 \mathrm{E}+06$ \\
\hline 40 & 4.5 & 4.7 & 23.2 & 0.061 & 317 & $1.9 \mathrm{E}+06$ \\
\hline 45 & 4.3 & 4.5 & 22.9 & 0.058 & 285 & $1.6 \mathrm{E}+06$ \\
\hline 50 & 4.1 & 4.3 & 22.8 & 0.055 & 258 & $1.4 \mathrm{E}+06$ \\
\hline 55 & 4.0 & 4.2 & 22.8 & 0.053 & 235 & $1.1 \mathrm{E}+06$ \\
\hline 60 & 3.8 & 4.1 & 22.8 & 0.052 & 215 & $1.0 \mathrm{E}+06$ \\
\hline
\end{tabular}

Note:

'Henry`s Law constants are taken from Table 3-2.

Screening tests were performed with two slurry simulant mixtures to determine whether ammonia sorbed onto tank solids in significant quantities. Henry's Law constants were determined as a function of temperature for the decantate (no solids) and the complete simulant and were found to be indistinguishable. Although ammonia sorption onto solid surfaces may well occur, the amount adsorbed appears to be a very small fraction of the total ammonia inventory.

\subsection{DETERMINATION OF IN-TANK GAS COMPOSITION}

Gas compositions in tank 241-SY-101 are well known. Pasamehmetoglu et al. (1994) have analyzed a large body of gas composition data and have provided a best and conservative estimate for the composition of gases released during a gas release event. The results are shown in Table 3-4. Hydrogen is less than one-third the total gas volume. Nitrogen and nitrous oxide are similar in concentration; ammonia is also a principal component. 
Table 3-4. Estimates of the Overall Composition of Gases at $46^{\circ} \mathrm{C}$ in Tank $241-\mathrm{SY}-101$.

\begin{tabular}{|c|c|c|}
\hline : & Best Gostimate & 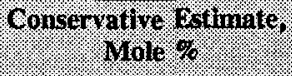 \\
\hline Hydrogen & 28.77 & 31.41 \\
\hline Nitrous Oxide & 24.45 & 26.69 \\
\hline Ammonia & 10.95 & 14.95 \\
\hline Nitrogen & 32.82 & 23.51 \\
\hline Methane & 0.35 & 0.53 \\
\hline Carbon Monoxide & 0.25 & 0.50 \\
\hline Water & 2.40 & 2.40 \\
\hline
\end{tabular}

In-tank gas composition data were collected by mass spectrometry analysis of grab samples taken from the headspace of various Hanford tanks (see Table 3-5). A particularly wide variation in the ratio of hydrogen to nitrous oxide concentrations was noted among tanks, from a high of $33+19$ for tank $241-\mathrm{AW}-101$ to a low of $0.40+0.17$ for tank $241-\mathrm{U}-105$. In laboratory tests with simulated and actual wastes, hydrogen yields were enhanced and nitrogen-containing gas yields were depressed by the presence of oxygen. Because dilution with air prevents the determination of oxygen concentrations in grab samples, this relation could not be verified. Gas composition results determined in laboratory tests with waste samples agreed within experimental error with grab sample composition results.

The retained gas sampler enables the composition of gases trapped in Hanford wastes to be determined without dilution by air. Waste samples from tank 241-AW-101, the first tank to be sampled using this device, were extracted using the retained gas sampler. The major species found were nitrogen, ammonia, hydrogen, and nitrous oxide. Insoluble gases in tank 241-AW-101 wastes range from 670 to $4,100 \mu$ moles per liter.

Nitrogen made up more than $50 \mathrm{~mol} \%$ of the gases found. Hydrogen was the next most predominant product. Nitrous oxide made up less than $8 \%$ of the total gas within the sludge layer and less than $2 \%$ of the gases in the supernatant (Cannon and Knight 1995). The remainder consisted of oxygen, nitrous oxide, methane, argon, and other hydrocarbons. It is suspected the oxygen was introduced into the sample during the core sampling operation and is not present in the waste.

Retained gas samples were taken from tanks 241-A-101, 241-AN-103, 241-AN-104, and 241-AN-105; analyses are underway. 
Table 3-5. Hydrogen to Nitrous Oxide Ratios Calculated from Mass Spectrometry Analyses of Grab Samples. (2 sheets)

\begin{tabular}{|c|c|c|c|c|c|c|c|}
\hline $\begin{array}{l}\text { Tanll. } \\
\text { Number }\end{array}$ & $\begin{array}{l}\mathrm{H}_{2} / \mathrm{NO}_{4} \\
\mathrm{Rutio}\end{array}$ & $\begin{array}{l}\text { Standard } \\
\text { Deviation }\end{array}$ & $\begin{array}{l}\text { No. of } \\
\text { Samples }\end{array}$ & $\begin{array}{c}\text { Hrg Wol\% } \\
\text { H, }_{2}\end{array}$ & 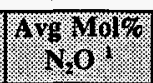 & Whe remp & $\begin{array}{l}\text { Watcl } \\
\text { Ther }\end{array}$ \\
\hline AN-103 & 15 & 2.00 & 2 & 0.0054 & 0.001 & 45 & $\mathrm{H}_{2}$ \\
\hline AN-104 & 7 & 1.00 & 8 & 0.0058 & 0.0008 & 49 & $\mathrm{H}_{2}$ \\
\hline $\mathrm{AN}-105$ & 6.9 & 4.40 & 13 & 0.016 & 0.0019 & 45 & $\mathrm{H}_{2}$ \\
\hline$\overline{\mathrm{AW}}-101$ & 33 & 19.00 & 14 & 0.088 & 0.0027 & 40 & $\mathrm{H}_{2}$ \\
\hline SY-101 & 1.48 & 0.90 & 28 & 0.0029 & 0.0023 & 49 & $\mathrm{H}_{2}$ \\
\hline SY-103 & 2.5 & 1.50 & 12 & 0.024 & 0.018 & 38 & $\mathrm{H}_{2}$ \\
\hline A-101 & 6.3 & 0.60 & 10 & 0.11 & 0.018 & 66 & $\mathrm{H}_{2}$, organic \\
\hline$\overline{A X}-101$ & 9.6 & 1.30 & 9 & 0.0063 & 0.0007 & 56 & $\mathrm{H}_{2}$ \\
\hline $\mathrm{AX}-103$ & 1.2 & 0.13 & 7 & 0.0026 & 0.0022 & 43 & $\mathrm{H}_{2}$ \\
\hline BY-106 & 1.23 & 0.20 & 4 & 0.039 & 0.033 & 51 & $\mathrm{FeCN}$ \\
\hline BY-109 & 9.4 & 5.20 & 3 & 0.0074 & 0.0019 & - & none \\
\hline S-107 & 7.6 & & 1 & 0.68 & 0.09 & - & none \\
\hline$S-110$ & 9.1 & 1.80 & 2 & 0.013 & 0.0014 & - & none \\
\hline S-111 & 5 & 0.70 & 2 & 0.0066 & 0.0028 & 35 & $\mathrm{H}_{2}$, organic \\
\hline$S-112$ & 3.5 & 0.70 & 2 & 0.0028 & 0.0008 & 31 & $\mathrm{H}_{2}$ \\
\hline SX-102 & 3.5 & 1.90 & 7 & 0.0019 & 0.001 & 66 & $\mathrm{H}_{2}$, organic \\
\hline SX-103 & 4.2 & 1.10 & 12 & 0.0031 & 0.0009 & 78 & $\mathrm{H}_{2}$, organic \\
\hline SX-105 & 5.4 & - & 1 & 0.0014 & 0.001 & 83 & $\mathrm{H}_{2}$ \\
\hline$\overline{S X-106}$ & 2.7 & 1.50 & 13 & 0.0034 & 0.0002 & 44 & $\mathrm{H}_{2}$, organic \\
\hline SX-109 & 2.8 & 0.20 & 2 & 0.0009 & 0.0004 & 66 & $\mathrm{H}_{2}$ \\
\hline TY.302B & 0.133 & 0.02 & 3 & 0.0011 & 0.0083 & - & none \\
\hline $\mathrm{U}-103$ & 0.81 & 0.13 & 10 & 0.063 & 0.78 & 31 & $\mathrm{H}_{2}$, organic \\
\hline $\mathrm{U}-105$ & 0.4 & 0.17 & 8 & 0.052 & 0.12 & 33 & $\mathrm{H}_{2}$, organic \\
\hline $\mathrm{U}-107$ & 0.74 & 0.18 & 14 & 0.032 & 0.045 & 28 & $\mathrm{H}_{2}$, organic \\
\hline U-108 & 1.08 & 0.22 & 15 & 0.036 & 0.038 & 32 & $\mathrm{H}_{2}$ \\
\hline
\end{tabular}

Notes

Bryan and Pederson (1996b)

${ }^{2}$ Average of all determinations for the indicated tank.

'Temperature data taken from Hanlon 1996; - indicates no temperature data were available.

"Watch list types includes Flammable $\mathrm{Gas}\left(\mathrm{H}_{2}\right)$, ferrocyanide $(\mathrm{FeCN})$, and organic tanks; "none" indicates the tank is not included on a Watch List (Hanlon 1996). 
WHC-SP-1193 Rev. 0

\subsection{KINETICS OF GAS GENERATION}

Although flammable gas generation rates in tanks 241-SY-101 and 241-SY-103 are well established through laboratory studies and tank observations, the rates for many other tanks are not known. Equations were developed to estimate the rate of hydrogen generation from tank wastes as a function of temperature and waste composition (Hopkins 1994 and Graves 1994). Kinetic gas generation parameters were determined in laboratory tests using actual waste samples, enabling incremental improvements to be made in estimates.

Tank 241-SY-103 waste was chosen as the benchmark from which to estimate generation rates in other tanks because its kinetic paraneters have the best statistical basis.

A modified expression (PNNL 1996) is given to estimate the thermal component of hydrogen generation from a given waste, based on tank $241-\mathrm{SY}-103$ behavior is as follows:

$$
\begin{aligned}
\text { Rate in waste } \mathrm{X}= & \text { rate in tank } 241-\mathrm{SY}-103 \\
& \mathrm{x} \% \mathrm{TOC} \text { in waste } \mathrm{X} / \% \text { TOC in tank } 241-\mathrm{SY}-103 \\
& \mathrm{x} \% \mathrm{Al} \text { in waste } \mathrm{X} / \% \mathrm{Al} \text { in tank } 241-\mathrm{SY}-103 \\
& \mathrm{x} \% \mathrm{OH} \text { in waste } \mathrm{X} / \% \mathrm{OH} \text { in } \operatorname{tank} 241-\mathrm{SY}-103 \\
& \mathrm{x} \exp \left[-91 \pm 9 \mathrm{~kJ} / \mathrm{mol} / \mathrm{R}\left(1 / \mathrm{T}_{\mathrm{x}}-1 / \mathrm{T}_{\mathrm{sY}-103}\right)\right]
\end{aligned}
$$

The baseline rate for tank $241-\mathrm{SY}-103$ is $3.5 \times 10^{-7} \mathrm{~mol} / \mathrm{kg} / \mathrm{day}$ at $31.7^{\circ} \mathrm{C}\left(89.1^{\circ} \mathrm{F}\right)$. Other parameters are (in wt \%) TOC $=0.74 \%$ (convective layer), $\mathrm{Al}=2.8 \%, \mathrm{OH}=1.94 \%$. The activation energy for hydrogen generation of $91 \pm 9 \mathrm{~kJ} / \mathrm{mol}$ is similar to the $90 \pm 45 \mathrm{~kJ} / \mathrm{mol}$ for wastes maintained at temperatures greater than that in tank 241-SY-101 but with a substantial improvement in measurement uncertainty. The results reflect a $95 \%$ confidence level.

The estimated radiolytic yield of hydrogen, based on laboratory data for tank 241-SY-103 wastes and a developed correlation is as follows:

$$
\mathrm{G}\left(\mathrm{H}_{2}\right)=0.031+0.15 \times \mathrm{TOC}=0.19 \text { molecules } \mathrm{H}_{2} / 100 \mathrm{eV}
$$

This expression predicts radiolytic hydrogen generation rates for tank 241-SY-101 that are approximately double that assumed previously.

Significant differences exist in composition among Hanford waste tanks. As a result, gas generation behavior is expected to vary considerably. In waste mixtures studied in laboratory tests, most organic fraction derived from chelator and chelator fragments, which dissolved in the liquid fraction. Other wastes contain solvents which are largely insoluble in the liquid fraction and may decompose by totally different pathways. Laboratory gas generation studies using actual waste mixtures that represent different waste classes would significantly enhance the ability to estimate gas generation behavior in Hanford wastes. 


\subsection{STORED GAS RETENTION}

An understanding of stored gas retention is important for assessing the potential hazard and likelihood of gas releases. The primary means for storing gas in the tank wastes is by retained gas bubbles (Gauglitz et al. 1996). The retention and release of bubbles from the wastes involve two physical processes.

\subsection{GAS BUBBLE RETENTION MECHANISMS}

Retained bubbles provide the primary mechanism for storing large quantities of flammable gases in tank waste that could be released rapidly. The principal mechanisms of bubble retention can be grouped into three categories: bubbles retained by the strength of the waste material, bubbles retained by capillary forces, and bubbles retained by direct attachment to particles (armored bubbles, bubble attachment, and aggregates, respectively). In layers of materials, bubble retention is dominated by the waste strength and capillary forces; armored bubbles play a minor role ${ }^{11}$.

The distinction between yield strength and capillary force retention depends on a Bond number (Gauglitz et al. 1994 and 1995). This dimensionless group contains two parameters: a ratio of gravitational force to surface tension force and a ratio of waste strength force to surface tension force:

$$
\begin{aligned}
& \frac{\text { gravitational Force }}{\text { Surface Tension Force }}=\frac{\Delta \mathrm{pghD}_{\text {parricle }}}{4_{\gamma}} \\
& \frac{\text { Strength Force }}{\text { Surface Tension Force }}=\frac{\tau_{1} \mathrm{D}_{\text {paricle }}}{4 \gamma}\left(\frac{\mathrm{A}_{2}}{\mathrm{~A}_{1}}\right)
\end{aligned}
$$

The surface tension force in these dimensionless groups reflects the resistance the bubble experiences as it seeks to move between particles. Hence, the appropriate length scale is the pore-throat diameter. For beds of packed particles, the pore-throat diameter is roughly the particle diameter (Dullien 1992); therefore the pore-throat diameter is approximated as the particle diameter $\mathrm{D}^{\text {particle }}$. In the first dimensionless parameter, $\Delta \mathrm{p}$ is the density difference between the settled solids and the liquid, $g$ is the gravitational acceleration, and $h$ is the

\footnotetext{
"In a companion study, frothing tests of SY-103 waste were conducted to probe the ability of waste particles to armor bubbles. In waste tanks, this effect potentially leads to smaller, shielded bubbles, which are not easily released to the tank headspace.
} 
depth below the top of the settled solids. In the second parameter, the constant $A_{2} / A_{1}$ is a ratio of areas that resulted from the original scaling analysis, and $t_{8}$ represents the shear strength of the material. Although it is expected that tensile and shear strengths are important in the growth of bubbles, the two measures of strength are commonly directly related (see Gauglitz et al. [1995] for a discussion of tensile and shear strength measurements).

The two parameters described above define the transition between two regimes of bubble retention: particle-displacing bubbles that are retained by yield strength forces and interstitial-liquid-displacing bubbles that finger between the particles composing the particulate media. Figure 4-1 shows both situations.

\subsection{EFFECT OF WASTE STRENGTH ON BUBBLE RETENTION}

When bubbles grow in a deformable material such as a bentonite clay or actual waste sludge, the dominant factors controlling their growth are surface tension forces, which seek to keep the bubbles round, and the strength of the material that the bubble must overcome to displace the particles. Simple scaling of the relative importance of sludge strength to surface tension gives the following dimensionless group that: governs bubble growth in deformable materials:

$$
\frac{\text { Strength Force }}{\text { Surface Tension Force }}=\frac{\tau_{s} D_{\text {particle }}}{\gamma}
$$

where $D_{\text {particle }}$ is the bubble diameter. In this case, the surface tension $(\gamma)$ force is related to the bubble size, so that the bubble diameter, $D_{\text {partick }}$ is the appropriate length scale. Again, for this scaling, we have chosen the strength of the material to be represented by the shear strength. This simple scaling assumes that the particles composing the waste are sufficiently small (small Bond number) that the bubbles never finger between the particles. As reported previously (Gauglitz et al. 1995), the shear and tensile strengths of bentonite clay sludges decrease with increasing gas bubble content, a detail this simple scaling analysis neglects.

Figure 4-2 shows the bubble shapes that are expected in fine-particulate materials where surface tension or waste strength dominates. When surface tension dominates, the bubble shape is round. When the waste strength dominates, the bubbles grow by displacing the weakest material adjacent to the bubble. In this case, if any small non-uniformity exists in the material, the bubbles will follow that path and evolve into some dendritic shape.

Although the overall shape may be dendritic, surface tension will dominate on a sufficiently small scale, and the interface between the gas and waste should be smoothly curved. 
Figure 4-1. Schematic of Bubble Displacing Particles and a Dendritic Bubble Fingering.

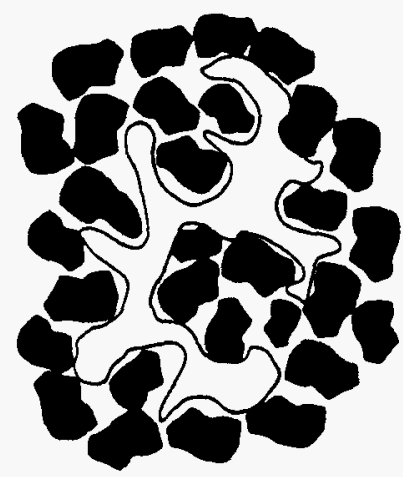

Dendritic-Shaped Bubble Fingering Between Particles

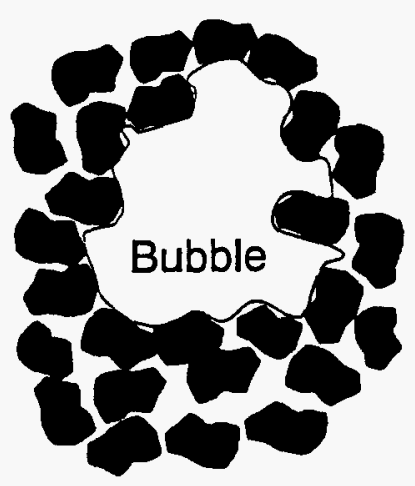

Bubble Displacing Particles

$\frac{\text { Strength Forece }}{\text { Surface Tension Force }}=\frac{\tau_{2} D_{\text {partick }}}{\gamma}$ 
Figure 4-2. Bubbles Displacing Waste when Surface Tension Dominates $\left(\tau, D_{\text {particle }} / \gamma<<1\right)$ and when the Waste Strength Dominates $\left(\tau_{\mathrm{s}} \mathrm{D}_{\text {particle }} / \gamma>>1\right)$.
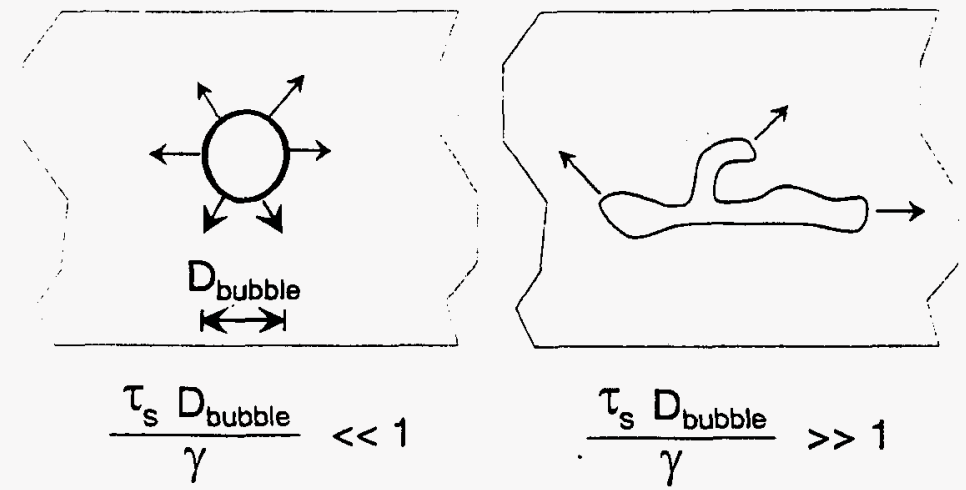

Figure 4-3 shows the different regimes of bubble retention, and the solid curve denotes the transition between interstitial liquid-displacing bubbles and particle-displacing bubbles. The particle-displacing bubbles are retained by yield strength forces and the interstitial liquid-displacing bubbles are retained by capillary forces. The particle-displacing region, within the solid curve of Figure 4-3, is further subdivided. The figure also shows the characteristic shape of bubbles in the different areas of the plot.

\subsection{EFFECT OF WASTE STRENGTH ON BUBBLE RELEASE}

As retained bubbles grow, and in the absence of large episodic gas releases, they will eventually connect and provide a flow path for gas to be continuously released. Figure 4-4 shows two situations of individual bubbles and connected bubbles. When the void fraction is small, the bubbles are separated. As the individual bubbles grow or more bubbles nucleate 
WHC-SP-1193 Rev. 0

Figure 4-3. Plot Showing the Location of Different Bubble Retention Regimes.

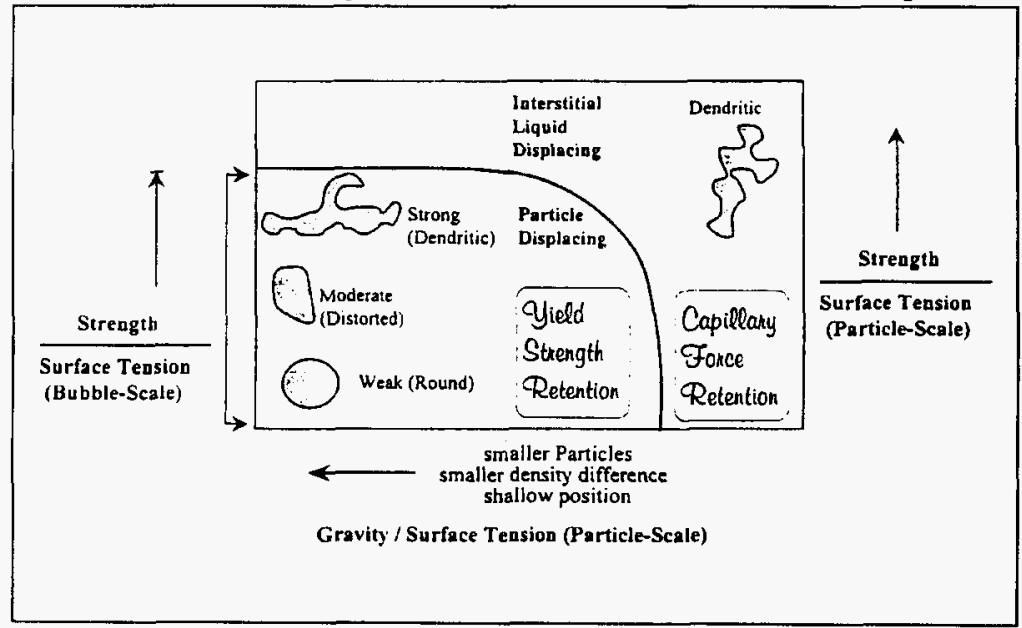

Figure 4-4. Bubble Growth and the Formation of a Connect Pathway of Bubbles.

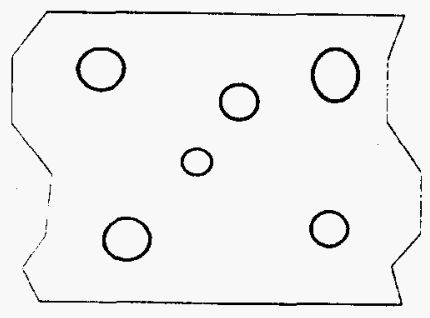

Individual Bubbles

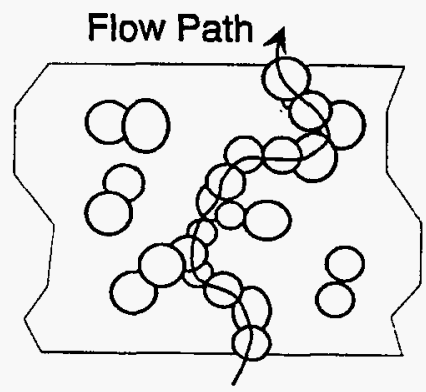

Connected Bubbles 
between previously existing bubbles, a connected path will eventually form. This pathway is likely to be very tortuous, particularly when considering the three-dimensional character of the connections. While many aspects of the bubble growth process will affect the connection between bubbles, percolation theory offers a framework to understand the minimum void fraction above which bubbles begin to connect (Stauffer 1985).

The connecting of separate objects and the conductivity of the connected paths were studied with percolation theory (Stauffer 1985). The situation of growing round bubbles is most closely associated with site percolation, which describes the connection of objects that occupy volume, such as bubbles. The alternative percolation process is bond percolation, but this represents things that essentially connect at points (specifically, resistors between nodes of a lattice). The percolation threshold, which occurs at a specific fraction of an occupied site, represents the void fraction above which a continuous path forms.

The percolation threshold has been calculated for a number of three-dimensional lattices, and values have been reported as follows: diamond, 0.428 ; simple cubic, 0.312 ; and body centered cubic, 0.245 (Stauffer 1985). These values are equivalent to the void fraction of bubbles above which a continuous path exists. Although a range of values were reported, it suggests that the bubbles will not connect until a moderate void fraction is reached. Finally, it is expected that bubbles of different shape will form a percolating path at different void fractions. The more long and slender bubbles shown in Figure 4-1 are expected to connect at a lower void fraction because long and skinny objects connect more easily.

\subsection{COMPARISONS OF BUBBLE RETENTION MECHANISMS}

Understanding the mechanisms of stored gas retention has a direct bearing on understanding the quantities of gas retained and on possible gas release mechanisms. The approach to quantifying bubble retention mechanisms has been to investigate the behavior of retained bubbles in waste simulants and in actual waste. Studies with simulants were used to provide a general picture of the range of expected behavior and how this behavior scales with waste properties. The actual waste behavior is then compared with the simulant behavior to highlight similarities and differences.

Section 4.5 compares currently available actual waste results to simulant results on bubble shapes and maximum retention. The shape of retained bubbles corresponds directly to the mechanisms of bubble retention. Competition between forces acting on the bubbles governs the shape and behavior of the bubbles and the retention mechanism. Although the range of behavior is large, distinct regimes of bubble retention behavior occur and the regimes can be used to classify bubble retention mechanisms. 


\subsection{MECHANISMS DEPICTION OF GAS RETENTION}

Figure 4-5 shows the bubble retention mechanisms for all results currently available. The central graph has the three dimensionless groups that determine the mechanism of bubble retention on three of the axis. The solid curve of the plot indicates the transition between particle displacing bubbles and interstitial liquid displacing bubbles. The square symbols overlaying this curve are data for the location of the transition as reported by Gauglitz et al. (1995) for glass bead simulants. Surrounding this plot are images of retained bubbles reported in (Gauglitz et al. 1996) and described in previous studies (Bredt and Tingey 1996; Bredt et al. 1995; Gauglitz et al. 1994 and 1995). The bubble images are taken from experiments with simulants and with actual waste.

The dimensionless groups shown on the axis of the plot contain a number of parameters. Although it is difficult to measure all these parameters for each experiment, it is possible to make reasonable estimates of them. Each retained bubble image has an arrow showing the approximate location on the plot. The axes for the plot have quantitative scales, so the plot is a quantitative expression of the bubble retention mechanisms. In most cases, the arrows point to circles on the graphs to indicate estimates are uncertain.

In each location on the plot, the images of retained bubbles in actual waste and simulants are quite similar. Starting on the left side of the plot for sludges (particle displacing bubbles), the stiff tank 241-S-102 sludge shows slit-shaped bubbles that are visually equivalent to the slit-shaped bubbles observed in the 1,040-Pa bentonite clay. For the softer tank 241-S-102 sludge, the retained bubbles were distorted from spherical but were not as slit-shaped as the stiffer sludge, behavior that lies between that of the round bubbles seen in the $67-\mathrm{Pa}$ bentonite clay and the slit-shaped bubbles observed in 1040-Pa bentonite clay. The tank 241-SY-103 waste samples studies in this work and by Bredt and Tingey (1996) and the tank 241-SY-101 waste sample studied by Bredt et al. (1995) ${ }^{12}$ were all weak materials with very fine particles. Although the original waste samples were of moderate strength, these samples were composites prepared for laboratory testing, and the strength had been degraded. Because these samples would pour relatively easily, they are located in the lower left region of the plot corresponding to weak particle-displacing bubbles. The round bubbles observed in all these actual waste samples correspond to the round bubbles observed in the weak bentonite clays $(6.7$ to $67 \mathrm{~Pa})$.

\footnotetext{
${ }^{12}$ The video images of bubbles in tank 241-SY-101 waste were from experiments that continued those of Bredt et al. (1995). Although similar, the specifics of the experiments differ, and the details have not been reported previously. In the context of the bubble retention studies, the primary difference was that the tank 24l-SY-101 sample was maintained at the hot cell temperature rather than at the actual tank temperature.
} 
WHC-SP-1193 Rev. 0

This page intentionally left blank. 


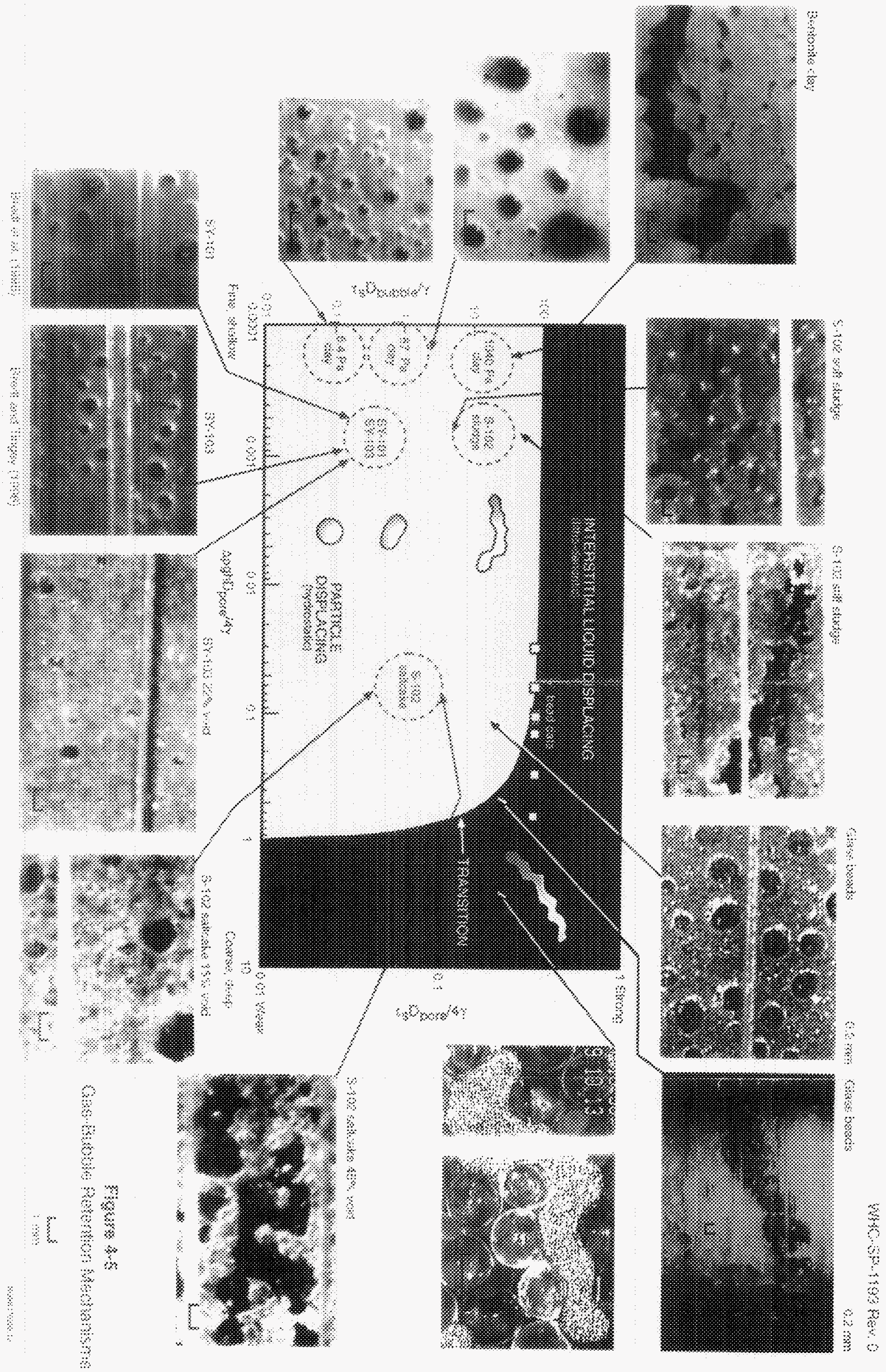


THIS PAGE INTENTIONALLT LEHT BIANTS

\section{4}




\subsection{ACTUAL WASTE STUDY, TANK 241-S-102 SALTCAKE}

Tank 241-S-102 saltcake samples show bubble retention in actual waste with a distinctly particulate character. The images of bubbles in tank 241-S-102 saltcake show bubbles displacing the particles. This is expected for small samples with a shallow depth $(\mathrm{h})$. In the case of $15 \%$ void, the retained bubbles in tank $241-\mathrm{S}-102$ are distorted from spherical but are qualitatively similar to the image of bubbles displacing $0.2 \mathrm{~mm}$ beads. At the higher void fraction of $45 \%$, the bubbles in tank 241-S-102 saltcake appear more dendritic. This may result from this sample being close to the transition between particle-displacing and interstitial liquid-displacing bubbles (farther to the right on the plot in Figure 4-6). It may also be caused by the strength of the sample affecting the bubble shape (farther upward on the plot in Figure 4-6). The final image is a dendritic bubble in a 1-mm beadpack that has displaced the interstitial liquid. Although it is believed that saltcake waste, such as the tank 241-S-102 samples, will retain interstitial-liquid-displacing (dendritic) bubbles, the existing laboratory studies used samples that are too small (h too small on $x$-axis) to readily observe this behavior.

\subsection{MECHANISM OF RETENTION AND MAXIMUM RETENTION}

The maximum retention of gas bubbles also provides information on the mechanism of bubble retention. Figure 4-6 compares the maximum retention results for the actual waste to bentonite clays. The strength of the actual waste samples was estimated independently (from waste behavior during one extrusion and in sample transfers), and the range bars for these data represent the order of magnitude span of these estimates. The tank 241-S-102 sludge-like material and the tank 24l-SY-103 composite samples were clearly fine-particle materials and can be compared to the bentonite clays. The tank 241-S-102 saltcake samples, while clearly particulate in character, retained particle-displacing bubbles, so these results are included in this comparison with the sludge-like materials.

The actual waste materials show a wide range of maximum retention, spanning from $20 \%$ void for the stiff tank 241-S-102 sludge to about 50\% void for the tank 241-S-102 saltcake. This range is somewhat larger than bentonite clay results. The $20 \%$ void maximum retention in the stiff tank 241-S-102 sample, although lower than bentonite clay results, agrees with the trend (beyond the maximum) of decreasing maximum retention with increasing strength. (Slit-shaped bubbles are expected to form a connected path at a gas fraction which is lower than when round bubbles form a connected path.) Because the stiff tank 241-S-102 sample retained slit-shaped bubbles, which are similar to the bubbles in the $1,040-\mathrm{Pa}$ bentonite clay, the lower maximum retention agrees with what was expected. The $45 \%$ to $50 \%$ maximum retention for the tank 241-S-102 saltcake samples, although greater than the bentonite clay results, shows reasonable similarity between the simulant and actual waste. The bubbles retained in the saltcake samples were less round than bubbles in bentonite clay, and this is probably caused by the strength or the particulate character of the tank 241-S-102 saltcake. 
Figure 4-6. Comparison of the Maximum Retention in Actual Waste Samples with the Results for Bentonite Clay Simulants. ${ }^{13}$

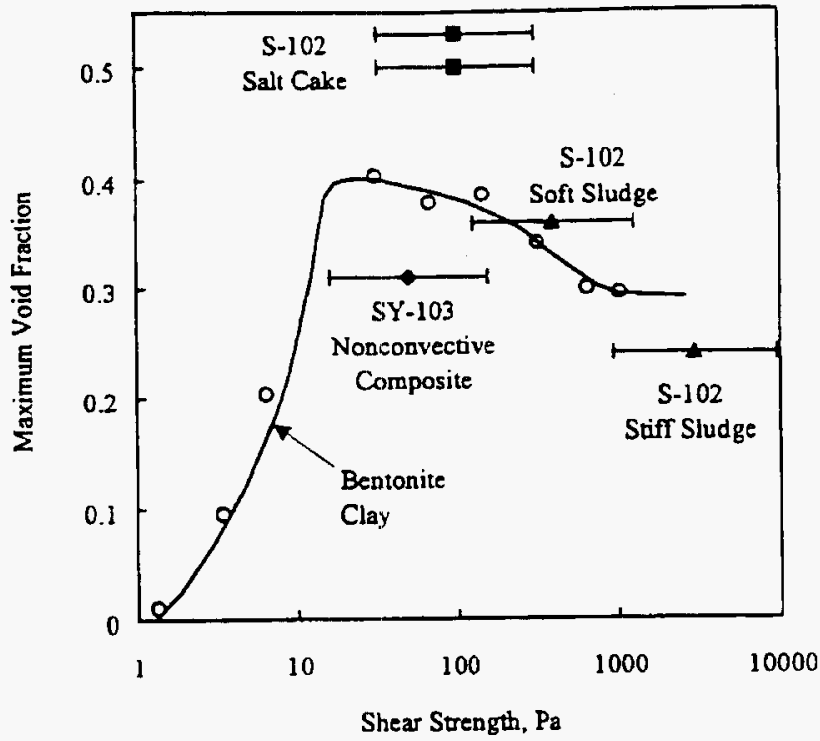

The results for maximum retention for actual single-shell waste samples and the bentonite clay show higher values than are generally found in the actual waste tanks. This implies there are release mechanisms in the actual tanks (specifically those without continuing level rise) that are not represented in the relatively small and rapid laboratory experiments.

${ }^{13}$ Gauglitz et al. (1996) 
WHC-SP-1193 Rev. 0

\subsection{ESTIMATION OF RETAINED GAS}

The underlying principal of the model used is the ideal gas law. This model is simple and appears to explain the variability observed in the Hanford tank level data.

The level measurements in Hanford waste tanks often show a strong correlation to barometric pressure, indicating the presence of retained gas. This level response can be used to estimate the retained gas volume provided information about the pressure at which the gas is held is available. The level response for six tanks (tanks 241-SY-101, 241-SY-103, 241-AW-101, 241-AN-103, 241-AN-104, and 241-AN-105) have been characterized by the void fraction instrument (VFI).

The VFI estimates the void fraction in yielding wastes, that is, liquid and the softer sludges. It does not provide information about the void fraction in the crust. The method presented here demonstrates that a reconciliation of the level response to the measured void fraction can be used to verify estimates of crust void fraction. Current estimates of level response are too inaccurate to significantly increase the accuracy of the total retained gas volume. This result could be achieved with more accurate estimates, particularly from greater level sampling rates. Further, a knowledge of the void distribution allows estimates of the level response from other time periods to be used for more accurate retained gas volume histories.

Linear regression is applied to detrended level (ENRAF) and barometric pressure data to estimate the level response. The level response caused by a non-crust void is estimated from the VFI measurements and equation (2.1), using an average pressure for each layer. The level response that is not accounted for by the non-crust void is attributed to crust void.

Gas in the crust is held at 1 atmosphere pressure; therefore, an estimate can be made of the crust gas volume from the remaining level response. Based on this estimate of void distribution, an effective pressure is determined which may be used to interpret future level response values to estimate retained gas volume, provided the relative gas distribution within the tank remains constant.

Table 4-1 summarizes the results of the calculations described above, including the following:

- Total retained gas estimate derived from VFI measurements

- Level response from correlation of detrended data

- Effective pressure, relating the level response to the reconciled gas volume, which can be used to estimate the total gas volume from the level response calculated for other time periods

- $\quad$ Revised gas volume estimates reconciled with both the VFI measurements and the measured level response by adjustment of the crust gas volume. 
A notable result of the reconciliation is the smaller estimate of retained gas volume in tanks 241-SY-103 and 241-AW-101 while tanks 241-AN-103 and 241-AN-104 show increases. Tanks 241-SY-101 and 241-AN-105 indicate very little discrepancy between original and reconciled gas volume estimates. The volume estimates are used to estimate the uncertainty introduced by the layer assumptions. Whitney et al. (1996) contains a further discussion of the validity of the level response estimation procedures.

The present analysis allots the difference in VFI estimated retained gas volume and the reconciled gas volume to the crust gas volume estimates. It appears that some or all the discrepancy is attributable to differences in estimated sludge retained gas volume and is caused by localized VFI measurements, while the pressure response data are a whole tank average. Another plausible explanation is that the sludge is not a uniform height. Some tanks show sludge level spatial variation, and the VFI data calculations use a one-dimensional analogy for discrete level retained gas volume estimates.

Table 4-1. Summary of Results.

\begin{tabular}{|c|c|c|c|c|c|c|}
\hline Tank & $S x-10$ & 84103 & $41 \mathrm{~s} 101$ & $4 \mathrm{a}-\mathrm{ms}$ & $4 \mathrm{~N} / 104$ & $4 / 405$. \\
\hline $\begin{array}{l}\text { Gas volume }\left(\mathrm{m}^{3} \text { at }\right. \\
\text { STP) from VFI } \\
\text { measurements }\end{array}$ & $218 \pm 52$ & $192 \pm 73$ & $209 \pm 46$ & $464 \pm 30$ & $213 \pm 41$ & $180 \pm 26$ \\
\hline $\begin{array}{l}\text { Level response }(\mathrm{dL} / \mathrm{dP}) \\
(\mathrm{cm} / \mathrm{kPa}) \text { from } \\
\text { correlation of level and } \\
\text { pressure measurements }\end{array}$ & $0.30 \pm 0.07$ & $\begin{array}{l}0.14 \pm \\
0.04\end{array}$ & $\begin{array}{l}0.18 \pm \\
0.04\end{array}$ & $\begin{array}{l}0.518 \pm \\
0.02\end{array}$ & $\begin{array}{l}0.20 \pm \\
0.04\end{array}$ & $\begin{array}{l}0.14 \pm \\
0.02\end{array}$ \\
\hline $\begin{array}{l}\text { Effective pressure } \\
\text { (atmosphere), relating } \\
\text { the level response } \\
\text { above to the reconciled } \\
\text { gas volume below }\end{array}$ & 1.39 & 1.71 & 1.61 & 1.58 & 1.77 & 1.82 \\
\hline $\begin{array}{l}\text { Reconciled gas volume } \\
\left(\mathrm{m}^{3} \text { at } \mathrm{STP}\right) \text {, derived } \\
\text { from both VFI } \\
\text { measurements and the } \\
\text { measured level } \\
\text { response }\end{array}$ & $215 \pm 49$ & $167 \pm 39$ & $185 \pm 42$ & $497 \pm 22$ & $244 \pm 28$ & $180 \pm 35$ \\
\hline
\end{tabular}




\subsection{RETAINED GAS VOLUME DETERMINATION FROM LEVEL DATA}

Evaluating the flammable gas hazard in a particular tank requires an estimate of the volume of gas retained, the fraction of the retained gas that can be released, and how rapidly it might enter the tank headspace. One method of obtaining this information has been by determining the void fraction at specific locations in a tank. Table 4-1 shows the data taken in six Flammable Gas Watch List double-shell tanks and the resulting calculated gas volume data. Tank 241-AN-103 contained the most gas; it was comparable to tank 241-SY-101 prior to mixing. Tank 241-AW-101 contained the least gas in the nonconvective layer, but tanks, 241-AN-104, 241-AN-105, 241-AW-101, and 241-SY-103 were very similar.

Most results focus on the quality of available data, estimating the amount of gas trapped in the waste and development of algorithms to detect release of trapped gas. Each Hanford tank has a primary device to measure surface level. In the past several years, many level measuring instruments were replaced with ENRAF gauges.

A level/pressure correlation with a method for estimating the associated physical parameters is used to determine whether a level rise in a tank is caused by an increase in trapped gas volume or to an intrusion, assuming only two alternatives are valid. Calculated results have varied in consistency with observations. The range of variability is shown in the following three examples:

1. The waste level increase in tank 241-S-106 is not consistent with the growth caused by increased amounts of trapped gas in the tank.

2. The waste level growth in tank $241-\mathrm{U}-109$ has been more consistent with the growth caused by increased amounts of trapped gas.

3. The waste level in tank $241-\mathrm{S}-111$ has been steady as has the estimated amount of trapped gas.

\subsection{RETAINED GAS SAMPLING SYSTEM}

The Retained Gas Sampling System was developed to measure the void volume and composition of gases retained in the waste. The system has been successfully used in characterizing double-shell tanks using the push mode core sampling system. Recently, attempts have been made to apply the system to single-shell tanks. This should be successful if the waste is soft enough to be sampled with the push mode core sampling system. 
The retained gas sampling system has four main subsystems: the push mode core sampling system, the retained gas sampling system, the extrusion/extraction/data collection system, and the gas sample analysis system.

\subsubsection{Push Mode Core Sampling System}

This is commonly referred to as "Truck 1." This is a custom designed and built system for obtaining waste samples from deep inside the tanks. This system uses water tagged with lithium bromide as the fluid for maintaining the hydrostatic balance as the sampling progresses deeper into the waste. The component used to collect the sample is the universal sampler. Another important component of this system is the $\mathrm{X}$-ray cart. The system records radiographs to video tape sampler contents immediately after the sample has been obtained.

\subsubsection{Retained Gas Sampler}

The retained gas sampler is a modified version of the universal sampler. The modifications made to the sampler are primarily improvernent of the seals to ensure that the gas obtained with the waste sample does not escape.

\subsubsection{Extrusion/Extraction/Data Collection System}

This custom designed and built system is installed in a hot cell in the 222-S Laboratory. The retained gas sampler is unloaded from the transfer cask directly into the hot cell. It is loaded into the extruder and sealed to the extraction vessel, then the entire contents of the sampler are pushed into the extraction vessel. The extraction vessel is a vacuum system which uses a mercury displacement pump to draw the gas released from the waste into sample collection bottles located outside the cell wall. System temperatures and pressures are continuously monitored and recorded during the extraction process for analysis.

\subsubsection{Gas Sample Analysis System}

This system is made up of several general use laboratory instruments. The main analysis system is a mass spectrometer used for identifying and quantifying the gas species present in the sample collection bottles. Ammonia concentrations are made separately because this gas is difficult to analyze accurately with the sample collection system used for the mass spectrometer. Lithium and bromide concentrations are measured to determine the magnitude of contamination of the sample by the hydrostatic head balancing fluid.

Four double-shell tanks (241-AW-101, 241-AN-105, 241-AN-104, and 241-AN-103) and one single-shell tank (241-A-101) were successfully sampled using the retained gas sampler. A total of 39 retained gas samples were taken; 28 were successfully extracted and analyzed. 
The seven samples from tank 241-AN-103 are waiting for extraction processing. Of the remaining four samples, two were lost because of sampling difficulties, one was lost because of extraction error, and one was eliminated from testing because it was a duplicate. Final data reports were issued for tank 241-AW-101 (Shekarriz 1996b) and tank 241-A-101 (Shekarriz 1996a). Overall the retained gas sampler has met or exceeded design expectations.

Double-shell Watch List tanks were targeted for the first deployments of the retained gas sampler because of the risk of episodic release of gases from these tanks. The data from the retained gas sampler will be used to support closure of the USQ on these tanks. The retained gas sampler was not applied to tank 241-SY-101 and 241-SY-103 because the USQ closure process is complete or well enough developed that the additional data provided by the retained gas sampler was not necessary.

Applying the retained gas sampler to single-shell tanks is more uncertain. The system is limited to tanks which can be sampled in push mode, which means tanks with relatively soft waste such as the sludges at the bottom of double-shell tanks. There are single-shell tanks that may be able to be push mode sampled, but success is not guaranteed. This was the case with tank 241-A-101 where the sampling went very smoothly with complete samples obtained from top to bottom.

Because of the success of the retained gas sampler, plans are being made to sample additional single-shell tanks. Because it is not practical (or even possible) to sample all tanks on the USQ list, the approach will be to sample "representative" tanks and apply the results to tanks containing similar waste. The method for selecting the tanks is to choose tanks that have a combination of waste types defined in Brewster and Palmer (1995) and that are on the USQ list. There are four distinct waste types; only types 1 (saltcake and slurry) and 2 (saltcake) are of interest for the retained gas sampler. Type 3 waste cannot be push mode sampled, and type 4 waste does not contain enough gas to be of interest. 
WHC-SP-1193 Rev, 0

This page intentionally left blank. 


\subsection{GAS RELEASE ${ }^{14}$}

Gas releases occur two ways: (1) free gas bubbles are released by breaking free of the solid matrix that holds them, or (2) gas dissolved in the liquid is released by evaporation from the liquid surface. Free gas in the waste consists mainly of the "insoluble" species including hydrogen, nitrogen, nitrous oxide, and various hydrocarbons. The dissolved gas consists mainly of ammonia with much smaller amounts of nitrous oxide. A major gas release by any mechanism includes contributions from both processes.

\subsection{RELEASE MECHANISMS: UNDISSOLVED GAS}

The free gas release mechanisms currently considered most credible are the buoyant "rollover" instability, percolation of dendritic bubbles, and mechanical disruption. Disruptions include local penetration (for example, core sampling), removal of waste by saltwell pumping of liquid or solids sluicing for retrieval, addition of liquid that might dissolve surface solids, and severe seismic events. Only rollover and seismic disruption are capable of a rapid release of a major fraction $(-50 \%)$ of the stored gas volume. Dendritic bubble percolation yields small, though possibly rapid releases. Disruptions release gas mainly from the region being disturbed. Local penetrations cause only small releases. Saltwell pumping may release a large fraction of stored gas, but the release occurs slowly over the entire campaign of one to two years. Likewise, most proposed retrieval scenarios should release essentially all insoluble retained gas, but the release rate follows the progress of the operation.

Rollover is a buoyant instability event where the settled solids layer accumulates enough gas to become buoyant with respect to the supernatant liquid above it. When this happens, the buoyant solids bob to the surface, trading places with the liquid. If sufficient mechanical energy is released during the rollover, the solid-liquid matrix containing the gas is disrupted and some stored gas is released. The amount of energy released increases with the depth of supernatant. It has been found both analytically and experimentally that, for typical tank conditions, the supernatant liquid layer must be at least half the depth of the solids layer for a significant gas release. This condition only exists in certain double-shell tanks. Without sufficient supernatant liquid, the buoyant instability occurs very gently, if at all, and no gas is released. This is true in single-shell tanks.

The gas release histories of the double-shell tanks subject to rollover suggest that tank 24l-SY-101 was unique in releasing 120 to $220 \mathrm{~m}^{3}$ of gas, or 25 to $50 \%$ of its retained gas approximately each 100 to 150 days. In contrast, the next highest release fractions are 15 to $25 \%$ in tanks $241-\mathrm{AW}-101$ and $241-\mathrm{AN}-105$. Tanks 241-SY-103, 241-AN-103, and 241-AN-104 released 5 to $12 \%$ of their retained gas on a random schedule. The actual release volumes are 26 to $40 \mathrm{~m}^{3}$ in tanks $241-\mathrm{AN}-104$ and $241-\mathrm{AN}-105$ and 14 to $24 \mathrm{~cm}^{3}$ in

\footnotetext{
${ }^{14}$ Gauglitz et al. 1996 and Stewart et al. 1996
} 
the other three tanks. Only the gas releases in tank 241-SY-101 were sufficiently large to make the tank headspace gas mixture flammable.

Percolation describes the situation where dendritic bubbles grow into each other, connect, and rapidly rise up until a new equilibrium is reached; or the gas escapes through the waste surface. The vertical extent of a connected dendritic region is limited by the balance of hydrostatic pressure with the capillary pressure and the yield strength of the material. Diffusional and probabilistic arguments limit the horizontal extent. Gas retained as particledisplacing dendritic bubbles potentially cause the largest releases because the solids collapse as the bubble rises. However, calculations indicate these releases are limited to a few cubic meters at most.

At most, a local disruption will release gas from the material actually disturbed by the penetration. The liquid surrounding a penetration maintains the hydrostatic pressure, and no "pressure sink" to the atmosphere is formed that could scavenge the gas from a wide region. Because of the limited volume of a connected source region described above, local disruptions do not trigger large gas releases when penetrating dendritic bubbles, and no instance has been observed of a penetration such as core sampling triggering a buoyant rollover event in a double-shell tank.

Saltwell pumping is the process of removing free and interstitial liquid. This process has been or is scheduled to be performed on most Hanford single-shell tanks to prevent future leaks. In saltcake tanks where gas is retained as pore-filling bubbles, saltwell pumping releases gas by uncovering trapped gas bubbles and by reducing the hydrostatic pressure, which causes further release by percolation. In sludge tanks where gas is stored as particledisplacing bubbles, very little gas may be released, although the initial gas volume may expand under reduced hydrostatic pressure. In either case, the gas release rate is slow and semi-controllable with the pumping rate, and gas accumulation is permanently prevented in the portion of the waste above the final liquid horizon. A potential hazard peculiar to saltwell pumping is a high ammonia concentration as the dissolved gas evaporates from the pores of newly exposed waste.

A severe seismic event has the potential to disturb all tank contents, possibly to the point of yielding and allowing a large fraction of the trapped gas to escape rapidly. An approximate (though probably conservative) calculation indicates that a 100 -year earthquake $(0.22 \mathrm{~g})$ deposits about the same amount of energy in double-shell tank waste as was released in large rollover events of tank 241-SY-101. These events released on the order of $50 \%$ of the stored gas. If the analogy holds, a 100-year earthquake might cause a gas release of similar magnitude. For single-shell tank waste with yield strength 1,500 to $3,000 \mathrm{~Pa}$, a 1,000 -year earthquake (assumed to be $0.35 \mathrm{~g}$ ) is required to deposit the same relative energy.

There are several gas release mechanisms that were once proposed but subsequently have been shown to be impossible, extremely unlikely, or not credible as sources of large, rapid gas releases. These include the following: penetration of a single or few very large bubbles, venting through a fracture, the uncovering of a gas reservoir by dryout, collapse of a 
"cavern" created by subsidence following saltwell pumping, or a "weak sludge" release that has been observed in the laboratory under specific conditions. See Stewart et al. (1996b) for a complete discussion of these proposed mechanisms.

The current understanding of the physics of gas retention and release in Hanford waste tanks considers that buoyancy-triggered rollover is the only credible mechanism for a large, rapid, spontaneous gas release. An energetic rollover can only occur with a supernatant liquid layer approximately as thick as the gas-bearing solids layer. This condition exists only in doubleshell tanks. Severe seismic events could potentially release as much gas as rapidly as did the large rollovers in tank 241-SY-101. A 100-year earthquake might do this in a double-shell tank, but a 1,000-year event would be required to produce the same result in an single-shell tank. There are no other credible mechanisrns likely to release flammable gas in an amount and at a rate that would pose an immediate hazard.

\subsection{RELEASE MECHANISMS: DISSOLVED GAS}

Soluble gas, almost entirely ammonia, is retained in solution in the liquid and is released mainly from a free liquid surface, although some gas is released with bubbles of insoluble gas. Transport from a stagnant surface is extremely limited by diffusion through the liquid. Even a thin crust or foam layer bars evolution of ammonia by inhibiting convection. Significant ammonia evaporation occurs only when the liquid surface is strongly disturbed. Such a disturbance is likely in a violent rollover or seismic event when liquid waste is transferred to a new tank and during major disruptions involved with retrieval. Saltwell pumping potentially releases large amounts of dissolved gas by exposing a huge surface area of moist, porous solids as the liquid level falls. A catastrophic effervescence release scenario has been proposed but is not credible in Hanford tanks. A detailed discussion of ammonia release mechanisms and the associated flammability hazard is in Palmer et al. (1996).

\subsection{ESTIMATION OF GAS RELEASE EVENT FREQUENCIES ${ }^{15}$}

Evaluating the magnitudes of potential hazards associated with the release of stored gases from tank wastes requires estimating the fraction of time during which a tank headspace may be hazardous because of the gas release, namely tank dome failure caused by the pressure from burning the gas. Two scenarios considered are:

1. Enough gas is released from the tank waste so that the entire headspace is above the LFL, and the tank dome would fail if the gas were ignited;

2. Enough gas is released as a "plume" so that the tank dome would fail if the plume were ignited.

\footnotetext{
${ }^{15}$ Brewster and Whitney (1996)
} 
For the second scenario to be credible without the first criteria being met, it is assumed that the cause of the plume is also the cause of ignition or that a continuous ignition source is available in the tank headspace.

The key data required to estimate the fraction of time that a tank headspace is in a hazardous state and the frequency of large gas release events includes the following:

- Expected amount of gas retained in the tank waste

- Gas retention and release history, or anticipated release mechanisms, of the tank waste

- Composition of the released gas

- Ventilation rate of the headspace

- Anticipated size and frequency of earthquakes at the Hanford Site

- Tank structural failure limits.

Table 5-1 shows the results of calculations to estimate the frequency of gas release events which could lead to a tank dome failure.

Tabie 5-1. Order of Magnitude Estimated Frequency of Gas Release Events Which Could Lead to Tank Dome Failure.

\begin{tabular}{|c|c|c|}
\hline Doublesthell Tanks & $\begin{array}{l}\text { Continums Spart Case' } \\
\text { (H per year) }\end{array}$ & $\begin{array}{l}\text { Ramubri Spart Gase } \\
\text { (T.oportion of Time) }\end{array}$ \\
\hline 241-AN-105 & $4 \mathrm{E}-3$ & $1 \mathrm{E}-4$ \\
\hline 241-SY-101 (historical) & $2 \mathrm{E}-1$ & $4 \mathrm{E}-3$ \\
\hline $241-S Y-103$ & 0 & 0 \\
\hline Single-Shell Tanks & & \\
\hline $241-5-102$ & $8 \mathrm{E}-3$ & $1 \mathrm{E}-4$ \\
\hline $241-5-103$ & $7 \mathrm{E}-4$ & $6 \mathrm{E}-6$ \\
\hline $241-5-106$ & $2 \mathrm{E}-2$ & $9 \mathrm{E}-5$ \\
\hline
\end{tabular}

The estimates are preliminary, and supporting documents are not available because they are still in preparation. Some numerical inputs in estimate calculations (for example, waste yield strength, amount of retained gas in single-shell tanks, and waste gas composition), and some 
models (single-shell tank gas release mechanisms, amount of gas released by earthquakes, tank dome failure), are subject to change.

\subsubsection{Applicability of the Estimates}

There is much uncertainty in frequency estimates because seismic induced releases and hypothesized large releases in single-shell tarks have not been observed. Therefore, the estimates are order-of-magnitude (that is, probably accurate to within multiple factors of $10^{ \pm 1}$ or $10^{ \pm 2}$ ) estimates only. Also, the concept of a representative tank is not clearly defined, and there are some tanks for which the estimates clearly are not representative.

\subsubsection{Potential for Improving the Results}

An additional level of effort would be required to quantify the uncertainties. The important benefits of such an effort would be to (1) understand how good the estimates are and (2) rank the importance of refining inputs to the estimates.

Some phenomena which may affect the estimates but have not been accounted for are as follows: background flammability of tank headspace, liquid intrusions, evaporation, no nitrogen in gas, complete burn of combustible gas, pressure increase caused by gas release, anticipated decrease in gas generation rate, and dissolved ammonia releases.

\subsection{MODELING RELEASED GAS MIXING/CONCENTRATIONS ${ }^{16}$}

Gas release events lead to gas mixing and changes in released gas constituent concentrations in tank headspaces. The transient concentrations of flammable gases occur is of interest because of the inherent risk of reaching and exceeding LFL or concentrations which can support rapid reaction propagation. Computer modeling of gas mixing was performed before actual tests in tank $241-S-102$. It was found that complete tracer gas mixing is achieved in less than an hour after the addition of the tracer.

Modeling was also performed on plume-type gas releases to evaluate the effects of hydrogen gas concentrations in the headspace as a result of the release and to evaluate the effects of the presence of other gases on the hydrogen concentrations. Three release locations were used. $A$ release directly under the riser resulted in a $3 \%$ concentration of hydrogen at the riser shortly after the release; and a release at an offset position from the riser resulted in lower hydrogen concentration values at the riser. It was also determined that for a constant volume of hydrogen released, the presence of other gases in the plume has a significant effect in decreasing peak hydrogen concentrations.

\footnotetext{
${ }^{16}$ Antoniak and Recknagle (1996)
} 
Another study addressed the effects of pre-release natural and forced convection flow fields on hydrogen concentrations in tank headspace after a plume-type of gas release. It was found that, with or without active vent flow, an established flow field before a plume-type release occurs has only a relatively small, short-term effects on hydrogen concentrations in single-shell tanks. Also, the vent flow rate in a ventilated tank has a negligible effect on peak hydrogen concentrations but exerts a significant influence over time.

\subsection{LEAN COMBUSTION OF GAS MIXTURES IN AIR}

Experimental studies were performed to determine the combustion characteristics of lean hydrogen, nitrous oxide, ammonia-air mixtures. The focus was on combustion limits, pressure histories and flame speeds of flammable gas mixtures.

The Pittsburgh Research Center of the U.S. Bureau of Mines investigated the flammability of various mixtures of hydrogen nitrous oxide ard air (Cashdollar et al. 1992). Flammability data were collected from more than 280 tests in a 120 - $\mathrm{L}$ spherical chamber. The researchers concluded that below $20 \%$ hydrogen, there is no significant difference in the flammability data for hydrogen-air or 1:1 or 3:2 ratios hydrogen to nitrous oxide in air. At higher hydrogen concentrations, the hydrogen-nitrous oxide-air mixtures are more hazardous, with higher maximum pressures and rates of pressure rise. Therefore, small amounts of nitrous oxide (relative to air) do not appear to have much effect on flammability, but high concentrations of nitrous oxide markedly increase the explosion hazard.

The LFL measured by Cashdoliar et al. were the same for the three mixtures (hydrogen-air, 1:1, and $3: 2$ ratios of hydrogen to nitrous oxide in air). The LFL a were:

$\begin{array}{ll}\text { Quiescent conditions, upward propagation } & 5 \% \mathrm{H}_{2} \\ \text { Quiescent conditions, downward propagation } & 8 \% \mathrm{H}_{2} \\ \text { Turbulent conditions, upward propagation } & 4 \% \mathrm{H}_{2} \\ \text { Turbulent conditions, downward propagation } & 6 \% \mathrm{H}_{2}\end{array}$

Tests were performed at an elevated temperature $\left(54{ }^{\circ} \mathrm{C}\right)$ and with added water vapor with no significant effect. Limited tests with ammonia added indicated that each added $1 \%$ ammonia exhibited fuel behavior approximately equivalent to an added $0.5 \%$ hydrogen.

The results demonstrated that nitrous oxide is inert in lean mixtures of hydrogen-air nitrous oxide and reactive in lean mixtures of ammonia-air-nitrous oxide. For mixtures of hydrogen-nitrous oxide-ammonia-air, the reactivity of the nitrous oxide depends on the hydrogen-ammonia ratio. A correlation between the adiabatic, constant pressure, flame temperature of the mixture and the reactivity threshold of the nitrous oxide was made. Nitrous oxide began reacting when the adiabatic flame temperature was between 1,100 and 1,300 degrees Kelvin. It was determined that for flame temperatures above this threshold, the presence of nitrous oxide effects the flammability limit, the pressure history, and the flame speed. 
Studies at the California Institute of Technology and Los Alamos National Laboratory (Breshears et al. 1996 and Ross and Shepherd 1996) with hydrogen-air, hydrogen-nitrous oxide, ammonia-air, and ammonia-nitrous oxide were conducted to compare results.

Pressure histories, final equilibrium pressures, and burning velocities were measured. The results were in reasonable agreement with previous experiments, taking into consideration the differences in the facilities. We observed that the nitrous oxide does not always participate in the combustion of hydrogen-nitrous oxide-air mixtures, but participates in the combustion of ammonia-nitrous oxide-air mixtures.

A mixture based on the conservative estimate of the gas release from tank 241-101-SY was studied to determine lean flammability and combustion characteristics. The upward propagation limit for the mixture is $8 \%$, and the downward propagation limit is $15.25 \%$. The burning velocity varies from $1 \mathrm{~cm} / \mathrm{see}$ at the lean limit to $8 \mathrm{~cm} / \mathrm{see}$ at $18 \%$.

Three other hydrogen-nitrous oxide-ammonia mixtures were examined to find the effect of the nitrous oxide on mixtures rich in ammonia. The nitrous oxide was found to begin participating in the combustion process when the constant pressure adiabatic flame temperature approached $1,100 \mathrm{~K}$. 
WHC-SP-1193 Rev. 0

This page intentionally left blank. 


\subsection{PATH FORWARD}

\subsection{INTRODUCTION}

Although considerable understanding has been gained about the phenomena related to the flammable gas safety issue, there are still technical issues that need further evaluation. This section will overview the work needed to extend the understanding of gas generation and retention. Considerable effort is needed to put this knowledge into the models and methods used to predict tank behavior. Additional data need to be obtained from various tanks to evaluate stored gas and gaseous evolution phenomena. One of the more important activities is updating the TWRS the Authorization Basis. A Basis for Interim Operation has been submitted to DOE-RL, and a Final Safety Analysis Report is in the final stages of preparation. Closure of the flammable gas USQ is a critical item and the path forward is provided. Finally, 25 tanks are on the Flammable Gas Watch List; the current approach for removing these tanks from the Watch List is outlined.

\subsection{LABORATORY WORK REMAINING TO UNDERSTAND GAS GENERATION}

Gas generation testing of tank waste samples is included in the path forward because the data obtained from testing are essential for estimating chemical hazards associated with tank wastes. Information is needed on the rates at which gases are produced and the types of gases produced to determine the safety of the tanks. This testing is best performed with actual waste samples to verify test results measured with simulant waste samples.

The rates at which gases are produced can be obtained by holding the sample under controlled conditions (gamma or thermal energy) while measuring the gas evolved as a function of time. Chemical analysis to identify gas constituents can be performed using standard gas chromatography/mass spectrometric techniques.

The data can be used to do the following:

- $\quad$ Perform engineering estimates of the steady state ventilation requirements of the waste tanks.

- Perform assessments of the changes in gas evolution from the wastes over long periods of time.

- $\quad$ Perform evaluations of the fuel value of the gases for combustion and explosion level analysis.

- Perform analyses to determine the effect of variations in waste constituent concentrations and $\mathrm{pH}$ on gas evolutions from the wastes. 
- Perform comparisons of gas evolution rates between convective and nonconvective waste layers in a given tank.

Satisfactory performance of these exercises on a sufficient number of waste samples will help focus understanding on the tanks that can be confidently removed from the Flammable Gas Watch List and on those that will require a more detailed series of testing.

Testing has already been performed on double-shell tanks 241-SY-101 and 241-SY-103. The next highest priority are double-shell tanks 241-AN-103, 241-AN-104 or 241-AN-105 which are Flammable Gas Watch List tanks in the AN farm. These tanks are followed tank 241-AW-101 because it has a high ratio of hydrogen to nitrous oxide.

For single-shell tanks, the U, SX and S tank farms are the highest priority. Tanks in U farm have a low hydrogen to nitrous oxide ratio. Tank $241-U-105$ is scheduled for addition of a SHMS E-plus gas monitoring system; therefore, it would be first priority of those in the farm so that a comparison can be made between the two different sets of analytical data. The tanks in farms $S$ and $S X$ are considered to have equal priorities; they have moderate hydrogen to nitrous oxide ratios. Two waste form types could be obtained from these farms because of the waste type variability in these farms.

The priorities outlined above are general guidelines. It is important to maintain flexibility in priorities so that program changes can be accommodated. The tank priorities given are not as important as the overall need to obtain more data from actual tank wastes. Given a choice in tanks available, the ones described above have first priority. However, data from other tanks may also be valuable in assessing the generation of gases from the tank wastes.

\subsection{LABORATORY WORK REMAINING TO UNDERSTAND GAS RETENTION}

Gas retention testing on actual tank wastes is a part of the path forward because the data is essential for estimating the potential physical hazard of the tank wastes. An understanding of the amount of gas that is retained in the solid waste is necessary to evaluate the hazard. It is necessary to perform testing on actual waste to verify that the retention behavior predicted from simulant studies can be applied to actual wastes with an acceptable level of confidence.

Gas retention methods are well developed. The standard bubble experiment is performed in which bubble growth is obtained by applying a vacuum to the waste sample following a few days of sample irradiation to ensure a small initial fraction of retained gas. Testing will also include increases in the experimental time (long-term) and increases in the amount of waste used (large-scale).

The two tank wastes of highest priority for Fiscal Year 1997 testing are tanks 241-AN-103 and 241-S-106. The standard bubble retention experiment (bubble growth by applying a vacuum following irradiation) will be conducted on samples from these tanks because they 
will provide the most valuable data for understanding gas bubble retention and release. Long-term and large-scale experiments will be conducted on waste material from tank 241-S106. Tank 241-AN-103 was selected because it has a large void fraction based on direct measurement, and because the waste type is double-shell slurry which differs from the complexant concentrate of the SY Farm tanks. This double-shell tank exhibits slurry growth similar to some single-shell tanks. Very few gas release events have been noted which indicates increased gas retention.

Tank 241-S-106 was selected for similar reasons. Analysis of the waste level rise and the effect of barometric pressure variations show a potential large void fraction. The waste type is noncomplexed waste which is different than that for the single-shell tanks tested in Fiscal Year 1996 (tank 241-S-102 which is double-shell slurry feed). This long term experiment will show how single-shell tanks release gas at steady state conditions while exhibiting continued slurry growth. Finally, the large scale test should enable understanding of the mechanism of interstitial liquid displacing bubbles. This mechanism is not well understood because observations of the mechanism have not been possible in the smaller vessels currently being used.

\subsection{DIRECT MEASUREMENTS OF GAS BEHAVIOR IN WASTE TANKS}

\subsubsection{Measurement of Stored Gas Volume}

The retained gas sampler was developed to measure the void volume and composition of gases retained in the waste. It was developed for and has been successfully used in characterizing double-shell tanks using the push mode sampling system. To date, one singleshell tank has also been sampled. A total of 39 retained gas samples have been obtained, and 28 have been extracted and analyzed.

Applying the retained gas sampler to additional single-shell tanks is more uncertain. Currently, the system is limited to tanks that can be sampled with the push mode system. The approach will be to sample selected tanks of the major waste types and apply the results to the other tanks within a given waste category. Tanks were selected based on a combination of the waste types defined by Brewster and Palmer (1995) and those tanks considered to be potential "push mode" tanks. At this time, the list of tanks include the following: 241-S-106 (Type 2A), 241-BY-101 (Type 2B), 241-BY-109 (Type 2B, alternate), 241-A-103 (Type 1B), 241-SX-106 (Type 1A, alternate; first choice was 241-U-103 on Fiscal Year 1996), 241-S-112 (Type 2A, alternate), 241-S-103 (Type 1A, altemate), and 241-U-111 (Type 1A, alternate). Type 3 cannot be push mode sampled, and type 4 waste does not contain enough gas to be of interest at this time.

The priorities outlined above are general guidelines. It is important to maintain flexibility in priorities so that program changes can be accommodated. The tank priorities given are not

as important as the overall need to obtain more data from actual tank wastes. Given a choice 
in tanks available, the ones described above have first priority. However, data from other tanks may also be valuable in assessing the retention of gases from the tank wastes.

\subsubsection{Measurement of Headspace Gases}

A revision to the approach for conducting continuous gas monitoring of flammable gas tanks was needed to be revised because of changes in planned waste intrusive activities (Lentsch 1996) of flammable gas monitoring needs developed by TWRS Engineering, Operations, and Safety Issue Resolution staff. The earlier approach had been transmitted to the DNFSB in August, 1996 (Wagoner 1996).

6.4.2.1 Tank Groupings and Data. Table 6-1 summarizes the information used to determine monitoring priorities. The waste tanks have been grouped as follows:

- Tanks with the potential to exceed $100 \%$ of the LFL in the headspace (Hodgson et al. 1996) caused by gas retention and an episodic release.

- Double-shell tanks that receive supernatant from saltwell pumping with the potential for gas retention and episodic release.

- Project tanks (W-320, W-030, W-151, and W-211) with the potential for gas retention and episodic release

- Aging waste tanks with high radiation source terms for gas generation.

- Other tanks currently equipped with Standard Hydrogen Monitoring Systems.

- Other tanks that are scheduled for saltwell pumping.

The potential percentage of the LFL (\%LFL) that might be observed during an episodic gas release, as determined in Hodgson et al. (1996) is presented for each tank in the table. The calculated \%LFL is based both on the surface level rise method and on the barometric pressure and waste level correlation method. The latter method is considered more accurate. Flammable Gas Watch List tanks are also annotated.

Table 6-1 shows the estimated dates of planned waste intrusive activities for each tank. This includes saltwell pumping start dates, push mode or rotary mode core sampling dates, and project start dates, such as mixer pump operation or waste sluicing.

Table 6- 1 also shows the currently installed gas monitoring systems and the dates when these systems were first installed. Six of the 28 Standard Hydrogen Monitoring Systems have not operated continuously since their installation because of moisture accumulations in the piping. Sample conditioning chillers are being installed on each unit to resolve this problem. 
Table 6-1. Waste Tank and Gas Monitor Prioritization. (4 sheets)

\begin{tabular}{|c|c|c|c|c|c|c|}
\hline (1. & . & 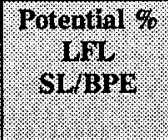 & 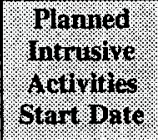 & 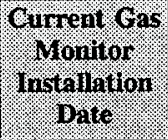 & $\begin{array}{l}\text { Proposed new } \\
\text { Gas nonitor }\end{array}$ & 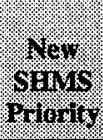 \\
\hline \multirow{17}{*}{$\begin{array}{l}\text { Tanks > } \\
100 \% \\
\text { LFL } \\
\text { Potential }\end{array}$} & SY-101 & WL $825 / 572$ & na & $\begin{array}{l}\text { GMS, SHMS } \\
(3 / 92)\end{array}$ & & \\
\hline & AN-105 & WL $743 / 411$ & na & $\begin{array}{l}\text { GCS, SHMS } \\
(9 / 94)\end{array}$ & & \\
\hline & AN-104 & WL $503 / 246$ & na & $\begin{array}{l}\text { SHMS (MTI) } \\
(9 / 94)\end{array}$ & & \\
\hline & A-101 & WL $0.99 / 379$ & 12/96 SWP & SHMS (3/95) & SHMS-E + 12/96 & 1 \\
\hline & AN-103 & WL 334/301 & na & SHMS (9/94) & & \\
\hline & U-105 & WL $270 / 129$ & $1 / 99 \mathrm{SWP}$ & SHMS (3/95) & SHMS-E+9/98 & 2 \\
\hline & AW-101 & WL 231/233 & na & $\begin{array}{l}\text { GCS, SHMS } \\
(9 / 94)\end{array}$ & & \\
\hline & $S-102$ & WL $190 / 226$ & 7/97 SWP & SHMS (3/95) & & \\
\hline & S-106 & $187 / 223$ & $\begin{array}{l}\text { 3/98 SWP } \\
\text { 11/96 PMCS }\end{array}$ & & SHMS-E + 11/96 & 1 \\
\hline & SX-103 & WL $2 / 216$ & $\begin{array}{ll}\text { 4/97 SWP } \\
\text { 3/97 RMCS }\end{array}$ & SHMS (3/95) & SHMS-E +1/97 & 1 \\
\hline & $\mathrm{U}-102$ & $152 / 203$ & $1 / 99$ SWP & & SHMS-E 9/98 & 2 \\
\hline & TX-112 & $66 / 195$ & 9/98 RMCS & & & 4 \\
\hline & S-111 & WL 80/181 & $1 / 98$ SWP & SHMS (3/95) & & \\
\hline & U-108 & WL $179 / \mathrm{nc}$ & $3 / 98$ & SHMS (3/95) & & \\
\hline & U-103 & WL $77 / 161$ & $\begin{array}{l}\text { 1/99 SWP } \\
10 / 96 \mathrm{PMCS}\end{array}$ & SHMS (3/95) & & 4 \\
\hline & S-109 & $16 / 145$ & 2/97 SWP & & SHMS-E + 11/96 & 1 \\
\hline & BY-105 & $13 / 145$ & $\begin{array}{l}2 / 97 \text { SWP } \\
10 / 98 \\
\text { RMCS }\end{array}$ & & SHMS-E+11/96 & 1 \\
\hline
\end{tabular}


WHC-SP-1193 Rev. 0

Table 6-1. Waste Tank and Gas Monitor Prioritization. (4 sheets)

\begin{tabular}{|c|c|c|c|c|c|c|}
\hline 48 & Tank & $\begin{array}{l}\text { Potential \% } \\
\text { SLPBPE }\end{array}$ & $\begin{array}{l}\text { Plamied: } \\
\text { Intrusive. } \\
\text { Activities. } \\
\text { Start Date }\end{array}$ & $\begin{array}{l}\text { Current Gas } \\
\text { Installation } \\
\text { Date }\end{array}$ & $\begin{array}{l}\text { Proposed Nev } \\
\text { Cas wonitor } \\
\text { mare) }\end{array}$ & 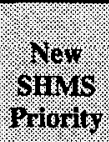 \\
\hline \multirow{7}{*}{$\begin{array}{l}\text { Tanks > } \\
100 \% \\
\text { LFL } \\
\text { Potential } \\
\text { (Cont'd) }\end{array}$} & S-107 & $138 / 34$ & 1/98 SWP & & SHMS 10/97 & 2 \\
\hline & $A W-104$ & $127 / 134$ & $\begin{array}{l}8 / 97 \\
\text { LLCE/PO }\end{array}$ & & SHMS-E 5/97 & $1 \mathrm{~T}$ \\
\hline & $Y-106$ & $123 / \mathrm{nc}$ & 7/97 SWP & SHMS $(8 / 95)$ & & $\mathrm{D}$ \\
\hline & $\mathrm{T}-201$ & $121 / \mathrm{nc}$ & 3/98 RMCS & & & 4 \\
\hline & U-109 & WL $81 / 118$ & $1 / 99$ SWP & SHMS (3/95) & & \\
\hline & AN-107 & $113 / \mathrm{nc}$ & $\sim 9 / 97$ C'A & & SHMS-E 6/97 & $1 \mathrm{VV}$ \\
\hline & $S-101$ & $109 / 47$ & $10 / 97$ SWP & & SHMS-E 7/97 & 1 \\
\hline \multirow{3}{*}{$\begin{array}{l}\text { DST } \\
\text { SWP } \\
\text { Receiver } \\
\text { Tanks }\end{array}$} & AN-101 & $0 / \mathrm{nc}$ & 12/96 SWP & & SHMS-E + 12/96 & 1 \\
\hline & AP-104 & $0 / n c$ & $12 / 98 \mathrm{CST}$ & & SHMS-E +9/98 & 2 \\
\hline & SY-102 & $15 / \mathrm{nc}$ & $\begin{array}{l}8 / 98 \text { W211 } \\
11 / 98 \text { PMCS } \\
2 / 97 \text { SWP }\end{array}$ & & SHMS-E + 12/96 & 1 \\
\hline \multirow[t]{2}{*}{$\begin{array}{l}\text { Project } \\
\text { W320 } \\
\text { Sluicing }\end{array}$} & $C-106$ & $0 / \mathrm{nc}$ & $\begin{array}{l}4 / 97 \text { W320 } \\
11 / 97 \\
\text { RMCS }\end{array}$ & & SHMS (MTI) $1 / 97$ & 1 \\
\hline & AY -102 & $0 / \mathrm{nc}$ & $4 / 97$ W320 & & SHMS (MTI) $1 / 97$ & 1 \\
\hline \multirow{3}{*}{$\begin{array}{l}\text { Aging } \\
\text { Waste } \\
\text { Tanks }\end{array}$} & AY -101 & $\sim 0 / 5$ & $\begin{array}{l}3 / 97 \\
W 030 / 80\end{array}$ & & & 4 \\
\hline & $A Z-101$ & $0 / \mathrm{nc}$ & $\begin{array}{l}\text { 4/99 RMCS } \\
12 / 96 \text { W151 } \\
3 / 97 \text { Wo30 }\end{array}$ & & SHMS-E $3 / 97$ & 1 \\
\hline & $A Z-102$ & $11 / \mathrm{nc}$ & $\begin{array}{l}\text { 7/99 PMCS } \\
12 / 96 \text { W030 }\end{array}$ & & SHMS-E 3/97 & 1 \\
\hline
\end{tabular}


WHC-SP-1193 Rev. 0

Table 6-1. Waste Tank and Gas Monitor Prioritization. (4 sheets)

\begin{tabular}{|c|c|c|c|c|c|c|}
\hline & tink & Potentipl & $\begin{array}{l}\text { Planned } \\
\text { minusive } \\
\text { Activities. } \\
\text { Start Date? }\end{array}$ & $\begin{array}{l}\text { Gurrent Gas } \\
\text { monitor } \\
\text { installation } \\
\text { Bate }\end{array}$ & $\begin{array}{l}\text { Proposed hew } \\
\text { Gas gionitor }\end{array}$ & 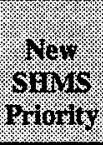 \\
\hline \multirow{14}{*}{$\begin{array}{l}\text { Other } \\
\text { tanks } \\
\text { with } \\
\text { SHMS }\end{array}$} & $S Y-103$ & WL $79 / 57$ & SHMS 5/92 & & & \\
\hline & AX-101 & 1/97 RMCS & SHMS 3/95 & & & D \\
\hline & $A X-103$ & 10/97 RMCS & SHMS 3/95 & & & D Now \\
\hline & SX-101 & WLO/28 & SHMS 3/95 & & & \\
\hline & SX-102 & WL 30/93 & SHMS 3/95 & & & \\
\hline & SX-104 & WL6/11 & SHMS 3/95 & & & D \\
\hline & SX-105 & WL87/- & SHMS 3/95 & & & \\
\hline & SX-106 & WL67/78 & SHMS 3/95 & & & \\
\hline & $S X-109$ & WLO/nc & SHMS 3/95 & & & $\mathrm{D}$ \\
\hline & $S-112$ & WL30/nc & SHMS 3/95 & & & D \\
\hline & U-107 & WLA2/87 & SHMS 3/95 & & & \\
\hline & $T-110$ & WL32/nc & SHMS 3/95 & & & D \\
\hline & BY -103 & $0 / 26$ & SHMS 8/95 & & & D \\
\hline & BY-109 & $-0 / 13$ & SHMS 8/95 & & & D \\
\hline \multirow{4}{*}{$\begin{array}{l}\text { Other } \\
\text { SWP } \\
\text { tanks }\end{array}$} & C-103 & $0 / \mathrm{nc}$ & & & & 4 \\
\hline & U-111 & $97 / \mathrm{nc}$ & & & & 4 \\
\hline & U-106 & $37 / 21$ & & & & 4 \\
\hline & S-103 & $57 / 72$ & & & & 4 \\
\hline
\end{tabular}


Table 6-1. Waste Tank and Gas Monitor Prioritization. (4 sheets)

\begin{tabular}{|c|c|c|c|c|c|c|}
\hline & Tani & $\begin{array}{l}\text { Potental \% } \\
\text { SLABP }\end{array}$ & $\begin{array}{l}\text { Planned } \\
\text { Intrusive } \\
\text { Activities } \\
\text { Start Date }\end{array}$ & $\begin{array}{l}\text { Gument Gas } \\
\text { Monitor } \\
\text { Batallo }\end{array}$ & $\begin{array}{l}\text { Proposed Wew } \\
\text { Gas Monitror }\end{array}$ & 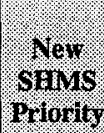 \\
\hline
\end{tabular}

Notes:

$\begin{array}{ll}\text { BPE } & \text { barometric pressure evaluation } \\ \text { CA } & =\text { caustic addition } \\ \text { CST } & =\text { cross site transfer } \\ \text { D } & =\text { delete after SWP or Fiscal Year 1998 } \\ \text { DST } & =\text { double-shell tank } \\ \text { GCS } & =\text { Gas Characterization System } \\ \text { GMS } & =\text { Gas Monitoring System } \\ \text { LFL } & =\text { lower flammability limit } \\ \text { LLCE } & =\text { long length contaminated equipment } \\ \text { MTI } & =\text { gas chromatograph } \\ \text { na } & =\text { not applicable } \\ \text { nc } & =\text { no correlation } \\ \text { PO } & =\text { pump out } \\ \text { SL } & =\text { surface level rise method } \\ \text { SHMS } & =\text { Standard Hydrogen Monitoring System } \\ \text { SHMS-E } & =\text { expendable SHMS } \\ \text { SHMS-E } & =\text { high sensitivity multi-gas SHMS } \\ \text { SWP } & =\text { saltwell pumping } \\ \text { VV } & =\text { reevaluate after void/viscometer measurements } \\ \text { WL } & =\text { Watch List } \\ \text { W030 } & =\text { Aging Waste Vent Upgrade Project } \\ \text { WI5! } & =\text { Retrieval Mixing Test Project } \\ \text { W211 } & =\text { lnitial Retrieval Project } \\ \text { W320 } & =\text { High heat Retrieval Project }\end{array}$

6.4.2.2 Gas Monitoring Priority and Criteria Methodology. The information in Table 6-1 was reviewed for each tank to determine the priority for installing continuous gas monitoring systems. Priorities were assigned as follows:

Priority 1: Monitor required in Fiscal Year 1997

Priority 2: Monitor required but defer installation until Fiscal Year 1998

Priority 3: Monitor required beyond Fiscal Year 1999 for retrieval operations

Priority 4: A new monitor is not required

Priority T: Temporary monitor required for short duration

Priority D: Remove the current monitor. 
Criteria were established for determining the priority of continuous monitors for each tank. The criteria are as follows.

- The potential exists for exceeding $100 \%$ of the LFL for the current waste state and planned intrusive work.

- Operational evolutions or events are planned that could lead to future gas retention or releases that would exceed $100 \%$ of the LFL.

The criteria for removing a current monitor are as follows.

- There is no potential to exceed $25 \%$ of the LFL.

- $\quad$ The tank has been interim stabilized.

- After adequate data have been acquired.

- No waste intrusive activities are planned for the tank.

Consideration must be given to the legal ramifications of deleting current monitoring systems on Watch List tanks because Public Law 101-510, "The Wyden Amendment," requires continuous monitoring for releases and/or pressure or temperature changes. Previously, credit was taken for using Standard Hydrogen Monitoring Systems in monitoring for release which would occur before a deflagration or release of waste from the tank.

Temporary continuous monitoring was recornmended when there was only one planned operational evolution for a limited duration, such as the pumpdown of tank 241-AW-104, with the potential for an episodic gas release. No monitoring was recommended if rotary core sampling was the only planned activity. This was because the rotary truck uses continuous gas monitoring instrumentation similar to a Standard Hydrogen Monitoring System.

6.4.2.3 Prioritization Results. Priorities are given in Table 6-1. At this time, no tanks are identified as priority 3 tanks. Future retrieval operations will evaluate the need for monitoring systems and will provide them as needed. Currently proposed monitoring systems may be redeployed for retrieval.

Table 6-1 shows the type of gas monitoring systems required when indicated by priority 1 or 2. To determine the gas composition and release rate, a Standard Hydrogen Monitoring System (SHMS-E+) with high sensitivity and multi-gas capabilities (Wagoner 1996) is proposed for ventilated tanks where gases are diluted. This includes the first tank in each tank farm to be saltwell pumped and appropriate double-contained receiver tanks where the potential exists for having gas releases and accumulations greater than $100 \%$ of the LFL. For example, the $\mathrm{W}-320$ Project sluicing tank (241-C-106) received a high sensitivity unit for hydrogen only. The SHMS-E units are designed for modular expansion to the -E+ 
capabilities if it is necessary after the initial monitoring results are obtained. All Standard Hydrogen Monitoring System units (normal SHMS, $-E$, or $-E+$ units) have the capability to collect automatic grab samples if the gas composition exceeds $25 \%$ of the LFL, or manual grab samples for gas composition analysis.

Gas sampling probes with double isolation valves will be installed in all double-shell tanks. Rapid measurements will also be possible using hand-held combustible gas meters during planned operational work or during unplanned events such as an extended loss of ventilation exhauster flow.

Two cart-mounted SHMS-E+ units will be provided, in conjunction with the installed gas sampling probes, for continuous but temporary characterization of tank vapor spaces. These units will be used for planned waste transfers or other operational or project evolutions to assess changes in gas generation and retention, for safety assessment purposes, and for operational monitoring.

For tanks in which current gas monitoring systems are proposed for deletion, the deletion would occur after adequate data have been acquired (approximately Fiscal Year 1998). For cases in which tanks have been saltwell pumped, a determination about monitoring will be made depending on gas measurement data unless noted otherwise in Table 6-1. When a unit is removed from a tank, the electrical connections, sample lines, and any cabinet foundations will be left in place for possible future use, such as during waste retrieval. The monitors will be relocated to other tanks, kept as spares, or maintained in storage for future use in other applications.

Plans are underway after Fiscal Year 1997 to integrate the gas monitoring functions of the SHMS-E+ units with the safety interlock functions of the flammable gas monitors provided with saltwell pumping skids. Competitive bids will be sought for single monitoring systems that perform both functions and use the technologies developed with these earlier units. This integration probably will result in additional savings, but the savings will not be available during Fiscal Year 1997.

\subsubsection{Summary}

Overall, the number of gas monitoring systems planned for installation in Fiscal Year 1997 has been reduced from 21 to 13. In Fiscal Year 1998, four systems will be installed not counting reductions from integration that is planned with the saltwell pumping flammable gas interlock system. By the end of Fiscal Year 1998, nine current Standard Hydrogen Monitoring Systems on single-shell tanks will be redeployed. As additional single-shell tanks are interim stabilized, more Standard Hydrogen Monitoring Systems probably can be redeployed. 
Using two cart-mounted SHMS-E+ systems, the installation of gas probes in tanks without continuous gas monitoring systems will allow 15 additional double-shell tanks to be monitored and characterized as needed in the future.

The net effect of this revised gas monitoring strategy is that at least 13 fewer continuous gas monitoring systems than originally planned will be needed through Fiscal Year 1998.

\subsection{UPDATING METHODOLOGY FOR EVALUATING POTENTIAL FLAMMABLE GAS TANKS}

The current methodology for evaluating tanks for flammable gas needs to be updated to reflect progress in understanding the mechanisms of gas generation, retention, and release.

The results of the methods for estimating retained gas volume will be compared to the results of the voidmeter and retained gas sampler to establish the validity and accuracy of each method. If necessary, the methods should be revised to provide more representative results.

The Flammable Gas Watch List criteria will be revised to remove the four-fold margin for error allowance inherent in the current calculation model. This will also clarified that the same criteria that were used to place tanks on the Flammable Gas Watch List will be used to remove tanks from that list. The revised criteria will require approval by DOE, thereby establishing clear ground rules for changing the Flammable Gas Watch List in the future.

Major method assumptions need to be assessed, validated, and improved based upon the progress that has been made in understanding the mechanisms for generation, retention, and release. These assumptions will be addressed in an order that makes the most impact on results or where sufficient information is available to establish better assumptions.

A careful reconciliation of all available data for a particular tank needs to be conducted to assure a consistent understanding of tank conditions, then an assessment can be made of the applicability of various models to determine whether quantitative calculations can be done. 
WHC-SP-1193 Rev. 0

\subsection{APPROACH FOR CLOSURE OF THE FLAMMABLE GAS USQ}

\subsubsection{Background}

During 1990, the Westinghouse Hanford Company investigated the retention and periodic release of gases in particular waste tanks. It was concluded that the creation, collection, and release of flammable gases was a safety concern that had not been considered adequately in the development of the Authorization Basis. The flammable gas issue was declared a USQ in May 1990 (Lawrence 1990). Since that time, the USQ was expanded to include other flammable gases (1996). Initially the applicability of the USQ to specific single- and doubleshell tanks and aging waste facilities was not always clearly defined, the USQ was expanded to cover an increasing number of tanks.

Understanding of the flammable gas phenomena has increased significantly through tank sampling and characterization, examining monitor data, laboratory experiments, and theoretical modeling and analysis. Considerable uncertainty still exists about the degree of gas retention and release for individual tanks. The concern about flammable gases in tanks containing radioactive wastes is the possibility of gases igniting which potentially could result in damage to tank structure, injury to personnel in the immediate vicinity, and dispersal of some tank contents to the environment.

On July 30, 1996, the Tank Waste Remediation System (TWRS) Plant Review Committee discovered USQ TF-96-0433. This USQ discovery or determination was prepared in accordance with the DOE Order 5480.21 (1991) to update and consolidate previous USQ determinations related to the generation of flammable gas by high-level waste in Hanford facilities. The USQ determination identified flammable gas hazards and affected facilities and updated information about them. Except for the Authorization Basis associated with tank 24l-SY-101, the USQ determination concludes that flammable gas hazards, the controls to manage them, and the technical bases for these controls are not adequately analyzed and documented.

Also on July 30, 1996, the TWRS Plant Review Committee approved a justification for continued operation (JCO) (Leach and Stahl 1.993) that addressed USQ determination TF-960433. The JCO provides detailed descriptions and data about the flammable gas hazards identified in USQD TF-96-0433 and develops work controls and equipment requirements related to them. Although a revised flammable gas USQ and JCO have been transmitted to DOE-RL (Bacon 1996), they are not yet formally approved by DOE-RL. However, TWRS is currently planning operations as though the new revised USQ were approved so that it can manage the identified risk. According to Johnson (1996b), TWRS personnel believe that while there is no merit to closing the original USQ on a tank-by-tank basis, closing should occur according to the revised USQ with its expanded and encompassing scope. Johnson summarizes issues related to the previous USQ closure strategy based on the limited definition of the USQ in 1990. Closure of the originally defined 1990 USQ would not result in effective management of the flammable gas hazard for all TWRS facilities. 


\subsubsection{Path Forward}

Johnson (1996b) has proposed a comprehensive path forward to resolve the flammable gas USQ and the safety issue. The scope of the revised USQ provides a more logical and efficient approach to USQ closure as discussed in Bacon (1996). Because the understanding of the flammable gas issue has increased, additional technical uncertainties, defined in the recently revised USQ TF-96-0433, must be resolved. The USQ also defined the scope of TWRS structures and facilities for which the flammable gas hazard has not been fully accounted for in the TWRS Authorization Basis and for which various levels of operational controls appear to be warranted.

The path forward is based on Safety Control Optimization by Performance Evaluation (SCOPE), a previously used and highly successful process. The SCOPE is based on the systematic application of expert elicitation methods to that quantify the uncertainty of phenomenological issues related to tank and waste behavior. The process enables costeffective, consistent decisions about hazard controls for TWRS to be made that take into account conservative viewpoints but do not constrain operations or impose costs that are too burdensome.

The proposed path forward includes interim milestones for the flammable gas USQ closure based on a graded approach for the respective "binning" of tanks as defined in the JCO (Bacon 1996). The ciosure will begin with well understood tanks that are expected to require minimal controls. A description of each major milestone based on the binning approach includes the following:

- $\quad$ Submit safety basis documentation to support closure of the flammable gas USQ for JCO facility group 3A; (115) interim stabilized single-shell tanks (August 15, 1997)

- Submit safety basis documentation to support closure of the flammable gas USQ for JCO facility group 3B; (34) non-interim stabilized single-shell tanks (September 30, 1997)

- Submit safety basis documentation to support closure of the flammable gas USQ for JCO facility group 2 single-shell tanks (June 30, 1998)

- Submit safety basis documentation to support closure of the flammable gas USQ for JCO facility group 1 and 2 double-shell and aging waste facility tanks by July 31, 1998. 
The completion of safety basis documentation and the submittal of the flammable gas USQ closure packages also supports the Hanford Federal Facility Agreement and Consent Order (Tri-Party Agreement), (Ecology et al. 1996), milestone M-40-09, "Close all Unreviewed Safety Questions (USQ) for Double-Shell and Single-Shell Tanks" (September 1998).

\subsection{EVALUATION OF TANKS FOR REMOVAL FROM THE WATCH LIST}

One item needing further development is the process for screening tanks against the Flammable Gas Watch List criteria. Methods were developed for screening tanks for gas retention (Whitney 1995), then applying the results to previously determined criteria (Hopkins 1995, Hodgson 1995). However, an evaluation (WHC 1996) of these methods was performed and areas were identified in which improvements were needed. To implement improvements, a process that builds upon the previous technical work and incorporates recommendations will be required. A summary of process elements is provided here. They apply to tank conditions in storage mode and will determine whether a significant flammable gas risk exists, that is, tanks wili be evaluated for an intrinsic flammable gas hazard during the period of time where no active, intrusive operations are taking place. (Active operations, such as sampling and pumping, require a safety authorization basis for that operation that evaluates a complete set of hazards, including the flammable gas hazard. The complete set of hazards for any operation must be shown to present an acceptable risk before receiving authorization to proceed.)

The Flammable Gas Watch List identifies tanks with a "serious potential" for "release of high-level waste due to uncontrolled increases in temperature or pressure" caused by a combustion of flammable gas. Only the specific event sequences that could lead to a combustion of flammable gas are considered. The combustion of flammable gases can only result if all or part of the tank headspace is at or above the LFL.

Two pathways could lead to a significant volume of flammable gas in the tank headspace:

- Persistent, steady-state evolution of gas

- An episodic gas release event. 


\subsubsection{Steady-State Release of Flammable Gas}

Placing more emphasis on flammable gas data from the headspace of tanks will make it easier to identify tanks at risk, because the persistent, steady-state release of flammable gas can lead to the tank headspace being above the LFL under the following conditions:

- The gas generation is high

- The ventilation rate (passive or active) is low.

Using estimated bounding parameters, it has been calculated that some tanks may exceed the LFL under steady-state conditions. However, tank measurements have always shown tanks, in the absence of a gas release event, to be well below the LFL. Although the potential exists, it is extremely unlikely that any tank would exceed the lower flammability limit solely due to the steady-state release of flammable gas. Because flammable gas measurements are available for the headspace of all tanks, these will be used as the basis for steady-state evaluations.

\subsubsection{Episodic Gas Release Events}

Improving and enhancing data will also make it easier to identify tanks at risk. After dispersal, an episodic gas release event could result in the entire tank dome being above the LFL, it could result in a gas plume that is flammable but disperses to a concentration below the LFL.

To provide a full analysis of a tank with an episodic gas release, both qualitative and quantitative information must be evaluated to gain a consistent picture of what happens in the tank. Once it is clear that available models apply to the tank condition, numeric estimates can be generated. Several factors influence the process of identifying and estimating whether a given tank will exceed the LFL. These factors include the following factors:

- The stored gas volume

- The fraction of stored gas released in an event

- The fraction of stored gas that is flammable

- The rate of gas release

- The headspace volume

- The degree of mixing and removing of gases from the headspace 
The factors can be estimated or measured using direct or indirect measurements. If measurements are not available, then estimates can be used based on analysis of other tanks, simulated wastes, or limiting physical conditions. Because the calculations are complex and are unique to each tank, it is desirable to screen out tanks which have no indication of flammable gas retention.

The movement of the tank waste surface can be used to determine the amount of gas trapped in the waste on a tank-by-tank basis. The movement of the surface when the barometric pressure changes has been correlated. As the pressure increases, the waste is compressed with a movement downward; as the pressure decreases, the waste expands with a movement upward. This method is referred to as the barometric pressure evaluation method. Efforts to validate this method are underway. Where this method is valid, it will be used to estimate the retained gas volume. Direct measures of retained gas by measurement of void fraction or retained gas sampling will be used where available and valid.

Some of the waste parameters used to estimate the gas retention and release include the following:

- Surface area of the waste being displaced
- Durface level of the waste
Density of the waste
-
-
-
-
-
-
-
-

Analyzing tanks for episodic gas release behavior must be based on a total reconciliation of all available data on the tank so that a consistent understanding of tank conditions is achieved. Once it is determined that a tank is a candidate for episodic gas release behavior, the data must be assessed to determine that sufficient quality exists to perform quantitative calculations. Only when the data are deemed to be of sufficient quality will calculations of magnitude for potential gas release events be performed. 


\subsection{REFERENCES}

Agnew, S. F., 1995, Hanford Defined Wastes: Chemical and Radionuclide Compositions, LA-UR-94-2657, Los Alamos National Laboratory, Los Alamos, New Mexico.

Agnew, S. F., 1995b, P. Baca, R. Corbin, K. Jurgensen, B. Young, T. Ortiz, and T. Duran, Tank Layer Model (TLM) for Northeast, Southwest, and Northwest Quadrants, LA-UR-94-4269, Los Alamos National Laboratory, Los Alamos, New Mexico.

Agnew, S. F., R. Corbin, J. Boyer, T. Duran, K. Jurgensen, T. Ortiz, B. Young, R. Anema, and C. Ungerecht, 1996, History of Organic Carbon in Hanford HLW Tanks: HDR Model, Rev. 3, LA-UR-96-989, Los Alamos National Laboratory, Los Alamos, New Mexico.

Antoniak, Z. I., and K. P. Recknagle, 1996, Modeling of Hydrogen Plume Concentrations in Single-and Double-Shell Tank Domes, TWSFG96.12, Pacific Northwest National Laboratory, Richland, Washington.

Bacon, R. F., 1996, Justification for Continued Operation for Flammable Gas Unreviewed Safety Question (Letter 9653371 to J. E. Kinzer, July 31), Westinghouse Hanford Company, Richland, Washington.

Barefield, E. K., D. Boatwright, A. Deshpande, F. Doctorovich, C. L. Liotta, H. M. Neumann, and S. Seymore, 1995, Mechanisms of Gas Generation from Simulated SY Tank Farm Wastes: FY 1994 Progress Report, PNL-10822, Pacific Northwest Laboratory, Richland, Washington.

Barefield, E. K., D. Boatwright, A. Deshpande, F. Doctorovich, C. L. Liotta, H. M. Neumann, and S. Seymore, 1996, Mechanisms of Gas Generation from Simulated SY Tank Farm Wastes: FY 1994 Progress Report, PNL-11247, Pacific Northwest National Laboratory, Richland, Washington.

Bracken, G. J., 1990, Flammable Gas/Slurry Growth Issues, (External letter 9001274B to President, WHC, April 2), U.S. Department of Energy, Richland Operations Office, Richland, Washington.

Bratzel, D. R., H. Babad, and J. L. Huckaby, 1995, Headspace Gas and Vapor Characterization Summary for 43 Vapor Program Suspect Tanks, WHC-SD-WM-ER-514, Rev. 0, Westinghouse Hanford Company, Richland, Washington.

Bredt, P. R., S. M. Tingey, and E. H. Shade, 1995, The Effect of Dilution on the Gas Retention Behavior of Tank 241-SY-101 Waste, PNL-10781, Pacific Northwest Laboratory, Richland, Washington. 
Bredt, P. R. and S. M. Tingey, 1996, The Effect of Dilution on the Gas Retention Behavior of Tank 241-SY-103 Waste, PNL-10893, Pacific Northwest National Laboratory, Richland, Washington.

Breshears, W. D., H. A. Fry, and J. L. Lyman, 1996, Interim Progress Report: Gas Flammability Modeling, 11. Analysis and Interpretation of Flammability Data for Hydrogen-Ammonia-Nitrous Oxide-Air Mixtures, TSA-10-96-503, Los Alamos National Laboratory, Los Alamos, New Mexico.

Brewster, M. E. and B. J. Palmer, 1995, Prioritization of Single-Shell Tanks for Study for Gas Retention and Episodic Release, (PNNL letter report PNL-WTS122295 to G. D. Johnson, December 1995), Pacific Northwest National Laboratory, Richland, Washington.

Brewster, M. E., and P. D. Whitney, 1996, Estimates of the Frequencies of Potentially Hazardous Gas Releases from Hanford Tank Waste, (PNNL letter report to G. D. Johnson, TWSFG96.24, Pacific Northwest National Laboratory, Richland, Washington.

Brown, T. M., S. J. Eberlein, and T. J. Kunthara, 1995, Tank Waste Characterization Basis, WHC-SD-WM-TA-164, Rev. 1, Westinghouse Hanford Company, Richland, Washington.

Bryan, S. A., and L. R. Pederson, 1995, Thermal and Combined Thermal and Radiolytic Reactions Involving Nitrous Oxide, Hydrogen, and Nitrogen in the Gas Phrase; Comparison of Gas Generation Rates in Supernate and Solid Fractions of Tank 241-SY-101 Simulated Wastes, PNL-10490, Pacific Northwest Laboratory, Richland, Washington.

Bryan, S. A. and L. R. Pederson, 1996a, Status and Integration of Studies of Gas Generation in Hanford Wastes, PNNL-11297, Pacific Northwest Laboratory, Richland, Washington.

Bryan, S. A. and L. R. Pederson, 1996b, Thermal and Combined Thermal and Radiolytic Reactions Involving Nitrous Oxide, Hydrogen, and Nitrogen in the Gas Phrase; Comparison of Gas Generation Rates in Supernate and Solid Fractions of Tank 241-SY-101 Simulated Wastes, PNNL-10490, Pacific Northwest National Laboratory, Richland, Washington.

Bryan, S. A., C. M. King, L. R. Pederson, S. V. Forbes, and R. L. Sell, 1996, Gas Generation from Tank 24l-SY-103 Waste, PNNL-10978, Pacific Northwest National Laboratory, Richland, Washington. 
Cannon, N. S. and R. C. Knight, 1995, Retained Gas Sampler System Acceptance Test Report, WHC-SD-WM-ATR-137, Rev. 0, Westinghouse Hanford Company, Richland, Washington.

Cashdollar, K. L., G. M. Green, M. Hertzog, C. E. Lucci, R. A., Thomas, I. A. Zachower, 1992, Laboratory Flammability Studies of Mixtures of Hydrogen Nitrous Oxide and Air, WHC-SD-WM-ES-219, Rev. 0, Westinghouse Hanford Company, Richland, Washington.

DOE, 1991, Unreviewed Safety Questions, DOE Order 5480.21, U.S. Department of Energy, Washington, D.C.

DOE-RL, 1996, Recommendation 93-5 Implementation Plan, DOE-RL-94-0001, Rev. 1, U.S. Department of Energy, Richland Operations, Richland, Washington.

Dullien, F. A. L., 1992, Porous Media: Fluid Transpont and Pore Structure, Academic Press, San Diego, California.

Ecology, EPA, and DOE, 1996, Hanford Federal Facility Agreement and Consent Order, as amended, Washington State Department of Ecology, U.S. Environmental Protection Agency, and U.S. Department of Energy, Olympia, Washington.

Gauglitz, P. A., L. A. Mahoney, D. P. Mendoza, and M. C. Miller, 1994, Mechanisms of Gas Bubble Retention, PNL-10120, Pacific Northwest Laboratory, Richland, Washington.

Gauglitz, P. A., S. D. Rassat, M. R. Powell, R. R. Shah, and L. A. Mahoney, 1995, Gas Bubble Retention and its Effect on Waste Properties: Retention Mechanisms, Viscosity, and Tensile and Shear Strength, PNL-10740, Pacific Northwest Labortary, Richland, Washington.

Gauglitz, P. A., P. R. Bredt, J. H. Konynenbelt, D. P. Mendoza, S. D. Rassat, S. M. Tingey, 1966, Mechanisms of Gas Retention and Releasse: Result for Hanfrod Waste Tanks 241-2-102 and 241-SY-103 and Single-Shell Tank Simulants, PNNL-11298, Pacific Northwest National Laboratory, Richland, Washington.

Graves, R. D., 1994, Topical Report on Flammable Gases in Non-Burping Waste Tanks, $W H C-S D-W M-S A R R-015$, Westinghouse Hanford Company, Richland, Washington. 
Grigsby, J. M. and C. E. Leach, 1996, Flammable Gas/Slurry Growth Unreviewed Safety Question: Justification for Continued Operation for the Tank Farms, WHC-SD-WM-JCO-007, Rev. 0A, Westinghouse Hanford Company, Richland, Washington.

Hanlon, B. M., 1996, Waste Tank Summary Report for Month Ending February 29, 1996, Westinghouse Hanford Company, Richland, Washington.

Harmon, H. D., 1991a, Safety Measures for Waste Tanks at the Hanford Site, Ruchland. Washingon, (External letter 9059124 to R. E. Gerton, U.S. Department of Energy, Richland Operations Office, January 8), Westinghouse Hanford Company, Richland, Washington.

Harmon, H. D., 1991b, Watch List for Tanks Which May Have Hydrogen Buildup, (External letter 9001478B R1 to R. E. Gerton, U.S. Department of Energy, Richland Operations Office, February 8), Westinghouse Hanford Company, Richland, Washington.

Hermann, C. 1. Dewes, and A. Schumpe, 1995, "Chemical Engineering Science," 50:1673 Need city and state.

Hodgson, K. M., 1995, Evaluation of Hanford Tanks for Trapped Gas, WHC-SD-WM-E-526, Rev. 0, Westinghouse Hanford Company, Richland, Washington.

Hodgson, K. M., R. P. Anantamula, S. A. Barker, K. D. Fowler, D. C. Hedengren, J. D. Hopkins, J. A. Lechelt, D. A. Reynolds, R. E. Stout, and R. T. Winward, 1996, Evaluation of Hanford Tanks for Trapped Gas, WHC-SD-WM-ER-526, Rev. 1 Westinghouse Hanford Company, Richland, Washington.

Hopkins, J. D., 1994, Criteria for Flammable Gas Watch List Tanks, WHC-EP-0702, Rev. 0, Westinghouse Hanford Company, Richland, Washington.

Hopkins, J. D., 1995, Methodology for Flammable Gas Evaluations, WHC-SD-WM-TI-724, Rev. O, Westinghouse Hanford Company, Richland, Washington.

Hopkins, J. D., 1996, Methodology for Flanmable Gas Evaluations, WHC-SD-WM-TI-724, Rev. 1, Westinghouse Hanford Company, Richland, Washington.

Johnson, G. D., 1995, Strategy for Resolution of the Flammable Gas Safety Issue, WHC-SD-WM-TI-691, Rev. 0, Westinghouse Hanford Company, Richland, Washington. 
Johnson, G. D., 1996a, Evaluation of Recommendation for Addition of Tanks to the Flammable Gas Watch List, WHC-SD-WM-ER-594, Rev. 0, Westinghouse Hanford Company, Richland, Washington.

Johnson, G. D., 1996b, Flammable Gas Project: Unreviewed Safety Question Closure Path Forward and Milestone T22-96-119, (Letter 9653533.1 to J. K. McClusky August 28), Westinghouse Hanford Company, Richland, Washington.

Lawrence, M. J., 1990, Unreviewed Safety Question--Waste Storage Tanks, (Letter to L. P. Duffy, May 14), U.S. Department of Energy, Richland Operations, Richland, Washington.

Leach C. E. and S. M. Stahl, 1993, Hanford Site Tank Farms Facilities Interim Safety Basis, WHC-SD-WM-15B-001, Rev. 0, Westinghouse Hanford Company, Richland, Washington.

Lentsch, J. W., 1996, Flammable Gas Project: Revised Strategy for Continuous Monitoring, (Letter 9654881 to S. Marchetti, October 15), Duke Engineering Services Hanford, Richland, Washington.

Meisel, D.,H. Diamond, E. P. Horowitz, C. D. Jonah, M. S. Matheson, M. C. Sauer, and J. C. Sulivan, 1991, Radiation Chemistry of Synthetic Waste, ANL-91/40, Argonne National Laboratory, Argonne, Mllinois.

Meisel, D., C. D. Jonah, S. Kapoor, M. S. Matheson, and M. C. Sauer, 1993, Radiolytic and Radiolytically Induced Generation of Gases from Synthetic Wastes, ANL-93/43, Argonne National Laboratory, Argonne, Illinois.

National Defense Authorization Act for Fiscal Year 1991, Public Law 101-510, Section 3137, "Safety Measures for Waste Tanks at the Hanford Nuclear Reservation," November 5, 1990.

Norton, J. D. and L. R. Pederson, 1994, Ammonia in Simulated Hanford Double-Shell Tank Wastes: Solubility and Effects of Surface Tension, PNL-10173, Pacific Northwest Laboratory, Richland, Washington.

Norton, J. D., and L. R. Pederson, 1995, Solubilities of Gases in Simulaated Tank 241 SY-101 Wastes, PNL-10785, Pacific Northwest Laboratory, Richland, Washington.

Pasamehmetoglu, 1994, Analyses of Gas Composition and Relevant Gas Concentration Measurements for the Release Gas in Tank 241-SY-101, N6-CN-WT-SA-GR-004, Los Alamos National Laboratory, Los Alamos, New Mexico. 
Person, J. C., 1996. Effects of Oxygen Cover Gas and NaOH Dilution on Gas Generation in Tank 241-SY-101 Waste, WHC-SD-WM-DTR-043, Westinghouse Hanford Company, Richland, Washington.

PNNL, 1996, Status and Integrating Studies of Gas Generation in Hanford Wastes, PNNL-11297, Pacific Northwest National Laboratory, Richland, Washington.

Remund, K. M., C. M. Anderson, and B. C. Simpson, 1995, Hanford Single-Shell Tank Grouping Study, PNL-10749, Pacific Northwest Laboratory, Richland, Washington.

Reynolds, 1992, Current Understanding of the Composition of Gas from 101-SY, (Internal memorandum 7K210-92-310 to C. E. Hansen May 4, 1992), Westinghouse Hanford Company, Richland, Washington.

Ross, M. C., J. E. Shepherd, 1996, Lean Combustion Characteristics of Hydrogen-Nitrous Oxide-Ammonia Mixtures in Air, Part 1, FM 96-4, California Institute of Technology, Pasadena, California.

Shekarriz, A., D. R. Rector, M. A. Chieda, and J. M. Bates, 1996, Retained Gas Sampler Measurement Results for Hanford Waste Tank 241-A-101, (PNNL letter report TWS-MIT-093096 to G. D. Johnson, September 1996), Pacific Northwest National Laboratory, Richland, Washington.

Shekarriz, A., D. R. Rector, M. A. Chieda, M. White, and J. M. Bates, 1996, Retained Gas Sampler Measurement Results for Hanford Waste Tank 241-A-101, (PNNL letter report TWS-MIT-071996 to G. D. Johnson, July 1996), Pacific Northwest National Laboratory, Richland, Washington.

Stauffer, D., 1985, Introduction to Percolation Theory, Taylor and Francis, London, England.

Stewart, C. W., M. E. Brewster, P. A. Gauglitz, L. A. Mahoney, P. A. Meyer, K. P. Recknagle, H. C. Reid, 1996a, Gas Retention and Release Behavior in Hanford Single-Shell Waste Tanks, PNNL-11391, Pacific Northwest National Laboratory, Richland, Washington.

Stewart, C. W., J. M. Alzheimer, M. E. Brewster, G. Chen, R. E. Mendoza, H. C. Reid, C. L. Shepard, and G.Terrpmes, 1996b, In Situ Rheology and Gas Volume in Hanford Double-Shell Waste Tanks, PNNL-11296, Pacific Northwest Laboratory, Richland, Washington.

Wagoner, J. D., 1996, Transmittal of Information to Complete Milestone 5.4.3.5.b, (Letter 96-WSD-161 to J. T. Conway, DNFSB, August 19), U.S. Department of Energy, Richland Operations Office, Richland, Washington. 
WHC, 1990, Hydrogen Gas Buildup, WHC-UOR-90-013-TF-02, Westinghouse Hanford Company, Richland, Washington.

WHC. 1996, Evaluation of Recommendation for Addition of Tanks to the Flammable Gas Watch List, WHC-SD-WM-ER-594, Westinghouse Hanford Company, Richland, Washington.

Whitney, P. D. 1995, Screening the Hanford Tanks for Trapped Gas, PNL-10821, Pacific Northwest Laboratory, Richland, Washington.

Whitney, P. D., P. A. Meyer, N. E. Wilkins, F. Gao, A. G. Wood, 1993, Flammable Gas Data Evaluation Progress Report, PNNL 11373, Pacific Northwest National Laboratory, Richland, Washington. 
WHC-SP-1193 Rev. 0

This page intentionally left blank. 
WHC-SP-1193 Rev. 0

\begin{abstract}
APPENDIX A
RESULTS OF VAPOR PHASE SAMPLING OF HANFORD SITE PASSIVELY VENTILATED SINGLE-SHELL TANKS
\end{abstract}


WHC-SP-1193 Rev. 0

This page intentionally left blank. 
WHC-SP-1193 Rev. 0

\section{A.0 RESULTS OF VAPOR PHASE SAMPLING OF HANFORD SITE PASSIVELY VENTILATED SINGLE-SHELL TANKS}

All 134 passsively ventilated single-shell tanks were vapor phase sampled for flammable gas by the vapor sampling system truck (Bratzel et al. 1995) or by direct measurement on a stream extracted from a tank's headspace using a combustable gas meter (Grigsby and Leach 1996). The results of sampling for each tank shown in Table A-1. Table A-1 lists each tank, the date on which the tank was sampled, the type of sampling preformed, and the percent of the lower flammablility limit obtained.

The tank showing the highest LFL percent tank $241-\mathrm{C}-103$. The result reported is $13 \%$ of the LFL, well below the action limit of $25 \%$. Tank $241-\mathrm{C}-103$ has a floating organic layer on its surface and is expected to have relatively higher concentrations of flammable organic vapors and hydrogen. The next highest tank was tank $241-\mathrm{S}-101$ at $7 \%$ of the lower flammability limit. Of the 134 tanks sampled, 27 showed flammable gas concentrations above $1 \%$ of the LFL.

The purpose of this sampling is to understand the steady state concentration of flammable gas in the tanks under normal operating conditions. There was no attempt made to sample during periods of restricted passive ventilation or gas release events. Although these conditions may occur and would result in elevated flammable gas conditions, it is important to understand that the normal condition for the headspace is nonflammable even in tanks that experience passive ventilation only. 
WHC-SP-1193 Rev. 0

Table A-1. Sampling Results for Passively Ventilated Single-Shell Tanks. (5 sheets)

\begin{tabular}{|c|c|c|c|}
\hline Tank H & Sample Date & Sample TYPe & TOWA LIT (\%) \\
\hline A-101 & $04 / 09 / 95$ & VSS & 2.5 \\
\hline$A-102$ & $11 / 10 / 95$ & VSS & 0.93 \\
\hline A-103 & $11 / 09 / 95$ & VSS & 1.38 \\
\hline A-104 & $01 / 14 / 96$ & CGM & $\overline{0}$ \\
\hline A-105 & $01 / 19 / 96$ & CGM & 0 \\
\hline A. 106 & $08 / 12 / 96$ & CGM & 2 \\
\hline $\mathrm{AX}-101$ & $04 / 15 / 95$ & VSS & 0.32 \\
\hline $\mathrm{AX}-102$ & $06 / 28 / 95$ & $\overline{\text { VSS }}$ & 0 \\
\hline AX-103 & $04 / 21 / 95$ & VSS & $<0.31$ \\
\hline $\mathrm{AX}-104$ & $01 / 14 / 96$ & CGM & 0 \\
\hline B-101 & $03 / 26 / 96$ & CGM & 0 \\
\hline B-102 & $04 / 18 / 96$ & VSS & 0 \\
\hline B-103 & $02 / 08 / 95$ & VSS & 0 \\
\hline B-104 & $03 / 26 / 96$ & $\overline{C G M}$ & 0 \\
\hline B-105 & $06 / 06 / 96$ & CGM & 0 \\
\hline B-106 & $04 / 26 / 96$ & CGM & 0 \\
\hline B-107 & $06 / 06 / 96$ & $\overline{\mathrm{CGM}}$ & 2 \\
\hline B-108 & $04 / 26 / 96$ & CGM & 0 \\
\hline B-109 & $06 / 12 / 96$ & CGM & 0 \\
\hline B-110 & $04 / 26 / 96$ & $\overline{\mathrm{CGM}}$ & 0 \\
\hline B-111 & $03 / 19 / 96$ & $\overline{\text { CGM }}$ & 0 \\
\hline B-112 & $08 / 30 / 95$ & CGM & 0 \\
\hline B-201 & $06 / 04 / 96$ & $\overline{\text { CGM }}$ & 0 \\
\hline B-202 & $06 / 04 / 96$ & $\overline{\mathrm{CGM}}$ & 0 \\
\hline B-203 & $11 / 20 / 95$ & $\overline{C G M}$ & 0 \\
\hline B-204 & $04 / 26 / 96$ & $\overline{\text { CGM }}$ & 0 \\
\hline BX-101 & $04 / 24 / 96$ & CGM & 0 \\
\hline BX-102 & $06 / 24 / 96$ & CGM & 0 \\
\hline BX-103 & $03 / 26 / 96$ & $\overline{\mathrm{CGM}}$ & 0 \\
\hline BX-104 & $12 / 30 / 94$ & VSS & 0.4 \\
\hline BX-105 & $04 / 24 / 96$ & VSS & 0 \\
\hline BX-106 & $12 / 19 / 95$ & CGM & 0 \\
\hline BX-107 & $11 / 17 / 95$ & VSS & 0.1 \\
\hline
\end{tabular}


WHC-SP-1193 Rev. 0

Table A-1. Sampling Results for Passively Ventilated Single-Shell Tanks. (5 sheets)

\begin{tabular}{|c|c|c|c|}
\hline Tank & Sample Date & Sample. Yype & Total OT (\%) \\
\hline BX-108 & $08 / 29 / 95$ & $\overline{\mathrm{CGM}}$ & 0 \\
\hline BX-109 & $04 / 24 / 96$ & $\overline{C G M}$ & 0 \\
\hline BX-110 & $10 / 02 / 95$ & CGM & 0 \\
\hline $\mathrm{BX}-111$ & $04 / 24 / 96$ & CGM & 0 \\
\hline $\mathrm{BX}-112$ & $04 / 16 / 95$ & $\overline{\mathrm{CGM}}$ & 0 \\
\hline BY-101 & $08 / 08 / 96$ & $\overline{\mathrm{CGM}}$ & 0 \\
\hline BY-102 & $11 / 21 / 95$ & VSS & 0.26 \\
\hline BY-103 & $11 / 01 / 94$ & VSS & 0.1 \\
\hline BY-104 & $06 / 24 / 94$ & VSS & 1 \\
\hline $\mathrm{BY}-105$ & $07 / 07 / 94$ & VSS & 0.3 \\
\hline BY-106 & $07 / 08 / 94$ & VSS & 0.2 \\
\hline BY-107 & $10 / 26 / 94$ & VSS & 2.3 \\
\hline BY-108 & $10 / 27 / 94$ & VSS & 3.4 \\
\hline BY-109 & $08 / 08 / 96$ & $\overline{C G M}$ & 0 \\
\hline $\mathrm{BY}-110$ & $11 / 11 / 94$ & VSS & 0.4 \\
\hline $\mathrm{BY}-111$ & $11 / 16 / 94$ & VSS & 0.2 \\
\hline BY-112 & $11 / 18 / 94$ & VSS & 0.1 \\
\hline $\mathrm{C}-101$ & $09 / 01 / 94$ & VSS & 1.8 \\
\hline $\mathrm{C}-102$ & $08 / 23 / 94$ & VSS & 1.2 \\
\hline $\mathrm{C}-103$ & $05 / 24 / 94$ & VSS & 13 \\
\hline $\mathrm{C}-104$ & $3 / 3 / 94$ & VSS & 0.3 \\
\hline C-107 & $09 / 29 / 94$ & VSS & 0.6 \\
\hline C- 108 & $08 / 05 / 94$ & VSS & 0 \\
\hline C-109 & $08 / 09 / 94$ & VSS & 0.3 \\
\hline$C-110$ & $08 / 24 / 94$ & VSS & 0.2 \\
\hline$C-111$ & $09 / 13 / 94$ & VSS & 0.03 \\
\hline$C-112$ & $08 / 11 / 94$ & VSS & 0.5 \\
\hline C-201 & $08 / 31 / 95$ & CGM & 0 \\
\hline C-202 & $08 / 31 / 95$ & CGM & 0 \\
\hline$C-203$ & $08 / 29 / 95$ & CGM & 0 \\
\hline C-204 & $06 / 03 / 96$ & CGM & 0 \\
\hline S-101 & $04 / 03 / 96$ & CGM & 7 \\
\hline S-102 & $03 / 14 / 95$ & VSS & 2 \\
\hline
\end{tabular}


WHC-SP-1193 Rev. 0

Table A-1. Sampling Results for Passively Ventilated Single-Shell Tanks. (5 sheets)

\begin{tabular}{|c|c|c|c|}
\hline Tans $\Rightarrow$ & Sample Date & Sample IYpe & TotrI IL (F) \\
\hline$S-103$ & $05 / 17 / 96$ & CGM & 0 \\
\hline S-104 & $03 / 19 / 96$ & CGM & 0 \\
\hline$\overline{S-105}$ & $12 / 07 / 95$ & VSS & 0.09 \\
\hline$\overline{S-106}$ & $05 / 17 / 96$ & CGM & 0 \\
\hline S-107 & $09 / 30 / 95$ & CGM & 4 \\
\hline$S-108$ & $12 / 06 / 95$ & VSS & 0.09 \\
\hline S-109 & $05 / 17 / 96$ & $\overline{C G M}$ & 0 \\
\hline$S-110$ & $12 / 05 / 95$ & VSS & 0.45 \\
\hline S-111 & $03 / 21 / 95$ & VSS & 1.1 \\
\hline $\mathrm{S}-112$ & $07 / 11 / 95$ & VSS & 0.1 \\
\hline $\mathrm{SX}-113$ & $08 / 18 / 95$ & $\overline{\mathrm{CGM}}$ & 0 \\
\hline$\overline{S X}-115$ & $03 / 08 / 96$ & CGM & 0 \\
\hline $\mathrm{T}-101$ & $07 / 30 / 96$ & $\mathrm{CGM}$ & 0 \\
\hline $\mathrm{T}-102$ & $05 / 09 / 96$ & $\overline{\mathrm{CGM}}$ & 0 \\
\hline $\mathrm{T}-103$ & $02 / 15 / 96$ & CGM & 0 \\
\hline$T-104$ & $2 / 7 / 96$ & VSS & 0 \\
\hline$T-105$ & $05 / 09 / 96$ & CGM & 0 \\
\hline$T-106$ & $05 / 09 / 96$ & $\mathrm{CGM}$ & 0 \\
\hline $\mathrm{T}-107$ & $12 / 18 / 95$ & VSS & 0.1 \\
\hline$T-108$ & $05 / 09 / 96$ & CGM & 0 \\
\hline$T-109$ & $05 / 09 / 96$ & $\overline{C G M}$ & 0 \\
\hline $\mathrm{T}-110$ & $08 / 31 / 95$ & VSS & 0.1 \\
\hline $\mathrm{T}-111$ & $12 / 20 / 95$ & VSS & 0.2 \\
\hline $\mathrm{T}-112$ & $05 / 09 / 96$ & CGM & 0 \\
\hline $\mathrm{T}-201$ & $07 / 31 / 96$ & CGM & 0 \\
\hline $\mathrm{T}-202$ & $08 / 09 / 96$ & $\overline{C G M}$ & 2 \\
\hline$\overline{T-203}$ & $03 / 19 / 96$ & $\mathrm{CGM}$ & 0 \\
\hline$T-204$ & $07 / 31 / 96$ & CGM & 0 \\
\hline TX-101 & $06 / 14 / 96$ & $\overline{\mathrm{CGM}}$ & 0 \\
\hline $\mathrm{TX}-102$ & $06 / 20 / 96$ & $\mathrm{CGM}$ & 0 \\
\hline $\mathrm{TX}-103$ & $06 / 17 / 96$ & $\overline{\mathrm{CGM}}$ & 0 \\
\hline TX-104 & $07 / 23 / 96$ & CGM & 0 \\
\hline TX-105 & $12 / 21 / 94$ & VSS & 0 \\
\hline
\end{tabular}


WHC-SP-1193 Rev. 0

Table A-1. Sampling Results for Passively Ventilated Single-Shell Tanks. (5 sheets)

\begin{tabular}{|c|c|c|c|}
\hline Tanik & Sample Date & Sample Iype & Total O ML (F) \\
\hline TX-106 & $07 / 23 / 96$ & CGM & 0 \\
\hline TX-107 & $01 / 17 / 96$ & $\overline{\mathrm{CGM}}$ & 0 \\
\hline TX-108 & $07 / 17 / 96$ & $\overline{\mathrm{CGM}}$ & 0 \\
\hline TX-109 & $07 / 17 / 96$ & CGM & 1 \\
\hline TX-110 & $07 / 17 / 96$ & CGM & 0 \\
\hline TX-111 & $10 / 12 / 95$ & VSS & 0.78 \\
\hline TX-112 & $07 / 24 / 96$ & $\overline{\mathrm{CGM}}$ & 0 \\
\hline $\mathrm{TX}-113$ & $06 / 18 / 96$ & CGM & 0 \\
\hline TX-114 & $06 / 18 / 96$ & CGM & 0 \\
\hline TX-115 & $08 / 01 / 96$ & CGM & 0 \\
\hline TX-116 & $3 / 19 / 96$ & $\overline{\mathrm{CGM}}$ & 0 \\
\hline TX-117 & $03 / 19 / 96$ & CGM & 0 \\
\hline $\mathrm{TX}-118$ & $12 / 16 / 94$ & VSS & 0.3 \\
\hline TY-101 & $04 / 06 / 95$ & VSS & 0 \\
\hline TY-102 & $04 / 05 / 96$ & CGM & 0 \\
\hline TY-103 & $04 / 11 / 95$ & VSS & 0.2 \\
\hline TY-104 & $04 / 27 / 95$ & VSS & 0 \\
\hline $\mathrm{TY}-105$ & $08 / 06 / 96$ & $\overline{C G M}$ & $\overline{2}$ \\
\hline TY-106 & $08 / 18 / 95$ & CGM & 0 \\
\hline $\mathrm{U}-101$ & $02 / 14 / 96$ & $\overline{\mathrm{CGM}}$ & 1 \\
\hline $\mathrm{U}-102$ & $04 / 30 / 96$ & $\overline{\mathrm{CGM}}$ & 3 \\
\hline U-103 & $02 / 15 / 95$ & VSS & 1.9 \\
\hline U-104 & $05 / 10 / 96$ & CGM & 0 \\
\hline $\mathrm{U}-105$ & $02 / 21 / 95$ & VSS & 0.2 \\
\hline U-106 & $03 / 08 / 95$ & VSS & 1.2 \\
\hline U- 107 & $02 / 17 / 95$ & VSS & 1.6 \\
\hline $\mathrm{U}-108$ & $08 / 29 / 95$ & $\overline{\text { VSS }}$ & 1.85 \\
\hline U-109 & $08 / 16 / 95$ & VSS & 2.33 \\
\hline $\mathrm{U}-110$ & $03 / 19 / 96$ & $\overline{\mathrm{CGM}}$ & 2 \\
\hline $\mathrm{U}-111$ & $02 / 28 / 95$ & VSS & 1.1 \\
\hline $\mathrm{U}-112$ & $07 / 03 / 96$ & $\overline{\mathrm{CGM}}$ & 2 \\
\hline $\mathrm{U}-201$ & $08 / 18 / 95$ & $\overline{\mathrm{CGM}}$ & 0 \\
\hline U-202 & $08 / 18 / 95$ & CGM & 0 \\
\hline
\end{tabular}


WHC-SP-1193 Rev. 0

Table A-1. Sampling Results for Passively Ventilated Single-Shell Tanks. (5 sheets)

\begin{tabular}{|l|c|c|c|}
\hline Tank $H$ & Sample Date & Sample Type & Total WAU (O) \\
\hline U-203 & $08 / 09 / 95$ & VSS & 0 \\
\hline U-204 & $08 / 08 / 95$ & VSS & 0 \\
\hline
\end{tabular}

Note:

'The date is given in the $\mathrm{mm} / \mathrm{dd} / \mathrm{yy}$ format. 


\section{DISTRIBUTION}

\section{Number of Copies}

\section{ONSITE}

U.S. Department of Energy. Field Office, Richland

M. H. Campbell

57-73

K. O. Chen

S7-54

J. M. Gray

S7-54

C. A. Groendyke

S7-54

G. W. Rosenwald

S7-54

H. Babad

S7-14

W. B. Barton

R2-11

R. E. Bauer

S7-14

D. R. Bratzel

S7-14

J. W. Brothers

K9-20

S. A. Bryan

P7-25

R. J. Cash

S7-14

A. F. Choho

H6-35

G. L. Dunford

A2-34

R. C. Hill

R1-51

G. D. Johnson

S7-14

P. A. Gauglitz

P7-41

J. M. Grigsby

A3-37

N. W. Kirch

R2-11

J. G. Kristofzski

R2-54

C. E. Leach

R1-49

J. W. Lentsch

S7-14

M. A. Payne

S7-84

L. R. Pederson

K2-44

L. D. Pennington

S7-21

G. R. Sawtelle

A3-37

O. M. Serrano

R2-12

J. P. Sloughter

R2-54

J. A. Smart

R1-08

C. W. Stewart

K7-15

R. J. Van Fleet

R3-27

D. J. Washenfelder

S7 -40

DPC

A3-94

Central Files 
WHC-SP-1193 Rev. 0

This page intentionally left blank.

Distr-2 